\title{
CONSTANTIN MUNTEANU
}

\section{HEALTHY AGING}
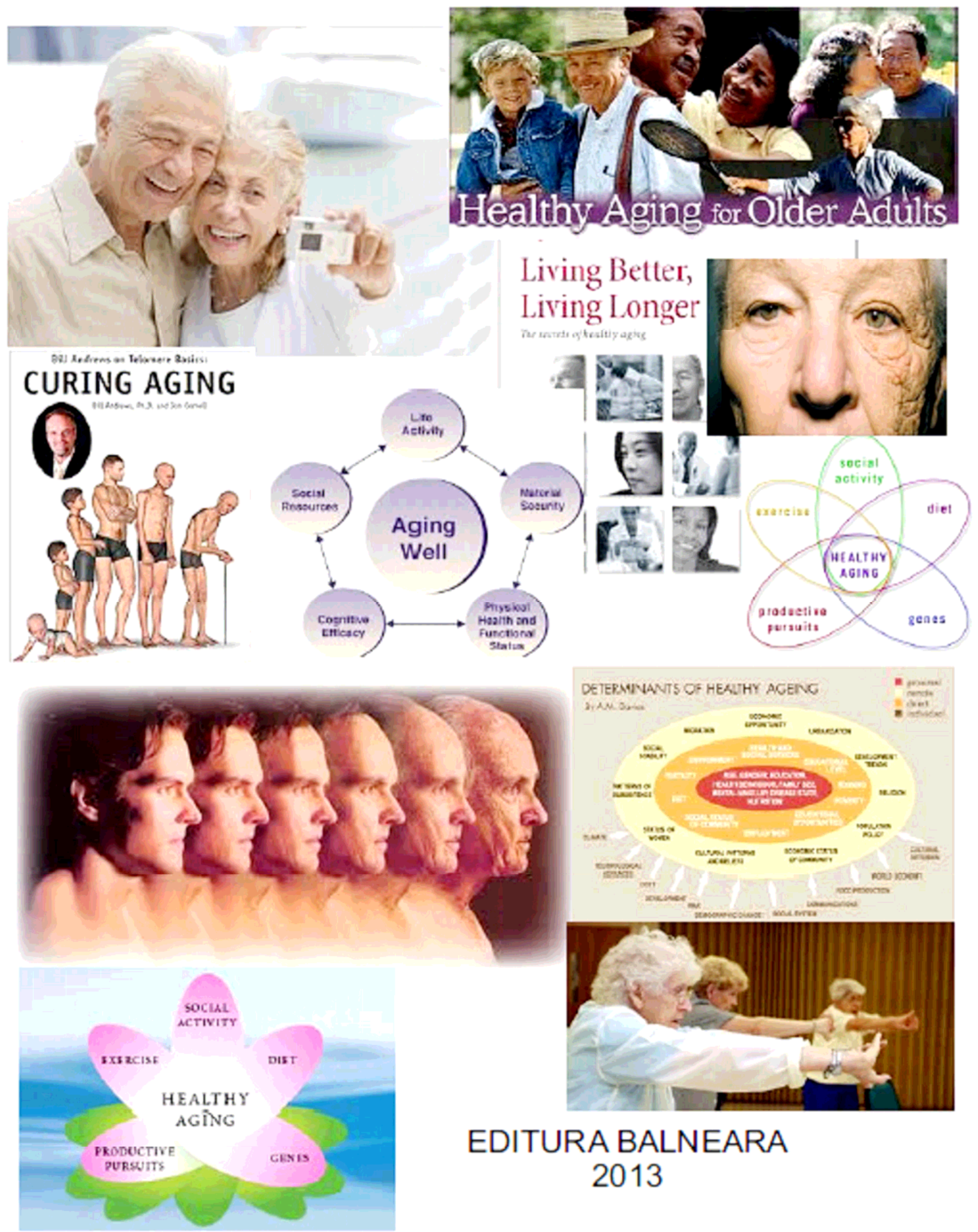

EDITURA BALNEARA 2013 


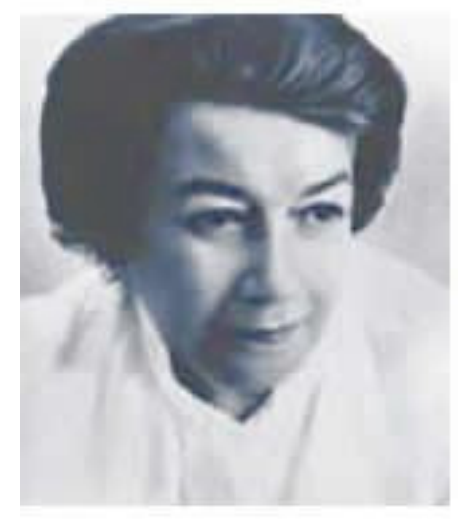

\section{"To be forever young doesn't mean to be 20. It means to be optimist, to feel good, to have an ideal to fight for and to achieve it. "}

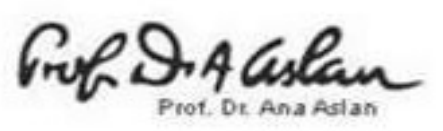

Descrierea CIP a Bibliotecii Naționale a României

MUNTEANU, CONSTANTIN

Healthy aging / Constantin Munteanu. - Bucureşti : Editura Balneară, 2013 Bibliogr.

Index

ISBN 978-606-93550-0-8

Published by

Editura Balneară - http://bioclima.ro

E-mail: secretar@bioclima.ro

B-dul Ion Mihalache, 11A, Sector 1, Bucharest, Romania 


\section{CONTENTS}

1. INTRODUCTION

2. AGEING AND SOCIETY

3. BIOLOGY OF AGEING

4. AGEING AND SYSTEMS BIOLOGY

5. BIOMARKERS OF AGEING

6. AGEING AND MORBIDITY

7. GEROPROTECTORS

8. NUTRITION AND AGEING

9. STRATEGIES FOR HEALTHY AGEING

10. REFERENCES 


\section{INTRODUCTION}

Ageing is the major biomedical challenge of our society, considered as a progressive and irreversible set of structural and functional changes for a living organism, in relation with both genes and environmental factors. The percentage of elderly people and the incidence of agerelated diseases such as cardio-vascular diseases, cancer and neurodegenerative diseases are main concerns for many scientists from worldwide. Improvements of nutrition, hygiene and public health in our society are the main vectors that guide the activities proposed by the consortium in order to target the state of healthy ageing.

Findings from model organisms have revealed that ageing is a surprisingly modifiable process that can be manipulated by both genetic and environmental factors. One well-studied dietary manipulation of ageing is caloric restriction, which consists of restricting the food intake of organisms without triggering malnutrition and has been shown to retard ageing in model organisms [451].

Ageing refers to the time sequential deterioration that occurs in most animals including weakness, increasing susceptibility to disease and adverse environment conditions, loss of mobility and agility, and agerelated physiological changes [3].

Ageing is an universal process whose manifestations are familiar and unambiguous, and old age in humans and even animals can be recognized readily after minimal assessment. Ageing has been defined as the progressive loss of function accompanied by decreasing fertility and increasing mortality and disability. In addition, ageing has dramatic effects on the response to pharmacological, surgical, and rehabilitative interventions [105].

The question of how to live longer, more fulfilling lives has driven the lights and shadows of science for generations. Leaders of powerful countries and regions have had to make difficult decisions about how to achieve certain right we all desire: to be free and healthy. But what means free whithout healthy? [2]

Demographic imbalanced pyramids and strong growth of the population aged over 65 years are a serious challenge for the humankind $[1,2,5,9]$ and the scientific community is called to respond to these challenges by maintaining the health of the elderly population to benefit from the positive role and experience that these people may have as emphasized also in the Healthy People 2020 program [4]. Ageing with all the subsequent socio-demographic and bio-medical consequences is a priority research area.

Human ageing and longevity are complex and multi-factorial traits that results from a combination of environmental, genetic, epigenetic and stochastic factors, each contributing to the overall phenotype. The multifactorial process of ageing acts at different levels of complexity, from 
molecule to cell, from organ to organ systems and finally to organism, giving rise to the dynamic "ageing mosaic" [12].

The study on human ageing and longevity has become a very hot topic in the last years because of the so-called revolution in demography, which led to the remarkable increase in the number of people over the age of 65 or 80 years. Ageing can be studied at several levels of increasing complexity: molecular, organelle, cellular, organ, organ system and organism level. For a long time the cellular level was used as the most integrate level to study ageing and longevity, generating a huge amount of data, directly transferred to tissues, organs, organ systems and the whole organism. Despite an enormous literature regarding physiological changes during ageing in different organs, only few studies have been performed at organ system and organism level and it is emerging that many findings obtained from studies at cellular level often are not informative about the scenario of higher levels of complexity [12].

Currently, health is understood as the removal of diseases in a defensive manner to the pathological process and with higher costs. Would be more effective the maintenance of health through prevention mechanisms identified by modern science $[2,6]$.

The study of the mechanisms by which various natural or health factors can influence positively or negatively the ageing process opens the path to design and obtain new products for the benefit of elderly people to maintain health for a long time and so to have socially active and positive role for others. Modern biotechnology allows today obtaining effective geroprotectors with medical use by which we can achieve the searched healthy-ageing effect [2.12].

Social inequality may have a significant negative effect on health. There are some evidences that social inequality and stressful conditions could lead to development and progression of various disorders. On the other hand, the results of some research studies have shown that reducing the consumed calorie could prolong the lifetime. In addition, limiting the consumed calorie could produce beneficial changes in the level of some hormones including blood insulin and may reduce body temperature. Meanwhile, food restriction could reduce genetic damage and may have protective effect against external toxins [111].

Healthy ageing should ideally start in childhood and take a lifelong perspective. Yet it is never too late to start. Investing in prevention can have important benefits for the individuals involved and has also societal benefits, since it is better to finance effective strategies to prevent diseases than to use the resources to cure them [6].

Combining the balneotherapy with using products with healthy-ageing effect provides a significant advantage and represents the sustainability of the strategies for healthy ageing, in the context of which the spas is the ideal place for the application of new treatments. 


\section{AGEING AND SOCIETY}

The matter of prolonging life should be considered both individually and in the social context. Longevity and quality of life are strategic investments in human capital, which in modern world are considered the most forward-looking and long-term preconditions for an innovative and competitive economy [2].

Throughout history, population resembled a pyramid, in which young children were the majority and formed the base of the pyramid, and the subsequent population brackets getting smaller, with the topmost and smallest component of the pyramid consisting of 70 - to 80 -years old people [2].

In the past, the population of most developing countries increased largely because of a high birth rate, which only partially was offset by the high infant mortality rate. This tendancy of birth rates to fall below the "replacement rate" began in 1970 in the Scandinavian countries. Today it has spread to 59 countries in Europe, Asia, South America and Middle East [2].

A recent study published in Nature anticipated a significant reduction in the world's population by 2070 , with an estimated world population in 2150 of half its current size. Much of this population is expected to consist of people older than 60 years of age [2].

The average human life expectancy in the world has been increasing steadily, rising by an average of 6 hours per day. The life expectancy of people aged 65 years continuous to increase significantly, and the prospects of increasing longevity for those who reach their $85^{\text {th }}$ birthday are even better [2].

Today the provision of health care in many countries is facing unprecendated challenges. They are related to demographic changes, the globalization of the world economy, the emergence of new and reemergence of old-infectious and non-communicable diseases, and environmental issues, as well as the necessity for restructuring the medical-education system and infrastructure for the delivery of medical care [2].

Compunding these challenges are high costs of medical technologies and the frequent lack of an evidence base for the selection of specific diagnostic and treatment methods for various diseases. High demand for expensive specialized care, especially in the elderly population, as well as an excessive focus on treatment rather than on prevention and proactive medicine are among factors contributing to the skyrocketing costs of health care [2].

In many countries, these challenges are still further complicated by the fragmentation of systems of health care, which adversaly affects the continuity of care. The process of developing and introducing new methods of disease diagnosis and treatment is often lengthy, costly, and 
ineffective. Scientific discoveries are rarely translated into real clinical practice. Currently, about 6000 different kinds of medicines and 4000 surgical and other interventions exist for more than 14000 known diseases [2].

Currently, health is most often understood as the result of disease control. We teach doctors how to help patients, we build and equip hospitals, and we work to cure disease. Clearly it would be better not to continue such a defensive posture but to instead take an offensive position against disease by preventing it whenever possible and detecting and treating it at an early stage when it does occur. Illness is often the result of our ignorance and unwillingness to prevent it [2].

The prevention of disease and prolongation of healthy years is not a very difficult task if one follows fairly simple rules, such as engageing in regular exercise, consuming a sufficient amount of clean water, maintaining balanced nutrition, keeping ones internal and external environment clean, early diagnosis and prevention of diseases, as well as having a positive emotional attitude and socializing with friends and relatives [2].

A recent study published in the Journal of American Medical Association demonstrated that even at older ages, changes in lifestyle that include starting regular physical activity and proper nutrition can prolong life. The scientists who conducted the study followed 15700 people, aged 45 to 64 years, over a 10-year period. They noted that 970 of these people decided to change their lifestyle in the sixth year of the study, beginning to exercise for an average of 3 hours per week, eat fruits and vegetables five or more times a day, stop smoking, and lose weight. After four years of such change it became clear that mortality among the study subjects who did this was $40 \%$ lower and their incidence of heart disease $35 \%$ lower than those of the subjects who continued with an unhealthy lifestyle [2].

On the basis of fairly simple principles of disease prevention, some developed countries have adopted national strategies and specific target indicators for extending the lives of their citizens. In the United States, 635 such target indicators were developed under the government initiative called "Healthy People 2010". For example, it set such goals as increasing the number of people engaged in physical activity to $80 \%$, reducing smoking by at least $12 \%$, and keeping a ceiling of $40 \%$ for the population with excess body weight. Priorities for achieving these goals included increasing the percentage of people regularly consuming fruits to $70 \%$ and those consuming vegetables to $50 \%$, and increasing the percentage of people consuming less than 2.5 grams of salt to $65 \%$. An important remaining goal is decrease the prevalence of diabetes to 25 persons per 1000 population. Although many of the goals of the Healthy People 2010 initiative have still not been met, its results show a clear 
motivation on the part of the government and most citizens of the United States to live a long life of high quality [2].

The relationship between the material well-being of society and demography is cyclical. Initially, a decline in birth rate could mean the allocation of more resources to the individual upbringing and education of a child. This may stimulate the economy. Low birth rate means a reduction in the number of potential consumers in an economy. Fewer young people also means fewer home buyers and fewer purchasers of furniture and other goods, as well as fewer people who are willing to risk starting new businesses [2].

In a consumers society such concerns as that from above are frequent. Furniture and other goods means also environment destruction. Healthy elderly people means more wisdom for the society in which they live. Maybe is the time for a change in our paradigm regarding demographic worries.

In the future society the role of physicians must be changed. Firstly they have to become Health Advisers and prevention must be their main objective. Health Tourism, balneotourism, spa and wellness must represent much more in the future global economy. In this context, low birth rate may means environment protection, healthy economy, wiser use of resources, non-consumers society, more responsibility for life and for democracy. The main pillar of the new social order must be the concept of healthy ageing. Evolution of human species starts now a new setup. Healthy ageing is the new force that is involved in this new step of the evolution. Societies are interested in the quality life of their citizens. But no government doctrine or investment can improve human health unless people themselves are genuinely interested in this. Healthy ageing is the responsibility of individuals, families, and the wider society of which they are a part.

Theories of lifespan evolution are a source of confusion amongst ageing researchers. After a century of ageing research the dispute over whatever the ageing process is active or passive persists and a comprehensive and universally accepted theoretical model remains elusive. Evolutionary ageing theories primarily dispute whatever the ageing process is exclusively adaptaed to favor the kin or exclusively non-adapted to favor the individual [18].

Everybody recognizes that the phenotypic future of an organism is largely dictated by its current design. Evolution by definition is incremental. The potential path followed by future evolution of an organism is largely constrained by its past. However, it is now increasingly recognized that the genome of an organism also has a particular design and that this design also incrementally evolves and additionally constrains the path of future evolution [3].

Darwin's theory proposes survival and reproductive capacity as factors driving evolution. Richard Dawkins, author of "Selfish gene" says 
that genes are actually competing and struggling for survival. Animals and humans are "survival machines" whose porpose is to propagate genes and whose every characteristic is evolved to propagate their underlying genes [3].

Evolvability theory refers to the idea that populations and species can vary in their capacity for evolution. Evolvability considerations provide explanations for all discrepancies with traditional evolution theory including programmed ageing, other life span limiting design futures (biological suicide), sexual reproduction, elaborate evolved inheritance mechanisms, altruism, mating rituals, and excess male puberty age.

It is generally accepted that organisms posses design futures that enable the process of evolution. For example, all organisms posses the ability to pass information describing their designs to descendants, to store that information during the life of the organism, and to copy the information for distribution to multiple descendants, in addition to mechanisms that support accumulative adaptive modification of that information [3].

Darwin's mechanics concept does not consider the capacity for evolution to be a variable. He assumed that all living organism had the capacity for evolution, that is the capability for adapting by means of natural selection to changes in their external world of predators, food, habitat etc. He also must have assumed that this capacity was a constant and not affected by other characteristics of organisms that might arise in the course of evolution [3].

Evolvability is substantially different from and in conflict with traditional individual fitness. An increase in evolvability could evolve despite an individual fitness disadvantage. The design of an organism is a compromise between fitness and evolvability [3].

The need for evolvability depends on evolutionary pressure. A species that, for whatever reason, did not encounter many changes in its external world would not need much evolvability. However, higher animals would have a great need for evolvability because, if for no reason, other organisms were evolving. An animal whose predators or prey were evolving would have great need for evolution itself. The rate at which a species could evolve could well determine its fate [3].

For humans, if external evolvability factors have decreased in importance, internal factors of evolvability are now much more evident. Diet, exercise, level o metabolism have for sure implications in the evolvability capacity.

A requirement of the theory of natural selection is that evolution requires deaths. Evolution results from the differences in average life span between more fit and less fit organisms. A hypothetical organism that did not die could not evolve.

In effect each life of an organism is a trial of "vote" for the combination of traits possessed by that organism. A longer than average life and 
therby production of more progeny represents a vote in favor of the combination of traits exhibited by that organism. A shorter life is a vote against. It should therefore be apparent that death rate is a factor in evolvability. A higher death rate will accumulate more votes and test more combinations more rapidly [3].

Most external survival traits of animals such as speed, intelligence, strengts, size, coloration, hunting ability, ability to withstand the environment, and so forth, are not fully expressed until the animal is a mature adult. Deaths of juveniles do not contribute to evolution of traits that are not fully expressed in juveniles. Therfore, traits that contribute to increasing adult death rate increase evolvability. We can consider adult death rate as the rate at which nature conducts tests of different combinations of mature inheritable traits. The more tests, the faster evolution can proceed [3].

When longevity is necessary, nature easily finds a way to extend lifespan. For instance, humans evolved a way to diminish those types of cancer that kill mice by the age of three. Both parasitic nematodes and queen honeybee have lifespan that are 100-fold longer than lifespan of soil nematodes and non-queen bees, respectively. A mere loss of germ cells extends lifespan of individual $C$. elegans and food restriction universally extends life span [43].

Animals that protect and nurture their young evolved from animals that did not. An animal that protects its young has a larger chance of itself dying and not having subsequent progeny than one that does not, a fitness disadvantage. However, the chance of progeny survival is presumably enhanced, a fitness advantage [3].

From an evolvability standpoint, protection of young has a great impact on effective adult death rate. If the adult young-protecting parents of an immature animal die, the progeny in wild situation will almost certainly die. This in effect, shifts deaths of some juveniles to the "adult" category because the death of a protecting, nurturing adult will very likely result in the death of its immature progeny. Protection of young increases "effective" adult death rate and therefore improve evolvability in mammals and other more advanced animals [3].

Darwin considered that populations of all organisms were controlled entirely by external "checks" such as predators, food supply, disease, and environmental conditions. However, it is obvious that more complex animals have internal, genetically programmed, futures that act as restraints on breeding, such as age at puberty, lengths and frequency of fertility periods, gestation periods, litter size, mating rituals, ageing and other behavior patterns such as societal restrictions, life cycle characteristics that have an evolvability purpose [3].

The problem with the idea that populations are controlled only by external checks is that it does not seem to be very efficient. A species that was not controlled by predators would tend to breed itself into 
overpopulation and subsequently by in a state of starvation and probably decimated by disease. Populations would constantly cycle up and down. In a down cycle, territory could be annexed by other species [3].

While populations of simple organisms may in fact be controlled exclusively by external checks, would it not make sense for more complex animals to evolve some internal methods for controlling population to avoid these consequences? Populations of animals do in fact experience these type of cyclesbut not to the extent that one would expect. Are back yard squirrels usually starving? Do they seem to be constantly diseased? Do predators constantly chase them? [3].

There is another problem with population being exclusively controlled by external checks. If a population of animals is controlled by starvation, adult death rate will tend to be adversaly affected. If every animal breeds when it reaches puberty (as proposed by traditional ageing theory models), than the only way to keep the birth-death equation balanced is if most animal die prior to puberty due to starvation, infant mortality, disease, etc. This obvious adversaly affects adult death rate and therby evolvability. The species (or at least more evolved descenent species) would be better off if it could somehow reduce birth rate so that more individuals lived to be adults [3].

Looking again at the birth-death ecuation, birts are controlled by the combined effect of all the life-cycle characteristics, and deaths are controlled by external checks and the interaction of ageing with external checks. If a species is in fact capable of (to some extent) controlling its own population to maximize adult death rate and otherwise optimize its ecositemic situation, than such control must be by means of varying one or more of the life-cycle traits. Of course, any trait leading to such control is adverse to individual fitness and therefore incompatible with traditional natural selection [3].

Perhaps the best way to describe whay ageing is a necessary evolved adaptation is to consider the many evolvability disadvantages that would be encountered by a non-ageing species. Animals without an ageing mechanism would not possess the challenge effect that ageing provides in helping select beneficial characteristics. Ageing would not constrain the older end of an animal's breeding period [3].

Actual animals, especially more advanced animals, have a capability for learning from experience. Even worms have some learning ability. Experience will make animals more capable of dealing with their external world of predators, prey, food supply, and environment. Because of this, an older, more experienced, non-ageing animal will be able to outsurvive and out-breed a genetically superior but less experienced younger animal, an obvious bad outcome from evolutionary standpoint. Death rates for animals capable of learning will therefore decline with age instead of being constant as a function of age as stated for the traditional ageing theories. Breeding rates for non-ageing animals will increase with 
age instead of being constant. Because of the experience factor and memory factor, the fitness impact of ageing is greater in actual animals than suggested by traditional theorists. In effect, an acquired non-genetic trait (experience) is competing with genetic traits for selection, an evolvability disadvantage.

The evolution of intelligence appears to be qualitatively different from the evolution of other animal characteristics such as claws and fur.

Let us define intelligence as the genetically transmitted characteristics that allow information acquired during an animal's life to alter its behavior in a fitness beneficial manner. Intelligence presumably includes the ability to store acquired information (memory) and many complex traits that facilitateacquisition of information (such as curiosity) or processing of acquired information (such as associative ability) [3].

We define experience as all of the animal's collected and stored (remembered) information concerning its world.

Wisdom is the beneficial combination of intelligence and experience. The probability of an animal surviving is affected by its wisdom. From a fitness viewpoint, intelligence without experience is useless. Intelligence is essentially the ability to learn from experience. Experience without intelligence is useless. Wisdom is the factor that would tend to be selected by natural selection. Evolution of intelligence apparently requires a relatively longer life span than other visible characteristics.

Our society aquired a high quantity of intelligent products (see all the new gadgets, computers, etc.) Now, humankind needs experience to reach the wisdom of evolution, and for this species goal, evolvability needs healthy long ageing people. In counterpart, low birth rate is associated with the new longer life span.

A very similar situation exists with regard to immunity from infectious diseases. If an animal is exposed to an infectious disease, it has some probability of dying from the disease (or from predators or environment or starvation as a result of the weakness resulting from the disease). If it survives, it obtains some immunity against subsequently contracting the same disease. Subsequently, that animal has a lower total chance of dying because of immunity to at least one disease. Because of this immunity factor, non-ageing animals have a further declining probability of death, as they get older.

Consider some hypothetical non-ageing animals. These animals have a group structure in which the dominant male mates with all the females and the other males do not mate. The females do the work of finding and gathering food, as well as protecting, and nurturing the young. This work represents most the hazardous activity. The dominant male is somewhat protected and served by other members of the group. If a young male exhibits traits that indicate that it might someday be a serious threat to the dominant male, it is killed or forced out of the group by the dominant male. Now consider the tremendous negative evolutionary effect 
"absence of ageing" would have for these animals. Because of the protection, experience factor, immunity factor, and group dynamics, the dominant male could expect to live for a very, very long time and sire all of the group's progeny during that period. He could be mating with many generations of his own descendents. Genetic diversity would be a joke. An animal that could have gained its dominant male position through luck as opposed to genetic merit can maintain it using acquired non-genetic factors. Notice the dramatic difference between this case and traditional (Medawar) model for non-ageing animals. These hypothetical animals resamble actual animals like lions, gorillas, and (probably) primitive humans than the traditional model [3].

Oponents of efforts to extend human longevity are convinced that research in various scientific fields will eventually lead to substantially prolonged lives and considerable changes in human development and the life cycle, social institutions, economic structures and family life. Several commentators argue that medical research is driven by fantasies concerning complete control over life and death [88].

In the spring of 2002, an international group of 52 biogerontologists scientists who conduct research on the biology of ageing - launched a war of words to discredit a burgeoning anti-ageing medicine movement. They issued a lengthy consensus position statement on "The Truth About Human Ageing", accompanied by an article in Scientific American entitled "No Truth to the Fountain of Youth". The biogerontologist's enemy in this war is what they regard as the pseudoscience of practitioners and entrepreneurs who purvey hormone injections, special mineral waters and other services and products purported to combat the effects of ageing. Yet, even as biogerontologists are attacking the contemporary anti-ageing medicine movement, many of them are themselves trying to develop interventions that will dramatically slow or arrest the fundamental processes of ageing [55].

But, Healthy Ageing Medicine belongs to a category of preventive medicine that aims to improve the quality of life among older persons [52]. During the process of ageing, the elderly usually suffer from chronic diseases, which can relieved with proper preventive solutions. Postponing clinical illness requires staying in a good state of health by reducing painful periods before death. The main aim of health improvement is to live a relatively healthy life and compress our illnesses into a short period of time just before death [49]. This means less profit for Pharama Companies.

Recently, many developing countries have been transformed into an ageing society. The change in the composition of the population toward an ageing society has had a great impact on the healthcare system. Antiageing medicine, which can neutralize risk factors for geriatric-associated diseases, has emerged and influenced the health behavior. Therefore, "anti-ageing" is one of the most important issues in society. 


\section{BIOLOGY OF AGEING}

Analysis of numerous theories of ageing [2,3] highlights several paradigm shifts of the researchers concerned with this area as a consequence of gradually scientific and technological development [2].

If early theories of ageing were centered at the level of organ dysfunction or systemic level of the body, the current theories see dysfunction of the cellular and molecular mechanisms [10].

Such modern approach reduced the differences between the existing theories on the mechanism of ageing, emphasizing their complementary elements, but at the moment there is no integrative theory for postreproductive ontogenetic development that can explain all the processes involved in the multiplicity aspects of ageing [10]

Post-reproductive ontogenetic concept based on synergistic and antagonistic interactions of genetic and phylogenetic processes involved in reproduction and development involves a reorganization of the regulatory developed evolutionary processes and ensures the body adaptation to internal and external factors, after reproductive function consumption. Thus, correction and rescheduling particular functions comes as a compensation to loss or damage of other processes with impact in the ageing mechanism [2,3].

Ageing is a degenerative process [11], extensively studied for which many theories have been formulated [10] which has as a target scheduled or non-scheduled nature [2, 3,10,13, 44].

In a frequently cited paper from 1990, Zhores Medvedev had attempted to make a rational classification of theories of ageing. He counted more than 300 theories, none of which could qualify as being the theory of ageing, and all of them could be, at best, labelled as "hypotheses" or "aspect theories". Over the years, gerontologists have become resigned to the futility of formulating a unified theory of ageing which can encompass its evolutionary, biological, and sociological aspects [11].

Programmed ageing theories are subdivided into three conceptual subcategories $[2,13,14]$

1. genetically programmed longevity theory which assumes that ageing is the result of starting or stopping certain genes being included the role of genetic instability (shortening of telomeres) in the dynamics of ageing processes [14, 17];

2. endocrine theory - according to which ageing is governed by a biological clock whose function is regulated by endocrine mechanisms, including insulin-like growth hormone IGF-1, which plays an essential role $[2,3,14]$;

3. immunity theory which states that the immune system can be programmed by a decrease in its functionality, 
immunosenescence, which will lead to increased susceptibility to infectious diseases, respectively ageing $[15,16,25,26]$.

Theories which put the ageing process due to internal and external environmental factors [10] are:

1. Wear and Tear Ageing Theory according to which cells and tissues become aged over time [2,14];

2. vital level activity theory - which states that a high level basal metabolism leads to a shortening of the life of the organism $[2,14]$;

3. cross-linking theory presented by Bjorksten (1942) according to which the cumulative chemical interchange of important macromolecules, including collagen, causes ageing [2,14];

4. somatic DNA damage theory [47] which considers that ageing results from genetic integrity degradation of somatic cell as a result of mutations registered both in the nucleus and in the mitochondria $[2,13,14,44]$;

5. free radicals theory which stipulates that the superoxide and other free radicals destroy the molecular components of cells and thus alter their normal function [11].

Traditional categorization of theories of ageing into programmed and stochastic ones is outdated and obsolete. Biological ageing is considered to occur mainly during the period of survival beyond the natural or essential lifespan in Darwinian terms. Organisms survive to achive essential lifespan by virtue of genetically determined longevity assuring maintenance and repair systems. Ageing at the molecular level is characterized by progressive accumulation of molecular damage caused by environmental and metabolically generated free radicals, by spontaneous errors in biochemical reactions, and by nutritional components [10].

Considering the ageing being a gradual loss of functional adjustment of some complex multifactorial biological processes, the individual genotype sure has an impact on the rate of ageing. However, there are not identified genetic markers of the ageing process, although in the last 20 years, sustained efforts have been made $[11,12,18]$.

The data collected during the last 20 years in different models suggest that the picture of the ageing phenotype is fragmented and above all qualitative and that we are far from an exhaustive and quantitative scenario. This incomplete knowledge comes out from several bias: 1) few studies evaluate many parameters at the same time in the same individual; 2) the collected data are not of high dimensionality; 3) longitudinal studies, which are most informative are scanty [12].

Another factor contributing to the complexity of the problem is that human ageing and longevity are complex and multi-factorial traits, generally considered as the result of the combination of environment, genetics (and epigenetics) and stochasticity, each making variable 
contributions to the overall phenotype. Moreover, these different components interact with each other, in particular genetics and environment [12].

To this regard, it has been reported that the identification of genetic variants underlying complex traits and diseases (such as psychopathology, hypertension, cardiovascular diseases and neurodegenerative diseases may take advantage from study of gene expression in particular environmental conditions [12].

The studies on human ageing and longevity are further complicated by the fact that human populations are heterogenous from the point of view of genetic pool, life style, cultural habits, education, economic status and social network. All these components are different from population to population, and each population is characterized by a unique combination of them. This fact renders the studies difficult to compare and the results very often discordant. Finally, all these considerations also aply to gender difference, since gender appears to be crucial player in the cross-talk between genes, environment and health. The development of effective and realistic trategies for ageing intervention, prevention and therapies may be facilitated by this integrated and multifaced view. Indeed, it has been proposed that the manipulation of both genes and environment at the same time can open up novel possibilities of ageing intervention and prevention [12].

The process of ageing involves changes in physiology, metabolism and reproduction in all eukariotic organisms. This is due to the appearance of deleterious mutations, malfunction in certain components of proteolytic systems and continuous accumulation of intracellular damaged proteins that lead to different pathologies and eventually to reduced lifespan [16].

Molecular studies on ageing mechanisms in model organisms have identified several longevity genes which can delay the ageing process and extend lifespan. The development of the organism is strictly genetically programmed but no genetic program has emerged to explain the ageing process [17].

The ageing models of Saccharomyces cerevisiae and Caenorabditis elegans have proved to be a cornucopia of novel molecular mechanisms of longevity. The Sir2 family of genes and budding yeast exhaustion model and the genes of DAF-2/insulin pathway in dauer larva formation have provided novel insights into the genetic background of longevity. It seems that resistance against cellular straess and environmental insults can ensure a successful ageing process and long lifespan. Interestingly, recent studies have demonstrated that lifespan can be extended by genetic, nutritional and pharmacological interventions in lower organisms. However, caloric restriction appears to be the only common way to extend lifespan in all species. 
Among the various theories and hypothesesfor explaining ageing, the free radical theory appears to be the most widely accepted plausible explanaition for the basic metabolic reactions responsible for ageing occurrence [2].

Reactive oxygen species (ROS) are probably the most significant free radicals with major implications in damage and cells and body ageing $[19,20]$. Free radical theory is currently considered the most acceptable explanation of ageing [19], although recent data obtained on a set of transgenic mutant SOD2 ${ }^{+/}$or Mclk1 ${ }^{+1}$ mice disprove the central dogma of the theory [11].

In 1957 Harman proposed the idea that a general process of accumulation of oxygen free radicals negatively affects internal environmental factors and changes genetic factors, mechanism responsible for ageing and death of all living things. The theory was revised in 1972 when was showed that mitochondria is the main center of some chemical reactions that generate free radicals.

Ageing is often accompanied by a pathological panoply from cancer and neurodegeneration until all these age-related diseases based on changes in the level of intracellular signaling pathways, there are two main alternative from these changes: loss of cellular functions, aspects that characterize degeneration and obtain new functions at the cellular level, aspects that characterize hyperplasia [69].

In the body, oxygen toxicity is generated by blockbuster of the reactive oxygen species- ROS. ROS have multiple sites of action on cardiac cells and may have a beneficial or toxic depending on the type and concentration of ROS. Furthermore, the effects of ROS depend not only on the concentration of pro-oxidant molecules generated but also by the tissue antioxidant reserves. At physiological concentrations, ROS can function as secondary messengers. ROS influence normal growth and division, stimulates DNA synthesis and induces c-fos gene expression, cjun, c-myc and activation of redox-sensitive kinase and phosphatase that modulate gene transcription. In pathological conditions increasing the amount of ROS causes significant alterations in the cellular proteins and nucleic acids.

In the category of ROS are part the superoxide anion (O-2), hydroxyl radical $(. \mathrm{OH})$, hydrogen peroxide $(\mathrm{H} 2 \mathrm{O} 2)$ and lipid peroxides. Superoxide and hydroxyl radicals are unstable, while hydrogen peroxide diffusion capacity has a relatively long lifetime.

The superoxide anion is formed by reducing of the oxygen molecule. Further reduction of this anion spontaneously or in the presence of superoxide dismutase (SOD) causes the formation of hydrogen peroxide. While hydrogen peroxide is decomposed by catalase or peroxidase to water and oxygen, hydroxyl radical is generated in the Fenton or HaberWeiss reaction. 
Major source of ROS is the mitochondrial electron transport chain. The NADH generated in the high volume during ischemia accelerates respiratory chain activity at the time of oxygen reintroduction. Thus, some of the oxygen undergo partial reduction that leading to the formation of superoxide anion. The superoxide radical production is done mainly in two points, of the electrons transport chain namely: complex I (NADH dehydrogenase) and complex III (ubiquinone-cytochrome c reductase). In the normal metabolic conditions, complex III is the main site of ROS formation. The electrons from I and II complexes are transferred to ubiquinone. Reduced form of ubiquinone $(\mathrm{QH} 2)$ undergoes two reduction reaction ( $Q$-cycle) resulting in superoxide generation from direct electron transfer of oxygen molecules. Once produced, superoxide can be reduced by SOD to form $\mathrm{H}_{2} \mathrm{O}_{2}$ which is further metabolised by catalase and glutathione reductase to $\mathrm{H}_{2} \mathrm{O}$ and $\mathrm{O}_{2}$. Superoxide generation otherwise it is an enzymatic reaction that lead to a high rate of metabolism and the rate high ROS production, on the other hand, destruction of mitochondria affected the release into the cytosol of the respiratory chain elements which produce a partial reduction of oxygen.

Another way for superoxide anion production in postischemic myocardium is the xanthine oxidase (type 0 ). In the healthy tissue it is synthesized in the form of $D$, as dehydrogenase, able to reduce NAD + and oxidizing xanthine to uric acid.

The arachidonic acid metabolism is the complex link in the mechanism of cellular death by radical attack. The arachidonic acid is the starting point of three very significant metabolic pathways: prostaglandins via cyclooxygenase, lipoxygenase via leukotriene and lipoxine way. Prostaglandin synthesis is initiated in the course of ischemic aggression completes during reperfusion because the cyclooxygenase use the cellular oxygen and requires heme present for his action. Of the PGG2 and $\mathrm{PGH} 2$ passing, it releases a hydroxyl radical that acts on cyclooxygenase by inactivation of prostaglandin synthesis pathway.

The heart is protected from ischemic injury by several defense systems.

The first system is represented by the intracellular antioxidants SOD, catalase, glutathione peroxidase (GPx), glutathione reductase.

SOD converts the superoxide anion to $\mathrm{H}_{2} \mathrm{O}_{2}$ and $\mathrm{O}_{2}$. There are three $\mathrm{SOD}$ isoforms that differ only by their subcellular localization. Thus, $\mathrm{Cu} /$ $\mathrm{Zn}-\mathrm{SOD}$ is located in the cytosol, Mn-SOD in the mitochondrial matrix and extracellular-SOD in the extracellular space.

It was experimentally demonstrated that transgenic mice knockout for Mn-SOD not live a long time, suffering severe lung damage and neurodegeneration. The phenotypic changes to knockout mice for $\mathrm{Cu} /$ $\mathrm{Zn}-\mathrm{SOD}$ are more subtle, but both enzymes are essential for aerobic life.

The catalase splits free form of $\mathrm{H}_{2} \mathrm{O}_{2}$ in $\mathrm{H}_{2} \mathrm{O}$ and $\mathrm{O}_{2}$. 
The glutathione peroxidase is an enzyme which has tetrameric isoforms located in the cytosol, mitochondria, nucleus and the extracellular space. This enzyme decomposes both the free form and organic $\mathrm{H}_{2} \mathrm{O}_{2}$.

Another protection system is represented by protein appeared as a result of oxidative stress. Thus, nuclear factor kB (NF-kB) and AP-1 are produced in large amounts in myocardium subjected to ischemiareperfusion. When the myocardium is adapted to ischemic stress by ischemia and reperfusion repeated NF-kB remains in high volume while AP-1 is linked to a small amount. NF-kB controls the anti-apoptotic gene $\mathrm{Bcl}-2$ and pro-apoptotic factors Bax and p53 in myocardium subjected to ischemia-reperfusion. NF-kB activation can be blocked by antioxidants such as $\mathrm{E}$ vitamin and $\alpha$-lipoic acid.

An important cardioprotective role is held by heat shock proteins (Hsp). Thus, the Hsp70 super expression stimulates the myocardial function metabolic functions and reduces infarct size after ischemiareperfusion. Besides Hsp70, Hsp27 and $\beta$-crystalline may protect in vitro cardiomyocytes against ischemic damage.

Also antiapoptotic genes $\mathrm{Bcl}-2$ and p53 play an essential role in cardioprotective. Bcl-2 gene expression is inhibited in ischemic myocardium -reperfused but is stimulated in adapted myocardium. Also, there is a significant increase in p53 gene expression due to ischemia.

The non- enzymatic antioxidants from foods represented of vitamins and phenolic compounds have been shown to have antioxidant effects. The effects of $E$ vitamin on cardiovascular disease are controversial. Thus, some studies have shown that $E$ vitamin decreases the incidence of cardiovascular events while others have shown that $E$ and $C$ vitamins and $\beta$-carotene have a great importance in the prevention of coronary heart disease. Regarding to the lipid peroxidation, in vivo studies have shown that $E$ vitamin has no significant effect on lipid peroxidation. The other authors have shown that $E$ vitamin, as well as $C$ vitamin, prevents lipid peroxidation in vivo. Treatment with vitamin $\mathrm{E}$ prevents the growth of malondialdehyde, restores activity $\mathrm{Na}^{+}-\mathrm{Ca}_{2}+$ exchanger, and attenuates cardiac dysfunction. In Antioxidant Supplementation in Atherosclerosis Prevention Study shows that supplementation with vitamins $E$ and $C$ prevents the progression of atherosclerosis.

Recently it was discovered that in Mediterranean countries with a diet rich in fat and cholesterol coronary heart disease incidence is lower than in eastern countries. This phenomenon called "French paradox" seems to be due to regular consumption of red wine. The antiatherogenic effect of red wine is due to the polyphenols. Numerous in vitro studies have shown that polyphenols inhibit protein kinase $C$, lipoxygenase, histamine release, angiogenesis, ACE (angiotensin converting enzyme), modulates the cellular cycle has SOD-like activity and antimutagenic. 
GSK-3 $\beta$ is an important component of signaling pathways coupled to receptors for insulin, various growth factors and neurotrophins as well as other signaling molecules; GSK-3 $\beta$ has an essential regulation role of transcriptional factors, which in turn controls the expression of genes; Lithium mimics Wnt signaling by inhibiting GSK-3 $\beta$, causing similar effects to Wnt stimulation. Blocking GSK-3 $\beta$ leads to increased cytoplasmic concentration of $\beta$-catenin and activation of gene transcription.

GSK-3 $\beta$ is a protein of $47 \mathrm{kDa}$ named after its ability to phosphorylate and thus inactivate glycogen synthase, the key process of glycogen synthesis. In the present, it is known that GSK-3 $\beta$ is an influential component of signaling pathways coupled to receptors for insulin, various growth factors and neurotrophins as well as other signaling molecules. GSK-3 $\beta$ is not only a component of signaling pathways, but also has an essential role regulating of transcriptional factors, which in turn controls the expression of genes (Grimes and Jope, 2001).

GSK-3 $\beta$ (Zeste-white or Shaggy) is a serine-threonine kinase component of the Wnt signaling pathway. Presents a specific catalytic domain of these kinases linked to a region unusually rich in glycine, serine and alanine. The gene is located on the long arm of chromosome 3 in the region q13.3.

The shaggy gene from Drosophila has multiple transcripts, generated by alternative splicing. From this process resulting five different proteins.Activation of the Wnt pathway inhibits GSK-3 $\beta$ activity, which can not phosphorylate $\beta$-catenin.

The Wnt signaling pathway is involved in mesoderm formation at vertebrates, in neural induction and pattern formation of limbs. The signaling pathway components are the Wnt ligand, Frizzled receptor and intracellular mediators: dishevelled, GSK-3 $\beta$ and $\beta$-catenin (Hedgepeth et all., 1997).

In the central nervous system of higher vertebrates after injury or as a result of trauma, disease, genetic abnormalities or chemical pollutants, the astrocytes become reactive and respond in a specific manner known as astrogliosis characterized by rapid synthesis of GFAP.

Glial fibrillary acidic protein (GFAP), a marker for identification of astrocytes in normal and pathological conditions is considered a sensitive indicator of toxicity.

The harmed astrocytes are hyperplastic, hypertrophic and have an increased GFAP content. These results demonstrated that damaged astrocytes in culture can become reactive in the absence of neurons express the glial behavior.

Glial fibrillary acidic protein (GFAP) is a protein of $51 \mathrm{kDa}$, which are polymerized to form intermediate filaments present in glial or cells of glial origin (Nagle, 1994). The antibodies made against to the GFAP do not interact with neurons, fibroblasts or muscle cells, which shows the 
presence of immunologically distinct epitopes that are not in vimentin, desmin or neurofilaments, although sequencing studies showed a relatively high homology of these structures. GFAP purified from mammalian brain in vitro assemble into filaments 8-9 $\mathrm{nm}$.

GFAP present not only in cytoplasmic fibrous astrocytes were identified in Bergmann glial cells in the cerebellum, ependymal cells and immature oligodendrocytes. GFAP expression was also noted in the interstitial cells of the hypophysis. In addition, GFAP has been shown in Schwann cells of the peripheral nervous system and even in some nonneural tissues.

GFAP immunoreactivity in the mature nervous system is limited to glial filaments of protoplasmic astrocytes in the gray matter, the fibrous astrocytes in the white matter, Bergmann glial fibers in the cerebellum and cerebral ventricles adjacent subependymal astrocytes. On the surface of the brain, GFAP immunoreactivity is mainly concentrated especially in the astrocytes that form external limiting membrane, socalled glia limitans (Eng et al., 2000).

In the culture, astrocytes at low density are flattened and polygonal and contain large amounts of actin, compared with intermediate filaments. To the contrary, astrocytes grown at high density, arise morphologically differentiated, often stellate shaped and with thin branched cytoplasmic extensions. These astrocytes contain fewer actin, but many more proteins of intermediate filaments (Eng and Lee, 1995).

In the central nervous system of higher vertebrates after injury or as a result of trauma, disease, genetic abnormalities or chemical pollutants, the astrocytes become reactive and respond in a specific manner known as astrogliosis. The astrogliosis is a characteristic appearance of reactive astrocytes adjacent to the lesion and is characterized by rapid synthesis of GFAP. The GFAP increase in the astrocytes occurs gradually lifelong to mice, rats and humans.

Although traditionally GFAP was considered an astrocytic marker, some studies have shown that a large percentage of astrocytes in the brain do not express GFAP (Walz and Lang, 1998; Ding and al., 2000). In addition, it was shown that increased expression of GFAP usually reflects astrocytes reactivity (Rohl et al., 2003).

In many neuropathological disorders are found hypertrophied astrocytic intermediate filaments accumulated in the cell body and cytoplasmic processes. Intermediate filament proteins cause the formation of Rosenthal fibers in the Alexander disease (Koyama et al., 1999).

The harmed astrocytes become hyperplastic, hypertrophic and have an increased GFAP content. These results demonstrated that damaged astrocytes in the culture can become reactive and express the glial behavior in the absence of neurons. 
Increase in the number GFAP fiber was observed in older people who showed visible signs of neurodegeneration (Unger, 1998).

In addition to the increase in the GFAP content, suffer a hypertrophy in response to physical and chemical trauma, in ageing and neurodegenerative diseases.

The astroglia undergoes a gliosis process and a rapid increase in GFAP levels in the Menkes disease, suggesting possible damage to cells due to the lack of side effects or poor distribution of the copper ion in the brain (Tiffany-Castiglioni, 1998).

Evaluation of therapeutic interventions and diagnostic methods may utilize a wide range of evidence sources: individual experience, retrospective studies, clinical case reports, case series, historical and geographical comparisons, drug surveillance studies (post-marketing), pharmaco-epidemiological data bases, crossover studies, case-control studies, cohort studies, randomized controlled trials and systematic reviews of trials and observational studies.

Ageing and cancer both occur as a result of accumulated cellular damage, and both are related to the regulation of specific genes in the damage response. Recent research has unveiled connections between the mechanisms of ageing and cancer, but how to prevent the development of cancer and increase longevity remain unknown [205].

The development of the organism is strictly geneticall programmed but no genetic program has emerged to explain the ageing process. In model organisms, several stress resistance and survival genes have been revealed which can delay the ageing process and extend the lifespan, especially in harsh environmental conditions. The homologs of these genes are also present in the human genome which indicates that the genetic component in the human lifespan regulation could be caused by variability in the survival genes. For instance, the protein interaction network of longevity genes shows a clear conservation of the ageing processes between human and invertebrate species. Genetic studies have estimated that heritability accounts for about $20-25 \%$ in human longevity [17].

The developmental determination genes, e.g. MyoD, were first discovered over twenty years ago. Determination genes are transcription factors, sequence specific DNA-binding proteins which can regulate the transcription of a number of inducible genes required to establish a distinct cellular phenotype. NF-kB (nuclear factor -kB) is also transcription factor but it is a pleiotropic mediator of gene expression which can interact with the sequences observed first in the immunoglobulin enhancer. The structural and functional characteristics of NF-kB system have been extensively studied during the last twenty years. The mammalian Rel/NF-kB family includes three rel proteins, RelA/p65, c-Rel and RelB, as well as two NF-kB components, p50 and p52. These components form dimeric complexes with each other which 
are trapped into cytoplasm when they become bound to several inhibitory $\mathrm{IkB}$ proteins (IkBa, IkB $, \mathrm{lkB} \varepsilon, \mathrm{IkB} \zeta$, and $\mathrm{Bcl}-2$ ). The mammalian NF-kB system represents an ancient host defence system which branched out into different signalling forms during evolution. In particular, NF-kB system is a cytoplasmic sensor which can be activated both by immune attacks and by a plethora of external and internal danger signals, such as oxidative stress, genotoxic stress and tissue injuries. As a consequence of its duties in defense, the NF-kB system is crucially activated in several age-related diseases [17].

The NF-kB system is an ancient defence system which is utilized to recognize danger signals and subsequently orchestrate the transcriptional defence responses. The ageing process can consist of a variety of insults to homeostasis, such as oxidative stress, genotoxic stress, and an abundance of accumulating proteotoxic waste products. It is reasonable that the NF-kB system is intended to respond to these insults to protect the host. However, the maintenance of the homeostasis requires that the responses are not overhelming and for that reson an efficient repressor system is required. Interestingly, it seems that longevity factors can inhibit the activation of NF-kB system [17].

Genomic instability seems to be a major stochastic mechanism of ageing. This hypothesis is supported by much experimental evidence of which human progeroid syndromes and transgenic animal models are the most convincing. DNA lesions appear during ageing in both the nuclear DNA and mitochondrial DNA. Several studies have indicated that free radicals and oxidative stress are probably the most important source of age-related DNA mutations. DNA damage activates ATM (Ataxia Telangiectasia Mutated) and ATR (ATM and Rad 3-related) kinases which trigger a complex host defence system, an attempt to repair the DNA damage and maintain cellular homeostasis. The major signalling pathways induced by genotoxic stress are p53, NF-kB and PARP-1 [17].

Mammalian Sirtuins can deacetylate several transcription factors, in addition to histones, and in that way regulate gene expression. SIRT1 can interact with the p65/RelA protein and specifically cleave the acetyl group from lysine-310 of p65 protein. This acetyl group is known to enhance greatly the transactivation efficiency of the NF-kB complex. The studies revealed that SIRT1 protein was a potent intracellular inhibitor of NF-kB signalling [17].

There is increasing evidence demonstrating that the NF-kB signalling system is activated during ageing. This is plausible since nearly all insults enhancing the ageing process are well-known activators of NF-kB, such as oxidative stress, DNA damage, UVB light, and activation of innate immunity. The NF-kB system is the lynchpin of host defence receiving the input signalling from danger recognition receptors and subsequently organizing the transcriptional output response against the acute threat [17]. 


\section{AGEING AND SYSTEMS BIOLOGY}

The study on human ageing and longevity has become a very hot topic in the last years because of the so-called revolution in demography, which led to the remarkable increase in the number of people over the age of 65 or 80 years [12].

It is conceivable that longevity could be achieved by different strategies and by different combinations of genetics, epigenetics, environment and stochasticity. Moreover, it is emerging that the multifactorial process of ageing does not occur only at organism level, but also acts differently in each organ system, organ, tissue and even in each single cell of the body, determining a different ageing rate for each of them. In mice it has been observed that different tissues age in a coordinated fashion, while in humans this is still to be ascertained. As a consequence of these different ageing rates, the aged body could be considered as a mosaic of tissues and organs displaying a different level of senescence, a situation indicated as "ageing mosaic" [12].

Thus, even in the same individual, the ageing process appears to follow different trajectories in different organs, tissues and cells, which are variably affected and accumulate unrepaired damages at different rates. An example, among many others, is the brain where different regions, such as cortex, hippocampus and cerebellum, show different levels of neurodegeneration and inflammation in the same subject. In mice a greatheterogeneity in the amount of transcriptional changes with age in different tissues was found. Based on the pattern of age-related transcriptional changes, three ageing patterns have been proposed: 1) a pattern common to neural tissues; 2) a pattern for vascular tissues, and 3) a pattern for steroid-responsive tissues [12].

Moreover, this mosaic is dynamic, meaning that it changes with time, owing to the complex non linear interactions among the different components, resulting in a final phenotype that is not easily predictable by the study of its single sub-components. Changes in this mosaic derive from different forms of stressors to which the body is exposed lifelong. The adaptive response to these perturbations can follow two trajectories: 1) in case of exposure to a repeated low grade stimulus, the mosaic is able to positively remodel the mechanisms of maintenance which are upregulated and the systemic result is the resistance to stress (hormesis); 2) conversely, in case of exposure to a stronger stimulus (over a specific threshold) in terms of intensity and persistence, the remodelling process still occurs, but the mechanisms of maintenance are less efficient and the global result is negative and detrimental for health and survival. Therefore, a strategy to increase healthy ageing and longevity could be to favour the hormetic response by transforming intense and persistent stressors into low-grade ones. In this perspective it is also interesting to note that low-grade stressors can be assimilated to what is referred to as 
functional or constructive noise. The role of noise in biological systems is under investigation, and, for example, it is now evident that the stochastic or inherently random nature of the biochemical reactions of gene expression may contribute to the phenotypic variability in individuals [12].

Currently, most of the studies focused on human ageing refer to a single district of the mosaic (generally the most easily available tissues). For example, experimental results indicate that in vivo cell types from skin of aged individuals are likely to compose a mosaic made of cells irreversibly growth arrested (replicative senescence) and cells maintaining a young proliferative phenotype [12].

To this regard, ex vivo studies performed on human diploid fibroblasts from young and centenarian subjects show interestinf results: they are characterized by the same proliferative capacity and the same telomere length, but they differ for the gene expression profile. Moreover, in vitro studies show for example that the higher level of stress to which these cells have been exposed throughout their lifespan, the higher proportion of the cells of this mosaic will undergo stress-induced premature senescence rather than telomere-shortening premature senescence. Human diploid fibroblasts exposed in vivo and in vitro to proinflammatory cytokines display biomarkers of senescence and might participate in the degradation of the extracellular matrix observed in ageing. In addition, despite support for the idea that senescence is a beneficial anticancer mechanism, it is emerging that the secretome of senescent cells display an inflammatory phenotype that can also be deleterious and might contribute to age-related pathologies [12].

Several experimental evidences suggest that the role of genes on physiology and pathology can change at different phases of human life. In genetics, these evidences are represented by complex trajectories in the frequencies of functional polymorphisms in population cohorts of different ages. The presence of such trajectories suggests that the same polymorphism can have different biological effects in young, middle-aged and extreme long-living individuals. This phenomenon was named Complex Allele Timing. The first example of such kind of trajectories was reported since 1998 on $\mathrm{APOB}$ and the latest one is represented by Klotho KL-VS polymorphism, for which a significant increase of the heterozygous Klotho genotype in the class of elderly people compared to young controls emerged, while no differences was present between centenarians and young controls. Thus, this KL-VS heterozygous genotype is favourable for survival in old people, its beneficial effect decreasing thereafter, and becoming no more evident at the extreme ages. Such a non monotonic age-related trajectory of the Klotho KL-VS genotype frequency is compatible with the hypothesis that alleles and genotypes involved in ageing and longevity may exert their biological effect at specific time windows. It is noteworthy that this conceptualisation is supported by the use of demographic information, 
that, togetherwith data on genetic markers, allowed to calculate hazard rates, relative risks, and survival functions for candidate genes or genotypes, providing a powerful tool for analysing their influence on longevity and survival. This modelling approach allowed to predict trajectories in genetic variationfrequencies that have been subsequently confirmed by experimental data [12].

Moreover, the role of epigenetics (DNA methylation, histone posttranscriptional modifications, including methylation, acetylation, ubiquitination and phosphorylation) in the ageing process should also be considered within this scenario because it includes regulatory mechanisms that could play a pivotal role in cellular homeostasis, agerelated diseases, such as human cancer, as well as lifespan. To this regard, "ageing epigenetics" become an emerging discipline. The epigenetic alterations that accumulate with age, such as the global DNA hypomethylation, the promoter hyper methylation of Werner Syndrome genes and lamin genes, aberrant $\mathrm{CpG}$ island promoter hypermethylation, DNA methyltransferase overexpression and histone modifications, could be responsible, at least in part, for the phenotype of aged cells, tissues and organs, being in turn responsible for age-related changes in gene expression. However, no data are available on the epigenetic of human (extreme) longevity and the global DNA methylation and methylation status of specific candidate loci for longevity is at present lacking, as well as epigenetics applied to population genetics studies [12].

In this complex scenario, where a unique model for the study of human ageing and longevity does not exist, a systems biology approach that combines and quantifies genetics, genomics, proteomics and other omics fields is necessary to handle the ever increasing amount of experimental data made available by new high-throughput technologies. Systems biology represents a strategy to integrate and quantify the existing knowledge and data from different sources into models, to be later tasted and then supported with experimental data for validation and refinement [12].

High-throughput technologies generate complex and high dimensionality data that need appropiate statistical analysis, such as nonlinear methods, and above all a sophisticated interpretative approach in order to get insight on their biological meaning. As an example, visualization techniques, interaction maps and pathway diagrams can be of great value in order to understand how all molecular and cellular components and modules are interwined and work together to determine the basic structures and the functions of the organism's complex machinery. In spite of this complex scenario, immunological studies and studies on centenarians reveald that common mechanisms occurred both in very different age-related diseases, such as diabetes and neurodegeneration, and in healthy long-living subjects. One is the persistent, low grade inflammatory process which develops with 
advancing age, named "inflammaging". Therefore, anti-inflammatory therapies could efficiently contribute to slow down ageing and ageassociated pathologies, thus increasing the possibility to reach longevity. In a general perspective, the prevention of the postponement of the ageing process could have much greater benefit than those targeted at individual disease. In addition, combining the already known empirical methods of anti-ageing medicine with unique genetic profile of each human (genepass) may render new awarding opportunities for the furthere advecements of human longevity programs [12].

Post-genome technologies, such as microarrays and RNAi, have provided researchers with powerful, hich-throughput tools to study ageing. To collect, manage, and organize the massive amounts of data generated and help researchers analyze the data, a number of resources and databases have been assembled. The Human Ageing Genomic Resources are one of such collections of databases and tools, which are of particular interest to systems biology of ageing. Databases include GenAge, an accurate database of genes associated with ageing in model organisms as well as a selection of candidate ageing-related human genes. By providing an annotated list of genes associated with ageing, GenAge can help researchers study how genes interact each and with the environment to collectively modulate ageing [12].

Microarrays, by measuring gene expression in a high-throughput fashion, allow molecular changes during ageing to be characterized with unprecedented power and several studies using microarrays have now been performed. One database of gene expression profiles during ageing, neurodegenerative diseases, and in interventions affecting ageing is in the Gene Ageing Nexus, which features a compilation of microarray data and a data analysis platform (http://gan.usc.edu). Another gene expression changes with age is AGEMAP, which provides a catalogue of gene expression changes with age in different mouse tissues. These resources open new opportunities to analyze how multiple genes and mechanisms affect ageing, how these gene expression changes are regulated, and which genes and mechanisms may represent target for manipulation.

One focus of the systems biology approach is to model data mathematically in order to better interpret the process under study, perform computer simulations, and gain novel insights. Ultimately, the goal of modelling biological processes is to shift from describing phenotypes to predicting their behaviour and how they can be manipulated. In the context of biogerontology, accurate in silico models of ageing would help identify key components (proteins) that influence ageing which would not only guide experiments but provide novel therapeutic targets to counteract the effects of ageing in particular agerelated diseases [12]. 


\section{BIOMARKERS OF AGEING}

Characterization of the rate of ageing of the body employs the concept of biomarker of the ageing [21,24,27], defined as quantitative or qualitative biological parameter that allows the prediction of functional status of the organism to a particular moment of its existence [22,24]. In this context, experts in the field suggest parameters that aim the age of nervous, cardiovascular, respiratory or excretory system and even advancing proposals for estimating the biological age of the cell. In humans, the biological age is surpassed by the psychological age, the intellectual age and the social age.

Specific combination of some parameters considered biomarkers of the ageing process and the use of refractive index as optical parameter to assess the biological status of the body, mathematical interpretation of the data by using a patented analysis method for bioclinical informations previously developed by members of the research team, lead us to consider that the efforts to identify the optimal set of biomarkers will represent a landmark for scientific research in the gerontology area.

Several authors have discussed the criteria for selection of some biomarkers of ageing, emphasizing the following critical points that they should fulfill [23]: ageing and longevity rate prediction, quantitative monitoring the biological quality of the body by parameters by which the determination will not harm the integrity of the organism, the data obtained must be reproducible and comparable for different species of laboratory animals and with relevance for humans [23,25,27,28].

Among the main biological markers used to predict the biological age and longevity, the American Federation of Ageing Research suggests as the set of biomarkers of ageing [27]: systolic and diastolic blood pressure, the heart rate at rest, total cholesterol, HDL and LDL cholesterol, lipid levels, blood glucose, body mass index [26], abdominal obesity index, T lymphocytes level, cortisol level and electrocardiogram.

Alostatic overstressing index [23] proposed by McEwen and Stellar 1993 denotes the body's dysfunctional response to chronic stress and reveal increased levels of adrenaline, noradrenaline and dopamine hormones [2]. This index was used by Karlamangla and collaborators in a recent study of mortality in people aged over 70 years, pursued over a period of 4.5 years. Patients with an alostatic overstressing increased index present a much higher risk of mortality. Thus, the study concludes that a uniform increase of alostatic overstressing index (normally located between -1.7 and 1.4) leads to an increase of 3.3 times in mortality measured in the range of 4.5 years.

The so-called matrix protocol [2] of ageing biomarkers used by the International Institute of Longevity Montclair (New Jersey) determines the rate of ageing on four levels: 
I.the overall functionality of the body measured by the ratio of weight and level of fat, flexibility, aerobic endurance, bone density, tactile response latency, forced expiration volume, vision and hearing [27];

II.functioning at the cellular level monitored at the skin level by determining the cytoarchitecture changes of basal membrane, epidermal turn-over, sebaceous glands architecture, microvascular changes, collagen ratio, elasticity of the fibers [28];

III.the molecular level consider the growth and thyroid hormone level but also of coenzyme Q10, sensitivity to insulin, the heat shock proteins level, the oncogenes level in the blood, serum level of antioxidants [25];

IV.at DNA level is studied the position and size of telomeres (set at WBC level) and the accumulation level of mutations in the genetic material.

The researchers from the International Longevity Institute are currently working on a new laboratory chemistry test that should reflect the damage level of DNA and should bring science-based predictions regarding the therapeutic value of anti-ageing interventions through the mutational changes occurring in the somatic genetic material [2, 28, 29].

Telomeres damage can be assessed indirectly by measuring some biomarkers that correlate with their shortening [28]. Thus, Jiang and Rudolph analyzed the telomeres shortening mechanism and the rate of ageing in several organs and tissues, identifying four proteins whose expression increases in relation to telomere shortening, as these: Cathelcidines from macrophages and polymorphonuclear leukocytes lysosomes activated by bacterial infection; Chitinaza 3 like3 (Chi 3L3) involved in the initiation of immune response; elongation factor $1 \alpha$ (EF-1 a) - which controls protein synthesis in human fibroblasts and Stathmins which control the intracellular microtubules stability, cell motility and mitosis [2].

The discovery of biomarkers able to predict biological age of individuals is a crucial goal in ageing research. Recently, researchers' attention has turn toward epigenetic markers of ageing [29].

Epigenome-wide association studies report that $\mathrm{CpG}$ island, mainly placed within genes promoter regions, are hypermethylated in the elderly. In a recent study were identified and validated 3 genes, ELOVL2, FHL2 and PENK, whose CpG islands methylation changes with age. ELOVL2 encodes for a transmembrane protein of long (C22 and C24) $\omega 3$ and $\omega 6$ polyunsaturated fatty acids (PUFA), and it is mainly expressed in the liver [29].

PUFAs are involved in crucial biological functions including energy production, modulation of inflammation, and maintenance of cell membrane integrity [29].

It is possible that ELOVL2 methylation plays a role in the ageing process through the regulation of different biological pathways [29]. 
The analysis of human gene expression through microarrays of DNA, or "gene chips", has provided considerable data about genes whose expression changes with age. For example, Golden and colleagues, in work directed at identifying markers of ageing in the nematode $C$. elegans, found strong correlations between changes in the expression of various genes and chronological and biological age. They developed a method that can define the biological age of wild $\mathrm{C}$. elegans worms with $70 \%$ accuracy. The expression of p16INK4a, a protein present in human T-lymphocytes and which correlates with biological age, increases exponentially with age. A further finding was that increased levels of this protein were associated with both smoking and physical inactivity. This indicates once again that the level of expression of some genes make them clear prospects as biomarkers of ageing [2].

The concept of oxidative stress caused by free radicals or generation systems of such radicals in concentrations that exceed antioxidant defenses capacity, represents the basis of taking into account as biomarkers of ageing, physiological and molecular indicators of oxidative stress. Carbonylate proteins represent, in this context, an example of the use of oxidative stress indicators as biomarkers of ageing [2, 25].

Many scientists consider the accumulation of carbonyls proteins in erythrocyte membrane as an indirect marker of ageing and the ferroreduction antioxidant potential (FRAP) in blood plasma as an indicator of the body's antioxidant defense capacity [2]. The oxidative and reductive activity of enzymes that act on glutathione, thioredoxin and other substrates of interest in the oxidation-reduction process reflects not only the level of antioxidative protection but are probably relevant biomarkers for ageing rate.

It has been suggested that microheteroplasmy could explain some of the pathological mechanisms related to ageing such as diabetes, cardiovascular diseases, Parkinson, Alzheimer, cancer $[2,23]$.

Mobile genetic elements (MGE) for whose description geneticist Barbara McClintock received the Nobel Prize in 1983 have been proposed as components of genetic instability and on these considerations as factors of cellular senescence for many species, with effects that include impaired gene expression and age-related disorders in cell physiology, blocking cell growth and eventually cell death or blastic transformation. According to this hypothesis, ageing is correlated at the cellular level with the trasposonic activity whereby a DNA sequence copy remains at its predetermined site in nucleus while the second copy, called transposon, can move to different locations in the genome [2].

NADH and FADH coenzymes - critical components of energetic transport in mitochondria may represent, by their expression level, biomarkers of mitochondrial activity and indirectly of senescence and body age. Their measurement can be made currently by polarizing microscopy techniques or by fluorescence [2]. 
Heat shock proteins (HSP) are other biomarkers of ageing, and there are studies showing that the change of these proteins expression correlates with changes in longevity, experimentally described in Caenorhabditis elegans [2].

Apolipoproteins synthesized in the liver and intestine are involved in the transport of cholesterol and triglycerides in the blood, are considered more eloquent predictors of death by coronary heart disease [23]. Particularly, apolipoprotein A1 that transports HDL cholesterol shows an inverse correlation with the risk of death by coronary heart disease, a high level being associated with a decreased risk while apolipoprotein B responsible for LDL-cholesterol transport has a direct correlation, the high level indicating a high risk of death. The ratio of the two apolipoproteins is an influential indicator for the rate of ageing [23].

Measuring the refractive index of a biological sample [96] is a relevant optical parameter used in the diagnosis and treatment [95], being an indicator of changes in the level of hydration, of the biological age of the sample or the level of intracellular dysfunction [93]. The refractive index measured in the serum of Wistar rats shows a time-dependence being measured an increase of 1,34136 from birth to $1.35175(250 \mathrm{~g})$ to adulthood [94]. The effective refractive index of a single cell [101] is determined by the refractive index of cellular constituents, and its determination provides us data on the size and volume of the cell, nucleus volume, setting of certain dysfunction at the cellular level $[97,99,100]$.

Using the Kramers-Kronig relations allows quantifying time dependent changes of the refractive index starting from reflectance measurement of samples that can be made both in biological serum samples or culture medium [99] but also at the skin surface [98]. Therefore, we can consider as a biomarker of ageing the refractive index of blood serum and in the skin and will correlate the application of the developed treatments in the project with the change of this index.

Biomarkers for healthy ageing identifiable in the serum would be of substantial use in detecting age associated morbidities and initiating therapeutic treatment. Previous studies have indicated as serum biomarkers Insulin-like growth factor 1 - IGF1, Pro-collagen III N-terminal peptide (PIIINP), PDEGFBB, eotaxin, IP-10, IL-12, IL-7, MIP1 $\beta$ and MIG, which decrease with increased age and have been associated with muscle declines [22].

One of the most studied areas for the detection of Biomakers of Ageing is the association between human ageing and pro-inflammatory state in which several cytokines, including interleukin-6 (IL-6), tumor necrosis factor $\alpha$ (TNF- $\alpha$ ) and interleukin-1 $\beta$ (IL-1 $\beta$ ), show increased expression. At the same time, ageing is associated with decrease in serum testosterone (T) levels. IL- 6 , TNF- $\alpha$ and IL- $1 \beta$ affect the central 
(hypothalamic-pituitary) and peripheral (testicular) components of the gonadal axis, inhibiting T secretion [23].

Interleukin 6 - IL6 is a multifunctional cytokine that plays an essential role in acute inflammation stage. Although normally in the absence of inflammation can not be detected in blood samples over time by losing his regulation expression, the expression level increases with age $[22,23]$.

Growth hormone, secreted by the pituitary gland has a decreasing level with age of the body being registered a decrease by $14 \%$ every decade after the age of 20-25 years and reaches half around the age of $60[2,21,22,26]$.

Ageing is also associated with quantitative and qualitative changes within the naïve $\mathrm{CD} 4^{+} \mathrm{T}$-cell compartment. Decreased numbersof recent thymic emigrants, shortened telomeres, hyporesponiveness to stimulation, decreased proliferative capacity, reduced IL-2 production, alterations in signal transduction and changes in cell surface phenotype have all been reported. These changes likely contribute to the poor response to vaccines and increased susceptibility to infectious diseases and neoplasms reported for older adults $[25,26]$.

Long-lived structural proteins such as collagen and lens crystallins have been reported to "age". That is, they change biochemically in a progressive unidirectional fashion with the age of the animal. In particular, collagen, which forms much of the structure and support for the vertebrate body, progressively "yellows" with age, displaying reduced solubility and digestibility. These changes are thought to be primarily due to nonenzymatic cross-links among and within collagen molecules as a consequence of Maillard reaction chemistry and the consequent formation of glycation end-products. Such changes with age occur in collagen molecules in a range of tissues and likely contribute to tissue dysfunction [28].

Many attempts have been made to use the body mass index (BMI) as a marker of ageing. Long-term clinical trials in patients over 21 years old have led to the conclusion that the total body potassium (TBK) content in the age of 20 to 30 years (as a reliable proxy to the body's free fat mass index), and that the value of the body cell mass (BCM) allows prediction of the body mass index (BMI) after the age of 60 years [2].

The blood level of erythropoietin (EPO) has been proposed as a predictor of mortality of elderly persons.

Because diseases of cardiovascular system have historically been the number one cause of early death, it is important to determine as precisely as possible the biological age of cardiovascular system. This is calculated as follows:

$$
\begin{gathered}
\mathrm{PBA}_{\mathrm{Cvs}}=\left(\mathrm{CA}_{\text {ind }}-\mathrm{CA}_{\text {mean }}\right) * \mathrm{R}^{2}+\mathrm{CA}_{\text {mean }}[2] \\
\mathrm{BA}_{\mathrm{cvs}} \text { for men }=0.19^{*} \mathrm{SBP}+2.98^{*} \mathrm{TCl}-7.23^{*} \mathrm{Cl}+26.45 \\
\mathrm{BA}_{\mathrm{Cvs}} \text { for women }=0.38{ }^{*} \mathrm{SBP}+3.07{ }^{*} \mathrm{TCl}-4.77^{*} \mathrm{Cl}-1.24{ }^{*} \mathrm{Cl}
\end{gathered}
$$


$\mathrm{PBA}_{\mathrm{CVs}}$ - corresponding age of cardiovascular system

$\mathrm{CA}_{\text {ind }}$ - calendar age of the individual

$\mathrm{CA}_{\text {mean }}$ - the average calendar age of the examiniees

$R$ - multiple correlation coefficient of the biological age (BA)

SBP - systolic blood pressure

$\mathrm{TCl}$ - total conjunctival index

$\mathrm{Cl}$ - cardiac index

$A$ value of $P B A_{C V S}-C_{B A}$ below -6.3 indicates a slowing rate of ageing of the cardiovascular system, a value of $P B A_{C V S}-C_{B A}$ between -6.3 an 5.5 is the average rate of ageing of the cardiovascular system, while a value of $\mathrm{PBA}_{\mathrm{CVS}}-\mathrm{CVS}_{\mathrm{BA}}$ above 5.5 indicates an increased rate of ageing of the cardiovascular system.

The simplest and most convenient definition of biological age (BA) is the definition made through the results of blood tests, in which:

$$
\begin{aligned}
& \mathrm{BA}=91.1512-1.17 * \mathrm{M}+0.5683{ }^{*} \mathrm{ESR}-0.4346 * \mathrm{TP}+2.2088 * \mathrm{U}-0.6613 * \mathrm{C} ; \\
& \mathrm{R}=0,53 ; \mathrm{P}<0.001[2] \\
& \mathrm{M}=\text { monocyte count } \\
& \mathrm{ESR}=\mathrm{Erytrocyte} \text { sedimentation rate; } \\
& \mathrm{TP}=\text { total protein content of the Urine; } \\
& U=\text { concentration of urea; } \\
& \mathrm{C}=\text { concentration of creatinin. } \\
& \text { An equation for calculating proper biological age }(\mathrm{PBA}) \text { is: }
\end{aligned}
$$

$$
\begin{gathered}
\mathrm{PBA}=53.281+0.2793 * \mathrm{HA} \\
\mathrm{HA}=\text { chronological age }
\end{gathered}
$$

The $\mathrm{CD} 4^{+} / \mathrm{CD}^{2} 5^{+}$subpopulations of $\mathrm{T}$ lymphocytes is considered an important biomarker of ageing of the immune system, especially in persons over the age of 60 years. In elderly patients with chronic inflammatory diseases, an increase in the population of monocytes with a $\mathrm{CD}_{14}{ }^{+} / \mathrm{CD} 16^{+}$phenotype may be associated with disease progression and ageing, and can be considered a marker of proinflammatory and proatherosclerotic activity [2].

The fundamental problem in developing an arsenal of biomarkers of ageing has been the lack of a method of biomarker validation. Selection of criteria of biomarker validity remains a controversial area.

Biomarkers of ageing are needed to evaluate proposed treatments to retard ageing rates. While there are many age sensitive physiological tests, age-sensitivity is not a sufficient condition to validate a biomarker of ageing. A fundamental problem in assembling an experimentally useful battery of biomarkers has been the lack of a practical method for their validation [27]. 


\section{AGEING AND MORBIDITY}

In the Programme of Community action in the field of Health 20082013, which is currently underway was developed a list of health indicators in the European Community (European Community Health Indicators - ECHI). The ultimate goal is to create an European system of information and knowledge of health, accessible to both European experts and general public. The set of $\mathrm{ECHI}$ indicators in complete form includes 88 health indicators, and in short form contains 40 indicators for which there are available and comparable European Union data.

The life expectancy at birth in Romania has steadily improved in both sexes in the past 10 years, similar to developments in the Member States of the European Union (EU), while remaining at a lower value, approximately six years, than the EU-27 (average EU-27 in 2007 was 76.06 years for males and 82.21 years for women years, and in Romania 69.71 years for men and 76.86 years for women). Gender development in 2000-2008 was different in men the increase was 1.97 years, from 67.74 (2000) to 69.71 (2008) and for women 2.47 years 74.75 to 76.86 , faster increased life expectancy in women than in men.

Considering the proportion of chronic disease in the mortality structure, it appears that Romania is among the EU countries with very high mortality of chronic diseases (227.4 deaths per 1 million people in 2007) almost double from the EU average (only 122.4 deaths)

Causes of death from circulatory system diseases are the first cause of death in this category remarking ischemic heart disease. Specific mortality by ischemic heart disease places Romania on one of the last places in the EU (194.1 deaths per 100,000 people in 2008 in Romania instead of 84.1 in the EU). The evolution of specific mortality by ischemic heart disease has a slightly decreasing trend in the last 10 years.

After circulatory diseases cancer is the most common cause of death in Romania. In 2008, the cancer-specific mortality in Romania was close to the EU average (179.7 deaths per 100,000 people compared to 173 in the EU). If in EU the specific cancer mortality evolution is in a decreasing trend in Romania the evolution is reversed.

Specific mortality rate of diabetes is lower in Romania than the EU average in 2008 (8 deaths per 100,000 people in Romania instead of 12.9 to the EU). Possible explanations could be undetected or underreporting the number of patients with diabetes deaths.

Pneumonia specific mortality rate ranks Romania of the last places in the EU, only Ireland, Portugal and Slovakia having higher rates of pneumonia mortality. Although still higher than the EU average in 2008, the specific rate of mortality from pneumonia in Romania has a clear decreasing trend.

Among the diseases commonly associated with ageing in the U.S., a significant percentage is represented by cardiovascular and 
cerebrovascular diseases, which together count for more than $35 \%$ of deaths in the elderly, followed by cancer $23 \%$, respiratory disease $5 \%$ and diabetes $3 \%$ [3].

Obesity is becoming a worldwide epidemic, both in children and adults. Currently it is estimated that, worldwide, more than 1 billion people are overweight and 300 million are obese. More than a third of children are overweight or obese [180].

It is now clear that adipose tissue, especially abdominal visceral adipose tissue is an endocrine organ metabolically active, able to synthesize and release into the blood a wide variety of peptide and nonpeptide compounds, which may play a role in cardiovascular homeostasis. Excessive adipose tissue is associated with increased production of free fatty acids, with hyperinsulinemia, insulin resistance, hypertension and dyslipidemia [180].

Increased heart rate has been shown to be associated with an increased risk of all-cause mortality, CVD mortality and the occurrence of CVD in the general population, in hypertensives, diabetics and people with pre-existing coronary artery disease [180].

In men, the risk of sudden death is associated in particular with an increased resting heart rate. A low heart rate may exert effects on CVD by antiarrhythmic or anti-ischemic effects. Other possible mechanisms are the direct effect of heart rate on hemostasis, causing the progression of atherosclerosis [180].

Hypertension represents, for both sexes, a risk factor for $\mathrm{BC}$, heart failure, CVD, peripheral vascular disease and renal failure. BP values correlate inversely with cognitive function and hypertension is associated with an increased incidence of dementia [180].

$\mathrm{BC}$ mortality and stroke increases progressively and linearly from the values of $115 \mathrm{mmHg}$ systolic and $75 \mathrm{mmHg}$ diastolic. In addition, longitudinal data obtained from the Framingham Study indicate that BP values in the ranges 130-139/85-89 $\mathrm{mmHg}$ are associated with an increase of more than 2 times the relative risk of CVD, as compared with the BP values under $120 / 80 \mathrm{mmHg}$ [180].

Lifestyle has a strong influence on all components of the metabolic syndrome and, therefore, the main focus in the management of metabolic syndrome should be placed on lifestyle modification, supervised by specialist, particularly on efforts to reduce weight and increase the physical activity.

Hypertension, dyslipidemia and hyperglycemia (within the definition of diabetes) may still require additional medication [180].

There are numerous scientific evidences for the fact that psychosocial factors contribute independently to the risk of CVD, even after statistically controlling for the effects of standard risk factors. Besides increasing the risk of a first CVD event and worsening prognosis, these factors may act as barriers to treatment adherence and 
efforts to improve the way of life, and promoting health and well-being of patients and at the population level [180].

There are also evidence of therapeutic and preventive methods that counteract psychosocial risk factors and promote healthy behavior and the way of life. Several psychosocial measures have demonstrated beneficial effects on risk factors related to stress and those physiological and some studies have indicated improved CVD outcomes, especially in Caucasian men and in patients who achieved the immediate objectives of the therapeutic interventions [180].

Risk factors can be divided into several hierarchical categories, as follows: classical, certified, being established, suspected and also risk markers.

These factors are associated with several different biological systems, such as those that control blood platelets, coagulation, fibrinolysis, endothelial function and inflammatory response. They interact in different ways that remain incompletely known, but for which the interest and scientific discoveries are considerable [180].

In addition to their potential utility in predicting long-term CVD was been demonstrated a close association between inflammatory markers, obesity and diabetes, which brings new arguments in favor of their scientific investigation [180].

A recent European report, part of the MONICA study conducted by $\mathrm{WHO}$ indicated that the population levels of various hemostatic factors differ between centers and the participating countries, with a significant association with the incidence of CVD in those centers.

Prospective epidemiological studies have correlated also the inflammatory markers with the appearance of type 2 diabetes, and interleukin-6 (IL-6) - a pro-inflammatory cytokine - with chronic heart failure [180].

Some studies have shown that $\mathrm{BC}$ risk prediction and the $\mathrm{BC}$ and stroke risk may be enhanced by the addition of these new risk factors on the risk assessment models that include all certified risk factors [180].

A recent report from the USA suggested using CRP as 'option' in current guidelines, but this proposal was questioned both in the USA and in Europe. For this reason, it is possible that the incorporation of CRP and other risk factors being established in routine practice for cardiovascular risk prediction is premature, being proposed criteria for a rigorous assessment of such factors. These criteria include: applicability for all relevant cardiovascular events, predictive capacity in short-term, intermediate and long term pursuing, standardized measurements, the examination of variability, the degree of correlation with certified risk factors, and improving the overall prediction, among other criteria [180].

A meta-analysis number of observational epidemiological studies was conducted, for example, for CRP and fibrinogen. Such meta-analyses will provide evidences on the possible future utilities in clinical practice on the 
determinants of inflammatory markers, including physical activity, dietary factors, alcohol and weight loss as protective factors and infections such as the periodontal, as potentially treatable risk factors, encourage detailed examination of this group of markers in future studies [180].

Another important aspect in this meta-analysis is that CRP (as fibrinogen and possibly other biological markers) is often severely affected by other variables unrated and subjected to reverse causality relations (subclinical disease which causes CRP increases). Consequently, large meta-analyses, such as those cited above, fall into the trap of promoting the idea that the evidences for a causal relationship are strong. Several groups have chosen an alternative approach that directly examines genotypes, demonstrating that the association provided between CRP genotypes coding elevated circulating CRP levels are not associated with CVD or risk factors. However, a large meta-analysis of seven hemostatic genes indicated that variants of the factor $\mathrm{V}$ gene and the gene that encoding the prothrombin may have a moderate association with the risk of coronary heart disease [180].

Since the early twentieth century, Growers correlated the Parkinson disease with early ageing, disease with a maximum frequency between 60 and 70 years. The disease is more common in men, the male / female ratio in Parkinson disease is higher than one in all statistics. There are observations that the age-related degeneration of the dopaminergic system is involved in the onset of disease [181].

The above data on morbidity, life expectancy and other risk factors will be examined also for the statistical population used to conduct the clinical trial of the project, achieving statistical correlation with the actual public health indicators in the European Union, United States, and particularly Romania.

Demographically - Romania is 19 years in the demographic decline. This population decline has not yet shown the economic results because these generations numerically smaller have not yet reached reproductive age at which time it will be uncontrollable slippage. If is maintained the current total fertility rate ( 1.3 children / woman), in 2050 the economically active population (20-64 years) will reach 9 million that mean with 4 million less than today, and the population over 65 years will reach 5 million from 3.2 million as it is today. That means that to 100 adults (economically active) will revert 54 seniors. If we add to this number the young people will reach 82 people to care by 100 adults. 


\section{GEROPROTECTORS}

Lifespan extension possibility was experimentally demonstrated for many geroprotector substances, including antioxidants [75], latirogene, chelating agents (carnosine [53]), adaptogens, neurotropes, monoamine oxidase inhibitors, dehydroepiandrosterone, sexual hormones, growth hormone, melatonin [50], preparations from the pineal gland, protease inhibitors, antidiabetic agents, thymic hormones, immunomodulators, superoxide dismutase and catalase mimetics, enterosorbents, etc. [47]. According to several authors, there are not geroprotectors with antiageing effect with unquestioned efficiency, scientifically proved, there are not a few cases of supposed geroprotector substances whose long term effects have proved difficult to predict initially [2].

In the past years, a new area of the gerontology becomes important, that of studying the so called HORMESIS mechanisms by which substances classified as toxic or very harmful, in subliminal doses, may have geroprotector effects, currently being numerous scientific investigations undertaken this regard [2, 35].

Reducing caloric intake has been shown experimentally to be a certain antiageing behavior $[31,58]$. Studying the mechanisms by which calorie intake reduction influences senescence and longevity rate in experimental animals [82], researchers have correlated this required behavior with reduce plasma levels of insulin [81], increase insulin receptor sensitivity, low body temperature, cholesterol, triglycerides, alpha-lipoproteins, blood pressure and an increase in HDL cholesterol. Setting all these processes is experimentally correlated with the expression of some genes called sirtuins existing phylogenetic from yeast and to humans [39]. Sirtuins are enzymes such as deacetylase and ADP-ribosyltransferase, whose name derived from Saccharomyces cerevisiae, where they were discovered. In mammals sirtuins family consists of seven genes of this type, called Sirt1 to Sirt7. Recent researches seek to identify their role in cell physiology and mechanisms or molecular agents by which can be influenced their activity $[31,32]$.

In 2011 there have been globally described 30 substances with geroprotector properties, along side Gerovital - Romanian geroprotector product prepared by Prof. Ana Aslan in 1951, based on anesthetic procaine, noteworthy resveratrol and other polyphenols of plant origin [30], Rapamycin, antioxidants (vitamins A, C and E, carotenoids, lipoic acid, coenzyme $Q$, selenium, etc.), hormones ( $\mathrm{GH}$, thyroid hormones, adrenal and sexual hormones, melatonin [50]), bioregulatory peptides (timalin, epithalmin), biguanides (metformin, fenformin) [77], adaptogens (ginseng [48]).

Sirolimus or rapamycin, described as immunosuppressive and antitumoral drug has been shown to be also an anti-ageing drug [41] whose goal is the TOR gene in yeast [43] and mTOR gene, its 
mammalian correspondent, also known as FK506 factor or FRAP1, a serine/threonine kinase that regulates cell growth, viability, mobility, protein synthesis and gene transcription $[31,45,78]$. Rapamycin, according to recent studies, may act preventively in atherosclerosis, hypertonia and hypercoagulation, thus preventing myocardial infarction, cardiovascular accidents, osteoporosis, cancer, autoimmune diseases, arthritis, fat diabetes, Alzheimer and Parkinson diseases [31,42,45].

Data from the specific literature shows that biguanides, particularly metformin [56.77], used in the treatment of type 2 diabetes due to their ability to inhibit gluconeogenesis and to determine the increase of sensitivity to insulin may also have geroprotective effects [56].

2 deoxyglucose [78] is a glucose analog that absorbed by cells determine glucose inhibition resulting in decreased cellular energetic metabolism, situation that mimics calorie restriction. Data concerning the geroprotectection of this substance is not yet relevant.

Antioxidants such as a-tocopherol, ascorbic acid, retinol, ubiquinone, selenium, as endogenous compounds or numerous synthetic molecules, intervene in gerossuppresion based on the ageing free radical theory [87].

Resveratrol is the best known current geroprotector, discovered in 2003, present in high concentrations in the epicarp, seeds and stalk of grapes and subsequently in red wine $[30,33]$, for which Romania is famous and is specified in collections, among other things, or in roots of Polygonum cuspidatum [2]. It is a natural phytoalexin used by certain plants in defense mechanism against pathogens such as bacteria and fungi, currently extensively studied, and that can influence the expression of sirtuins [35,37]. Since its discovery in 2003 until today there were registered worldwide over 2,000 experimental studies on resveratrol, and there are laboratories focused on the study of this substance [2].

Preclinical studies on resveratrol demonstrated an increase in the longevity of $S$. cerevisiae of $70 \%$ by cultivation in a medium containing 10 $\mathrm{mM}$ resveratrol, of $20 \%$ in C. elegans and $29 \%$ in Drosophila melanogaster by treatment with $100 \mathrm{mM}$ resveratrol [39, 40].

In studies on laboratory mice, resveratrol at doses around $20 \mathrm{mg} / \mathrm{kg}$ caused a statistically significant decrease of age-related parameters such as albuminuria, the inflammatory level, vascular endothelial apoptosis, decreases in the elasticity of the aorta, the incidence of cataract, etc., being inclusively registered data towards the decrease of genetic instability [2].

On MRC5 human fibroblasts, the resveratrol in concentration of $5 \mu \mathrm{m}$ induced a significant protection of DNA oxidative deterioration, preventing the growth of nuclear volume, reducing the generation of acetylated forms of $\mathrm{H} 3$ and $\mathrm{H} 4$ histones and p53 protein. In another study on human fibroblasts, using a concentration of $10 \mu \mathrm{m}$ and $25 \mu \mathrm{m}$ have 
been obtained data supporting the delay in the morphological alterations at the cellular level correlated with age [2].

It is supposed that polyphenols such as resveratrol inhibits senescence at the cellular level by activating genes such as p53 and AKT [39], sirtuins or inhibition of others, like mTOR [46]. These influence different intracellular signaling pathways by which are controlled the expression of genes involved in cell growth, the proliferation and cell viability [34].

Clinical trials regarding resveratrol action in oncology that used a commercial form of resveratrol called SRT501 showed a 39\% increase in apoptosis of malignant cells in patients with metastatic colorectal cancer [2].

Neuroprotective effects of resveratrol $[30,35]$ have been described in experimental studies on laboratory mice and were explained by researchers by the effect of resveratrol of increasing the cysteine level that can protect cells from oxidative stress by regulating proteic precursors of amylase plate [38]. Resveratrol acts also on manganese superoxide dismutase (MnSOD) a group of enzymes that degrades metabolic generated superoxide molecules thus having antioxidant effect [80].

Cardioprotective effects of resveratrol $[30,36]$, as well as the other polyphenolic antioxidants such as quercetin or catechins, was observed in in vitro studies that showed a reduction of cardiomyocyte apoptosis by decreasing the level of caspase-3 and other cytokines, including NFKB2, E-selectin, TNF- $\alpha$ or troponin [2].

Resveratrol also has an anti-inflammatory effect $[30,33]$, resulting in decreased activity of cyclo-oxygenase with a key role in the synthesis of other cytokines such as IL17.

The theory of using antidiabetics like resveratrol [30] is explained by activating SIRT1 and subsequent increase in sensitivity to insulin [32], improving microcirculation and peripheral nerve function [2].

Resveratrol acts on the cellular mechanisms involved in photo-ageing correlated with UV action, including MAP kinases, NF-kB nuclear factor and matrix metalloproteins. External applications of resveratrol in $\mathrm{SKH}-1$ hairless mice model prior to UV exposure caused a significant reduction of cell proliferation, protection mRNA and phosphorylation [30].

The pharmacology of resveratrol [34] is still marked by a number of limitations, having a low solubility in water and consistently a low bioavailability and stability, being easily oxidized in the presence of light or heat. There are even data that contradict the fact that resveratrol would determine the extent of longevity, obtained on Drosophila melanogasterand $C$. elegans and disseminated by some authors [36].

Among the many hormones above mentioned with geroprotector effects [49], greater relevance for this project have the substances with similar actions of sexual hormones. Substances such estrogen like, 
testosterone like, which stimulate or inhibit various neuroendocrine mechanisms [49] are detected in the organic component of therapeutical muds and their geroprotective action is currently intensively studied.

The testosterone serum level gradually decreases along with the advancing in age which caused a progressive muscle atrophy, fatigue, osteoporosis, reduced sexual function and increased fat levels, all this can be treated by administration of testosterone [22], which has as effect, in addition to a recovery of lipid levels also a decrease of concentration of plasma glucose correlated with increased sensitivity to insulin.

The last half of the century allowed due to numerous scientific results, the use of estrogen in postmenopausal women to prevent signs of ageing, such as osteoporosis, cardiovascular diseases, decrease sexual and cognitive functions [52].

However, the enthusiasm was diminished by the recent publication of the results of some studies that show the risks of using estrogen, including breast cancer, pulmonary embolism, stroke and coronary heart disease. In this context, we can discuss by the importance of phytoestrogens and estrogen like substances from peloids composition whose effects does not reach the mentioned risks [2, 55].

Investigating the physiological effects of Procaine, an anesthetic $[79,83,54]$ from Gerovital composition on bee neurons cultures, showed that this acts on $\mathrm{Na}^{+}$voltage- dependent channels or ligand-dependent channels [51].

Procaine has known neuroprotective properties, preventing the formation of amyloid plaques and preserving ATP depletion, most likely by inhibiting neurotoxic effect of glutamate, like has been shown in PC12 rat cells cultures [76].

Procaine is used in cardioplegia and in stabilizing the postischemic cardiac rhythm after the aortic decompression in cardiac surgery [84]. Anti-atherogenic effects of Gerovital and Aslavital were confirmed by recent studies regarding the LDL oxidation and inhibition of the generation of superoxide radicals, thus having antioxidant properties by which interfere with cellular and molecular mechanisms of ageing $[85,86]$.

The amount of procaine hydrochloride from Gerovital H3 - tablets / vials and Aslavital H3 - tablets / vial is $100 \mathrm{mg}$ plus $6 \mathrm{mg}$ of the benzoic acid, $5 \mathrm{mg}$ of potassium metabisulfite and $0.5 \mathrm{mg}$ biphasic sodium phosphate. The preventive treatment involves taking two tablets / day at 2-3 hours after meals, for 12 days. The treatment is resumed after a break of one month. Parenteral the treatment is made 3 times/week for 4 weeks. Treatment is resumed after a break of 1-2 months. A combination therapy is recommended - 4 weeks injection (12 vials) 30 days break followed by a 12 days treatment with tablets. After 24 days, a new course of treatment can be started. 


\section{NUTRITION AND AGEING}

A healthy diet from an early age contributes to a healthier older age. Policies and programmes are nedded to change children's present dietary habits and on developing measures to prevent obesity. However, a healthy diet is needed at all stages of life, especially in old age. Even though obesity is common in older people, the issue of malnutrition (in hospitals, nursing homes and home) is even more striking among older people. A healthy diet should provide the different nutrients one needs to remain healthy and should give the opportunity to engage socially and to have a good quality of life. However, the precise dietary needs of the older people are still largely unknown.

A 10-year longitudinal SENECA study conducted in 7 different European countries examined three risk factors (smoking, physical activity and diet quality) on 1,281 adults $(m=631, w=650)$. In general, smokers did not perform regular physical exercise and followed poor quality diets. The study found that this group had a mortality risk 3 to 4 times greater than those who had the opposite health behaviour. When only 2 out of the 3 mentioned risk factors were present, the mortality risk still remained 1.2 to 2 times higher $[\mathrm{x}]$.

Obesity at old age is very often associated with poor diet and frailty, which may lead to functional decline and disability; consequently, the quality of life can significantly be altered[26]. In the case of severe obesity, serious medical complications are frequent such as, type 2 diabetes, hypercholesterolemia, hypertriglyceridemia, gout, arterial hypertension and coronary diseases. Furthermore, the prevalence of cancer may be increased in obese women (breast, endometrial, gallbladder, cervix, and ovaries) as well as in obese men (colon and prostate) [27]. Other complications of obesity are deep venous embolism, pulmonary embolism, sleep apnea, Pickwickian syndrome and gallbladder disease, and more frequently, intertrigo, bed sores and poor wound healing. As previously mentioned, all these comorbidities influence functional decline and physical dependence in daily life $[\mathrm{x}]$.

Undernutrition is very common amongst the elderly. Risk factors for protein- energy malnutrition include i) socio-economic factors, such as poverty and social isolation, ii) psychological and mental factors, such as depression and dementia, and iii) physical factors, such as impaired mobility, severe visual deficit, poor dentition, chewing difficulties and somatic diseases (in particular hyperthyroidism and hyperparathyroidism). In addition, undernutrition in old age can also be linked to disability (limitations in basic and instrumental activities of daily life - such as the need for help for shopping and meal preparation, or feeding assistance) [1]. It can therefore be concluded that it is possible that undernutrition in old age results from interactions between ageing, social factors, psychological and medical difficulties and environment. 
The prevalence of undernutrition in old age varies with the nutrition assessment tool used, the place of residence (individual or nursing home) and the comorbidities and functional abilities of the studied population. The prevalence of undernutrition varies from 5 to $10 \%$ in independent healthy old people living at home, reaches 30 to $60 \%$ in hospitalized patients and culminates to 40 to $90 \%$ in long-term care institutions [29,30].

The consequences of undernutrition are multiple and often severe: decubitus ulcers, immune dysfunction which leads to infections, sarcopenia and osteopenia/osteoporosis, which in turn lead to falls and fractures, cognitive impairment, decreased breathing capacity, decreased glomerular filtration rate and indeed disturbed drug metabolism [27].

The impact of undernutrition on survival is evident. Among 83 acutely ill patients (83 \pm 7 years) admitted in an acute geriatric ward, it was shown that the undernourished (evaluated using either the subjective global assessment or the mini nutritional assessment) had significantly higher risks of dying within a 1-year and 3-year interval than the wellnourished (respectively $40 \%$ compared to $20 \%(p=0.03$ ) and $80 \%$ compared to $50 \%(p<0.05)$ [23].

Food and eating habits have nutritional, medical, psychological, cultural and social aspects. Good nutrition also plays a significant part in the well-being of healthy older people and in delaying and reducing the risk of contracting disease.

General dietary recommendations on what we should eat to fell well are also relevant and important for older people. They should, for example, not choose food that has a high salt or sugar content, but they should choose soft fats instead of hard fats, choose food with good carbohydrates and large amounts of fibre, and prepare their food with as little cooking fat as possible. Other important dietary components include vitamin $D$ and calcium, especially considering high prevalence of osteoporosis and hip fractures.

Even though older people's energy requirement is lower than younger people's, their need for essential nutrients is just as high or sometimes even higher. The nutrient density of food, i.e. its nutritional content in relation to its energy content, becomes increasingly important as a person gets older. Special attention needs therefore to be paid to the balance between energy and nutrients. Among older people, higher body weight does not necessarily mean poorer health. Retained body weight in older people can be seen as an indicator of sound health.

Plants / algae with healthy ageing recommendations:

1. Sea buckthorn (Hippophae rhamnoides L.) - Since the ancient Tibetans started using sea buckthorn more than one thousand years ago, hundreds of Asian traditional recipes have been developed and carried on through generations, utilizing the nutritional and medicinal properties 
of the berry. Through the long history of application as food and medicinal ingredients, sea buckthorn berry is known to be effective in treating wounds, inflammation, mucous-membrane-related disorders and diseases such as cough, sputum, gastric and gynecological problems. During the past few decades, inspired by the long traditional use and the increasing public recognition of the benefits of natural products, scientists have carried out extensive research on sea buckthorn. This has resulted in an improved understanding of the health effects and the chemical composition of the berry. It is known that the berry is rich in multiple lipophilic and hydrophilic bioactive compounds such as vitamin $\mathrm{C}$ and $\mathrm{E}$, carotenoids, flavonoids, fatty acids, plant sterols, lignans, and minerals [243]. Current research is now beginning to understand and support the traditional uses of sea buckthorn. A wide spectrum of pharmacological effects of sea buckthorn has been recently reported, including antioxidant, immunomodulatory, anti-atherogenic, anti-stress, hepatoprotective, radioprotective and tissue repair [343].

2. Hibiscus sabdariffa - an ingredient found in many herbal tea blends and other beverages, has antioxidant properties, and, in animal models, extracts of its calyces demonstrated hypocholesterolemic and antihypertensive properties. Concentrated beverages lower blood presure and have an effect similar to common hypotensive drugs [218].

3. Zingiber officinale - The main pharmacological actions of ginger and compounds isolated there from include immuno-modulatory, antitumorigenic, anti-inflammatory, anti-apoptotic, anti-hyperglycemic, antilipidemic and anti-emetic actions. Ginger is a strong anti-oxidant substance and may either mitigate or prevent generation of free radicals. It is considered a safe herbal medicine with only few and insignificant adverse/side effects. Ginger extracts have been extensively studied for a broad range of biological activities, especially antioxidant activities found that ginger significantly lowered lipid per oxidation by maintaining the activities of the antioxidant enzymes -super oxide dismutase, catalase and glutathione peroxides [355].

4. Spirulina platensis (Arthrospira) - Some of the early health effects of spirulina were in its role in diabetes management and its significant plasma triglycerides reduction effects (total- and LDL-cholesterol), blood pressure lowering, improving the antioxidant status, as well as inflammatory effects. Recent reports note the importance of spirulina for its immunomodulatory, anti fatigue and radio protective effects. Spirulina is commonly used in Asian cuisine. In America, spirulina is sold in health food stores as a powder or tablet. In Russia, it has been approved to treat symptoms of radiation sickness, because the carotenoids it contains absorb radiation. Spirulina also is reported to slow neurological damage in aging animals, and also to lessen the damage caused by stroke. Studies also show that spirulina can prevent the release of histamines, treating allergy symptoms. The melanosis and keratosis improving 
capacity of Spirulina has also been demonstrated. Spirulina: has profound antioxidant potential, Its true health-protective merit has only recently been discovered. Phycocyanobilin (PCB), the chromophore bound to chief protein, phycocyanin, can function as a potent inhibitor of NADPH oxidase, the enzyme complex that is the chief source of pathological oxidant stress in a wide range of health disorders. It appears to mimic the physiological activity of free bilirubin. NADPH oxidase overactivity in disorders had suggested that ample intakes of Spirulina may prevent and has therapeutic potential with respect to many vascular diseases (including atherogenesis, hypertension, and congestive heart failure), cancers, complications of diabetes, and a range of neurodegenerative, fibrotic, or inflammatory disorder. Oral administration of phycocyanin or of whole Spirulina has exerted central neuroprotective effects in rodent studies - an observation which strongly suggests that PCB can transit the blood-brain barrier [411-430].

5. Brown algae - The current application of chemical compounds isolated from diverse classes of algae is enormous. Since 1975, three areas of research in aquatic natural products have emerged: toxins, bioproducts and chemical ecology. Over 15,000 novel compounds have been chemically determined. Focusing on bioproducts, recent trends in drug research from natural sources suggest that algae are a promising group to furnish novel biochemically active substances. In many countries, the food industries consume awide range of algae, which are well known to have high contents of fiber, minerals, vitamins and different antioxidants. The investigation of new algal chemical compounds, a different source of natural products, has proved to be a promising area of pharmaceutical study. Many reports have been published about isolated compounds from algae with biological activity, demonstrating their ability to produce metabolites unlike those found in terrestrial species, with high complexity and unlimited diversity of pharmacological and/or biological properties [431-440].

6. Vitis vinifera - Together with aroma and taste, color is an essential feature in the sensory evaluation criteria of wine quality, influencing wine consumer selection. Polyphenols are the main contributors for certain organoleptic characteristics of wines, such as astringency and bitterness, but in particular color. In addition, interest in wine phenolics is still increasing due to their antioxidant and free radical-scavenging proprieties, supported by the health benefits resulting from the moderate wine consumption with respect to cardiovascular diseases, cancer, diabetes, and others [461]. Grapes and grape products have an economic value where they are mostly consumed as table grapes, grape juice or raisins. Extract of grape has been reported to exhibit antioxidant activity, scavenging both free radicals and reactive oxygen species both in vivo and in vitro. Also, it is well established that phenolic compounds play a vital role in determining the grapes antioxidant activity [462]. 
7. Echinaceae herba - The herb, Echinacea, after making its debut on the world's commercial markets more than a decade ago, has become one of the top-selling herbs of all time. Many of its ingredients are powerful immune system stimulators. Its contents include high molecular weight polysaccharides, essential oils, alkylamides such as echinacein, isobutylamides such as pentadecadienes and hexadecadienes, polyacetylene, tannins, inulin, heteroxylan, flavonoids and vitamin C. Indeed, the biochemistry and content definition of Echinacea and most other herbs has taken place decades before the medicinal value of the phytochemicals they contain ever merited investigation. Some of the contents of Echinacea are natural killer (NK) cell stimulants while others (the alkylamides) inhibit the endogenous suppressors of NK cells, i.e. the prostaglandins. Daily consumption of Echinacea is indeed prophylactic, extends the life span of aging mice, significantly abates leukemia and extends the life span of leukemic mice. Given that humans are $97 \%$ genetically common with mice and that virtually all our basic physiology is identical, it is neither unjustified to extrapolate these observations to humans nor would it be an arduous task to perform many of these studies in humans, thus establishing viable scientific evidence [463].

8. Rubus caesius L. - blackberry (Rosaceae) is a common species from the Romanian flora, in the steppe areas to the beech level, on balks, near fences, through plough lands, orchards, bush-like trees, forest edges, riverside coppices, water sides, especially in plain areas, rarely in mountainous areas. It blossoms in May-June, sometimes until September and has numerous varieties. Starting from the main principle of chemo-taxonomy, that is if a species includes some active principles, we can expect that its phylogenetically related species, especially if they come from the same genus, have a similar chemical composition from qualitative point of view. From phytochemical point of view, the leaves coming from the species of Rubus (Rubi caesii folium, Rubi idaei folium, Rubi fruticosi folium) include a variety of components like: Gallic tannin, flavonosides (heterosides with aglycons of quercetol and campherol), antocianosides (cyanidol heterosides), pentacyclic triperpenoids, pectines, organic acids (malic acids, citric acid, isocitric acid, succinic acid, oxalic acid), oze, lipids, vitamins, mineral salts. Rubus species have astringent, antidiarrheic, easy laxative, depurative, antiseptic, hypoglicemiant, nutritive, tonic, haemostatic, diuretic, vulnerary, antiinflammation action. Medicinal products taken from Rubus species are used in diarrhoeas, menometroraghias, pulmonary diseases, angina pectoris, laryngeal-pharyngeal inflammations, haemorrhoids, anal fissures, leukorrhea. For medicinal purposes Rubus species often serve as leaves infusions and decocts, as well as for syrups resulted from fruits pressing. The fruits taken from Rubus species are used in feeding, for making jam, marmalade, syrup [455]. 
9. Allium sativum - Garlic is one of the World's oldest medicines and has been employed not only for flavouring, but also as a medical herb for its diverse biological activities, including anti-carcinogenic, antiatherosclerotic, antithrombotic, antimicrobial, antiinflammatory and antioxidant effects. Recently the scientific community has taken it seriously and started to conduct proper investigation and clinical trials to confirm these activities. Indeed for its antioxidant properties the role of garlic in preventing age-related diseases and cardiovascular disease has been investigated extensively over the past 10-15 years. The more important clinical application is its role as an antihypertensive and protector of the cardiovascular system. Epidemiological studies showed an inverse correlation between garlic consumption and the progression of cardiovascular disease. Cardiovascular disease is associated with multiple factors (raised serum total cholesterol, raised LDL and an increase in LDL oxidation, increased platelet aggregation and hypertension) and numerous in vitro studies have confirmed the ability of garlic to reduce these parameters. However the numerous experimental findings are frequently conflicting. The negative results obtained in some clinical trials may also have originated from the use of different garlic preparations, unknown active components and their bioavailability, inadequate randomization, selection of inappropriate subjects and the short duration of trials. Nevertheless, garlic appears effective in reducing parameters associated with cardiovascular disease, even if more indepth and appropriate studies are required. The beneficial effects of garlic supplementation in reducing blood pressure and offering cardioprotection seems to be due to its ability to counteract oxidative stress. The antioxidant activity of Allium spp. has been attributed mainly to a variety of sulphur-containing compounds and their precursors. Scientific evidence shows that allicin, diallyl disulphide and diallyl trisulphide appeared to be the main antioxidative compounds. In addition, the antioxidant activity is also related to other bioactive compounds: dietary fibers, microelements (especially Se) and polyphenols [457].

10. Achillea millefolium - popularly known as "yarrow" , is a member of the Asteraceae family that has been used as medicine by many cultures for over 3000 years. The medicinal properties of A.millefolium are worldwide recognized. Different preparations of A.millefolium have been shown to have anti-inflammatory, antitumor, antimicrobial, liver protective and antioxidant properties. In addition, previous studies have reported that infusions prepared from Achillea species had an antioxidant capacity, which is consistent with their total flavonoid and phenol contents. It was found that Achillea infusions are good scavengers of active oxygen species, including the hydroxyl $(\mathrm{OH} \quad)$ and 2,2-diphenyl1-picrylhydrazyl (DPPH ) radicals, and H2O2 [458]. 


\section{STRATEGIES FOR HEALTHY AGEING}

Disease prevention and healthy ageing are not a very difficult task, at least theoretically, if simple rules should be strictly followed [52]: physical exercise, drinking enough water, balanced nutrition to maintain equilibrium, keeping the environment sanogenous, early diagnosis, maintaining positive emotional attitudes through appropriate socialization with friends and relatives [7]. In practice, unfortunately, things are not so easy.

For many medical problems that people may have, such as allergies, lung, dermatological, rheumatic, gynecological problems and many more, especially for disease prevention, stress reduction, prevention and comfort, using natural therapeutic factors through health tourism represents a concerned solution for the international scientific community by various experts, medical, social and environmental programs [48].

Generation and exploitation of knowledge have become vital sources of the welfare increased at the global level. Knowledge also represents the central element that determines competitiveness and such as states of the world, especially the developed ones, have engaged in its systematic generation, developing national systems and international interactions more sophisticated.

At international level, the scientific data on mud and mineral waters therapeutically used in various medical conditions are relatively few, and have a general aspect. Search through the literature has shown that in other European countries the situation is similar in terms of the scientific reasoning in the use of natural therapeutic factors in balneary cures.

This leads us to believe that the accumulation of a convincing experience in this scientifically field opens new opportunities for international collaboration.

The mechanisms of the human body adaptation to the dynamics biological and psychosocial factors represents the conceptual reference framework that allows to understanding biological phenomenon in all its complexity.

Anti-ageing medicine is a relatively new medical domain that is growing with a very fast rate. This is a domain of the advanced scientific and medical technologies application in the prevention, early detection, treatment and cure of age- related dysfunctions.

The purpose of anti- ageing medicine is not only the one of lifetime extension but chiefly to support a healthy life for a longer period of time. Therefore, the most often used term of the specialists today is the healthy-ageing instead of anti-ageing.

Healthy- Ageing is a clinical domain that includes more than 30,000 specialists from 80 worldwide countries (according to statistics from 2009). 
Anti- ageing medicine combines diagnostic and treatment biomedical technologies intended to detect early various diseases and prescription of an efficiently treatment. Computed tomography, ultrasonography, positron emission tomography, stem cell therapy, genetic engineering and medical nanotechnology are therefore components of Anti ageing medicine whose medical significance is fully understood today.

In balneary resorts, medical act may be oriented to prevention, treatment or recovery and has a direct connection with anti-ageing medicine. European balneary resorts offer a wide range of services. Currently, the use of natural therapeutic factors in the services carried under medical supervision, is accompanied by a number of techniques to help patients improve their health (physiotherapy, physiotherapy etc.).

The conceptions and orientations of modern medicine, which approaches health as a fundamental human right, the introduction of the criteria for the health assessment of the notions of quality of life, lifestyle, wealth led to a reassessment of healthcare in the climatic balneary resort as the balneology in general. Between traditional balneology and traditional tourism has emerged comfort tourism, health tourism or prophylactic health cures that are based on quality of life, closely intertwined with the protection of the health and psycho-physical valid ratio, targeted by the healthy-ageing medicine.

The new assessment criteria show the huge leap recorded in therapy with natural healing factors, from periods of crisis when the lack of a solid scientific substantiation of the methodology used being based mostly on empiricism it has criticized, to the many studies and scientific research proved efficiency and recovery of treatment cycles in different disease groups, on the basis of a complex methodology.

The modern assessment of health, welfare, quality of life, requires the continuation and development of scientific research to determine the mechanisms of action and therapeutic effects of natural therapeutic factors. Are prioritized the research on the methodology and the effects of "health cures" which is the most important area of primary prevention of major disease pathologies related to the civilization lifestyle in the new millennium. The awareness levels of the potential for development of balneary tourism in conjunction with the use of strategic advantages offered by natural factors research is unfortunately very low.

Implementation of most of the anti - ageing measures are based on the simple idea but logic which considers that ageing is determined solely by biological processes that adversely affect the functioning of the body. Therapeutic consequence of this idea is that the correct action on life processes related to ageing mechanism will have favorable results and will have positive effects on active longevity.

Ageing is the major driving factor of disease in the $21^{\text {st }}$ century. Manipulation of ageing-related genes by diet, lifestyle, and pharmaceuticals could dramatically improve human health and could be 
used to develop drugs against age-related diseases such as cancer, heart disease, type 2 diabetes, obesity, and neurodegenerative diseases. The hundreds of ageing-related genes and genes related to calorie restriction (CR) already identified offer enormous opportunities for target discovery. Although ageing-related genes cannot be modified in humans, a deepened understanding about how these can be manipulated by diet or pharmaceuticals can have a profound impact on health. In other words, work on the genetics of ageing allows the identification of novel genomic targets for drug development, opening the door for ageing pharmacogenomics [451].

Already more than 20 companies worldwide are focusing specifically on the ageing process (http://whoswho.senescence.info/corp.php), in addition to transnational pharma companies with ageing-oriented research and development projects. Although this number is modest, it shows the growing potential of a field that is bound to increase. In 2008, GlaxoSmithKline purchased Sirtris Pharmaceuticals for $\$ 720$ million, a huge amount for a company with no clinical data; presumably the purchase was based on the extraordinary potential suggested by a compound capable of delaying ageing - resveratrol. We now know hundreds of genes that regulate ageing in model organisms, dozens associated with longevity in humans, and hundreds differentially expressed with age. This vast amount of information yields increased power for personalized and stratified medicine, for identifying biomarkers of ageing, and for drug development to extend lifespan and ameliorate age-related diseases. Overall, it gives us a blueprint (albeit still imperfect) of how ageing is controlled that we can use to potentially manipulate the basic ageing process, whatever its underlying molecular mechanisms may be. Moreover, our knowledge of nutrient-sensing pathways that mediate the effects of CR has greatly increased in recent years, opening new opportunities for drug discovery and ultimately for perhaps developing an antiageing pill that retards ageing with minimal side effects [451].

Delaying the process of ageing, even slightly, would have profound social, medical and economic benefits. For example, slowing ageing by a mere 7 years would cut mortality of age-related diseases by half at every age. Therefore, the potential benefits from research on the basic biology and genetics of ageing are unparalleled in terms of improving quality of life and health. Unlocking this capacity to manipulate ageing in people would result in unprecedented human health benefits, and it opens new opportunities for industry [451].

Applied research based on ageing-related pathways is dominated by CR mimetics, and some developments have already captured widespread attention. Based on the NAD ${ }^{+}$-dependent class III of histone deacetylase enzymes called sirtuins, which have been reported to mediate the life-extending effects of $\mathrm{CR}$, a number of laboratories and 
companies, including Sirtris (http://www.sirtrispharma.com), cofounded by David Sinclair, have since focused on identifying compounds that modulate the activity of sirtuins [451].

Health Promotion means predominantly education: teaching health behaviour and attitudes in order to prevent disease. Balneoprevention is the term proposed for the prophylactic use of healing waters and peloids. Balneotherapeutical products at home would be a very useful initiative in the field of Balneotherapy. Standardised and effective balneological products could be used in comparative trials, helping accumulation of scientific evidence and decreasing the "locality" of balneotherapy [234].

The balneary and health tourism could benefit from results of this project based on new types of geriatric treatments and thus, influence Romania's tourism for which balneary potential is huge but untapped. Health tourism could be one of the directions of development of this area of business. Development of healthy ageing products could bring financial sustainability of healthy ageing businesses in which society as a whole becomes a beneficiary in many ways. Spa resorts can benefit by promoting and capitalization with scientific arguments of balneary resources and new healthy-ageing products. According to the principle of sustainable and efficient development of natural resources, considering that compliance with these principles and the future of the community depends, tourism development is an advantage for income, employment and social cohesion.

The plant kingdom has kept offering remedies for humans from time immemorial. Nearly a quarter of our current drug arsenal is from higher plants. Plants are still a major source for discovery of new lead compounds for the pharmaceutical industry. During the last two decades nearly $50 \%$ of the newly introduced drugs are of plant origin or analogues thereof. Bioprospecting has been the classical pharmaceutical view of plants as sources for discovery of new lead compounds or potent bioactive molecules. As potency is a rare trait of phytochemicals, bioprospecting is gradually overridden by the more holistic and integral view of using plant mixtures, extracts or partially purified extracts. Researchers have started discovering traditional and ethnomedicine anew. By 2016, the global nutraceutical market will exceed 207 billion U.S. dollars [212]. 


\section{REFERENCES}

1. Magalhães J.P., Wuttke D., Wood S.H., Plank M., Vora C., 2012, Genome-Environment Interactions That Modulate Aging: Powerful Targets for Drug Discovery, Pharmacol Rev 64(1):88-10

2. Sharman A., Zhumadilov Z., 2011, The Scientific Basis for Healthy Ageing and Antiageing Processes, New York

3. Goldsmith T.C., 2013, The Evolution of Ageing How New Theories Will Change the Future of Medicine, Third Edition

4. Healthy people 2020 http://www.healtypeople.gov/2020/default.aspx

5. Luts W., Sanderson W., Scherbov S., 2001, The end of world population growth. Nature 412: 543-545

6. Stegeman I., Otte-Trojel T., Costongs C., Considine J., 2012, Healthy and Active Ageing

7. Diener Ed., Chan M.Y., 2011, Happy People Live Longer: Subjective Well-Being Contributes to Health and Longevity, Applied Psychology: Health and Well-Being 3(1): $1-43$

8. Munteanu C., 2012, Namolul terapeutic, Editura Balneara

9. Peterson W., 1999, Founder of Modern Demography: Malthus. Transaction Publischers, New Brunswick, P 302

10. Rattan S.I.S., 2006, Theories of biological ageing: Genes, proteins and free radicals, Free Radical Research 40(12): 1230-1238

11. Lapointe J., Hekimi S., 2010, When a theory of ageing ages badly, Cell. Mol. Life Sci. 67: $1-8$

12. Cevenini E., Bellavista E., Tieri P., Castellani G., Lescai F., Francesconi M., Mishto M., Santoro A., Valensin S., Salvioli S., Capri M., Zaikin A., Monti D., de Magalhães J.P., Franceschi C., 2010, Systems Biology and Longevity: An Emerging Approach to Identify Innovative Anti-Ageing Targets and Strategies, Current Pharmaceutical Design 16: $802-813$

13. Liu G.H., Ding Z., Izpisua Belmonte J.C., 2012, iPSC technology to study human ageing and ageing-related disorders, Current Opinion in Cell Biology 24: 1-10

14. Bengtson V. et al., 2009, Handbook of theories of ageing, 2nd edition

15. De la Fuente M., 2002, Effects of antioxidants on immune system ageing, Eur. J. Clin. Nutr. 56: S5-S8

16. Eleftherianos I., Castillo J.C., 2012, Molecular Mechanism of Ageing and Immune System Regulation in Drosophila, Int. J. Mol. Sci. 13: 9826-9844

17. Salminen A., Kaarniranta K., 2010, Genetics vs. entropy: Longevity factors suppress the NF-kB-driven entropic ageing process, Ageing Research Reviews 9: 298-314

18. Trindale L.S., Aigaki T., Peixoto A.A., Balduino A., Mânica da Cruz I.B., Heddle J.G., 2013, A novel classification system for evolutionary ageing theories, Frontiers in Genetics 4 (25): 1-8

19. De Grey A.D.N.J., 1999, The Mitochondrial Free Radical Theory of Ageing (Molecular biology intelligence unit), R.G. Landers Company

20. Wickens A.P., 2001, Ageing and the free radical theory, Respiration Physiology 128: 379-391

21. Butler R.N., Sprott R., Warner H., Bland J., Feuers R., Forster M., Fillit H., Harman M., Hewitt M., Hyman M., Johnson K., Kligman E., McClearn G., Nelson J., Richardson A., Sonntag W., Weindruch R., Wolf N., 2004, Biomarkers of Ageing: From Primitive Ormanisms to Humans, Journal of Gerontology: Biological Sciences 59A(6): 560-567

22. Banerjee C., Ulloor J., Dillon E.L., Dahodwala Q., Franklin B., Storer T., Sebastiani P., Sheffield-Moore M., Urban R.J., Bhasin S., Montano M., 2011, Identification of serum biomarkers for ageing and anabolic response, Immunity \& Ageing 8: 5

23. Johnson T.E., 2006, Recent results: Biomarkers of ageing, Experimental Gerontology 41: $1243-1246$

24. Adelman R.C., 1987, Biomarkers of ageing, Experimental Gerontology 22: 227-229

25. Davinelli S., Vasto S., Caruso C., Zella D., Scapagnini G., 2012, Molecular Biomarkers of Ageing, Senescence, Edited by Dr. Tetsuji Nagata 
26. Anisimov V.N., Khavinson V.Kn., Mikhalski A.I., Yashin A.I., 2011, Effect of synthetic thymic and pineal peptides on biomarkers of ageing, survival and spontaneus tumour incidence in female CBA mice, Mechanisms of Ageing and Development 122: 41-68

27. Hochschild R., 1990, Can an Index of Ageing Be Constructed for Evaluating Treatments to Retard Ageing Rates? A 2,462 - Person Study, Journal of Gerontology: Biological Science 45(6): B187-214

28. Sloane L.B., Stout J.T., Austad S.N., McClearn G.E., 2011, Tail Tendon Break Time: A Biomarker of Ageing?, J. Gerontol. A Biol. Sci. Med. Sci. 66A(3): 287-294

29. Garagnani P., Bacalini M.G., Pirazzini C., Gori D., Giuliani C., Mari D., Di Blasio A.M., Gentilini D., Vitale G., Collino S., Rezzi S., Castellani G., Capri M., Salvioli S., Franceschi C., 2012, Methylation of ELOVL2 gene as a new epigenetic marker of age, Ageing Cell 11: 1132-1134

30. Baxter R.A., 2007, Anti-ageing properties of resveratrol: review and report of a potent new antioxidant skin care formulation, Journal of Cosmetic Dermatology 7: 2-7

31. Kaeberlein M., 2010, Resveratrol and rapamycin: are they anti-ageing drugs?, BioEssays 32: 96-99

32. Park S.J., Ahmad F., Philp A., Baar K., Williams T., Luo H., Ke H., Rehmann H., Taussig R., Brown A.L., Kim M.K., Beaven M.A., Burgin A.B., Manganiello V., Chung J.H., 2012, Resveratrol Ameliorates Ageing-Related Metabolic Phenotypes by Inhibiting cAMP Phosphodiesterases, Cell 148: 421-433

33. Valenzano D.R., Cellerino A., 2006, Resveratrol and The Pharmacology of Ageing A New Vertebrate Model to Validate an Olt Molecule, Cell Cycle 5(10): 1027-1032

34. Mishra R.N., 2011, Resveratrol - The New Rasayan (Anti ageing) Drug, Current Research in Medicine and Medical Science 1(1): 5-18

35. Camins A., Pelegri C., Vilaplana J., Cristofol R., Sanfeliu C., Pallàs M., 2009, Sirtuin and Resveratrol, Micronutrients and Brain Health 22: 329-340

36. Kelly G.S., 2010, A Review of the Sirtuin System, its Clinical Implications, and the Potential Role of Dietary Activators like Resveratrol: Part 2, Altern. Med. Rev. 15(4): 313-328

37. Kaeberlein M., McDonagh T., Heltweg B., Hixon J., Westman E.A., Caldwell S.D., Napper A., Curtis R., DiStefano P.S., Fields S., Bedalov A., Kennedy B.K., 2005, Substrate-specofic Activation of Sirtuins by Resveratrol, The Journal of Biological Chemistry 280(17): 17038-17045

38. Guarente L., 2011, Sirtuins, Ageing, and Medicine, N. Engl. J. Med. 364: 2235-2244

39. Wenzel U., 2006, Nutrition, Sirtuins and Ageing, Genes and Nutrition 1(2): 85-94

40. Wood J.G., Rogina B., Lavu S., Howitz K., Helfand S.L., Tatar M., Sinclair D., 2004, Sirtuin activators mimic caloric restriction and delay ageing in metazoans, Nature 430: 686-689

41. Robida-Stubbs S., Glover-Cutter K., Lamming D.W., Mizunuma M., Narasimhan S.D., Neumann-Haefelin E., Sabatini D.M., Blackwell T.K., 2012, TOR Signaling and Rapamycin influence Longevity by Regulating SKN-1/Nrf and DAF-16/FoxO, Cell Metabolism 15: 713-724

42. Wilkinson J.E., Burmeister L., Brooks S.V., Chan C.C., Friedline S., Harrison D.E., Hejtmancik J.F., Nadon N., Strong R., Wood L.K., Woodward M.A., Miller R.A., 2012, Rapamycin slows ageing in mice, Ageing Cell 1-8

43. Blagosklonny M.V., 2006, Ageing and Immortality Quasi-Programmed Senescence and Its Pharmacologic Inhibition, Cell Cycle 5(18): 2087-2102

44. Anisimov V.N., Sikora E., Pawelec G., 2009, Carcinogenesis and Ageing, Open Longevity Science 3: 1-10

45. Stanfel M.N., Shamieh L.S., Kaeberlein M., Kennedy B.K., 2009, The TOR pathway comes of age, Biochim. Biophys. Acta 1790: 1067-1074

46. Demidenko Z.N., Blagosklonny M.V., 2009, At concentrations that inhibits mTOR, resveratrol suppresses cellular senescence, Cell Cycle 8(12): 1901-1904

47. Pandey S., Devmurari V., Goyani M., Bhavika R., 2010, Anti Ageing Therapy: Various Alignments to Control Premature Ageing, Inter. J. of Pharma and Bio Sciences 1(2): 117 
48. Perazzo F.F., Fonseca F.L.A., Souza G.H.B., Maistro E.L., Rodrigues M., Carvalho J.C.T., 2010, Double-Blind Clinical Study of a Multivitamin and Polymineral Complex Associated with Panax ginseng Extract (Gerovital), The Open Complementary Medicine Journal 2: 100-104

49. Kim H.J., Kim H., Shin J-H., Ku S-Y., 2009, Current Status Of Anti-Ageing Medicine, Especially Involving Management of the Menopause, as a Component of Complementary and Alternative Medicine in Korea, Anti-Ageing Medicine 6(10): 95-101

50. Bhavsar B., Farooq M.U., Bhatt A., 2009, The Therapeutic Potential of Melatonin in Neurological Disorders, Recent Patents on Endocrine, Metabolic \& Immune Drug Discovery 3: 60-64

51. Devaud J-M., Blunk A., Podufall J., Giurfa M., Grünewald B., 2007, Using local anaesthetics to block neuronal activity and map specific learning tasks to the mushroom bodies of an insect brain, European Journal of Neuroscience 26: 3193-3206

52. Jinno M., Tamura H., Yonei Y., 2012, Anti-Ageing Medicine and Reproductive Health, Anti-Ageing Medicine 9(1): 6-13

53. Hipkiss A.R., Cartwright S.P., Bromley C., Gross S.R., Bill R.M., 2013, Carosine: can understanding its action on energy metabolism and protein homeostasis inform its therapeutic potential?, Chemistry Central Journal 7: 38

54. Dobosz M., Wajda Z., Hać S., Myśliwska J., Bryl E., Mionskowska L., Roszkiewicz A., Myśliwski A., 1999, Nitric Oxide, Heparine and Procaine Treatment in Experimental Ceruleine-Induced Acute Pancreatitis in Rats, Archivum Immunologiae et Therapiae Experimentalis 47: 155-160

55. Binstock R.H., Juengst E.T., Mehlman M.J., Post S.G., 2003, Anti-Ageing Medicine and Science: An Arena of Conflict and Profound Social implications, Geriatrics \& Ageing 6 (5): 61-63

56. Anisimov V.N., Egormin P.A., Piskunova T.S., Popovich I.G., Tyndyk M.L., Yurova M.N., Zabezhinski M.A., Anikin I.V., Karkach A.S., Romanyukha A.A., 2010, Metformin extends life span of HER-2/neu transgenic mice and in combination with melatonin inhibits growth of transplantable tumors in vivo, Cell Cycle 9(1): 188-197

57. Surwit R.S., Williams P.G., 1996, Animal Models Provide Insight Into Psychosomatic Factors in Diabets, Psychosomatic Medicine 58: 582-589

58. Gavrilova N.S., Gavrilov L.A., 2012, Comments on Dietary Restriction, Okinawa Diet and Longevity, Gerontology 58: 221-223

59. Demidenko Z.N., Blagosklonny M.V., 2008, Growth stimulation leads to cellular senescence when the cell cycle is blocked, Cell Cycle 7(21): 3355-3361

60. Ross R., 1971, Growth of Smooth Muscle in Culture and Formation of Elastic Fibers, The Journal of Cell Biology 50: 172-186

61. Innerarity T.L., Pitas R.E., Mahley R.W., 1980, Disparities in the Interaction of Rat and Human Lipoproteins with Cultured Rat Fibroblasts and Smooth Muscle Cells, The Journal of Biological Chemistry 255(23): 11163-11172

62. Bierman E.L., Stein O., Stein Y., 1974, Lipoprotein Uptake and Metabolism by Rat Smooth Muscle Cell in Tissue Culture, Circ. Res. 35: 136-150

63. Muramoto K., Quan R.D., Namba T., Kyotani S., Miyamura M., Nishioka Y., Tonosaki K., Doi Y.L., Kaba H., 2011, Ameliorative effects of Eriobotrya japonica seed extract on cellular ageing in cultured rat fibroblast., J. Nat. Med. 65:254-261

64. Robinson K.A., Sens D.A., Buse M.G., 1993, Pre-Exposure to Glucosamine Induces Insulin Resistance of Glucose Transport and Glycogen Synthesis in Isolated Rat Skeletal Muscle Study of Mechmanisms in Muscle and in Rat-1 Fibroblasts Overexpressing the Human Insulin Receptor, Diabets 42: 1333-1346

65. Metzinger L., Poindron P., Passaquin A-C., 1993, A rapid preparation of primary cultures of mouse skeletal muscle cells, Cytotechlology 13: 55-60

66. Pryde M.M., Kannel W.B., 2010, Efficacy of Dietary Behavior Modification for Preserving Cardiovascular Health and Longevity, Cardiol. Res. Pract. 28, 2011: 820457

67. Larsson O., 2005, Cellular senescence $\sim$ an integrated perspective, Cancer Therapy 3: 495-510

68. Sabin R.J., Anderson R.M., 2011, Cellular Senescence $~$ its role in cancer and the response to ionizing radiation, Genome Integrity 2: 7 
69. Campisi J., Andersen J.K., Kapahi P., Melov S., 2011, Cellular senescence: A link between cancer and age-related degenerative disease?, Seminars in Cancer Biology 21:354-359

70. Altun M., Bergman E., Edström E., Johnson H., Ulfhake B., 2007, Behavioral impairments of the ageing rat, Physiology \& Behavior 92: 911-923

71. Liu G.H., Ding Z., Izpisua Belmonte J.C., 2012, iPSC technology to study human ageing and ageing-related disorders, Current Opinion in Cell Biology 24: 1-10

72. Lawless C., Wang C., Jurk D., Merz A., von Zglinicki T., Passo J.F., 2010, Quantitative assessment of markers for cell senscence, Experimental Gerontology 45: 772-778

73. Ben-Porath I., Weinberg R.A., 2005, The signals and pathways activating cellular senescence, The International Journal of Biochemistry \& Cell Biology 37: 961-979

74. Ai J., Wang N., Yang M., Du Z-M., Zhang Y-C., Yang B-F., 2005, Development of Wistar rat model of insulin resistence, World J. Gastroenterol. 11(24): 3675-3679

75. Roginsky V.A., Tashlitsky V.N., Skulachev V.P., 2009, Chain-breaking antioxidant activity of reduced forms of mitochondria-targeted quinones, a novel type of geroprotectors, Ageing 1(5): 481-489

76. Lecanu L., Wenguo Y., Xu J., Greeson J., Papadopoulos V., 2005, Local Anesthetic Procaine Protects Rat Pheochromocytoma PC12 Cells against $\beta$-Amyloid-Induced Neurotoxicity, Pharmacology 74:65-78

77. Berstein L.M., 2012, Metformin in obesity cancer and ageing: addressing controversies, Ageing 4(5): 320-329

78. Halicka H.D., Zhao H., Li J., Lee Y-S., Hsieh T-C., Wu J.M., Darzynkiewicz Z., 2012, Potential anti-ageing agents suppress the level of constitutive mTOR and DNA damage-signaling, Ageing 4(12): 952-965

79. Schnaper H.W., Johnson R.L., Tuohy E.B., Freis E.D., 1951, The Effect of Hexamethonium as Compared to Procaine or Metycaine Lumbar Block on the Blood Flow to the Foot of Normal Subjects, J. Clin. Invest. 30(7): 786-791

80. Carmins A., Junyent F., Verdaguer E., Beas-Zarate C., Rojas-Mayorquín A.E., OrtuñoSahagún D., Pallàs M., 2009, Resveratrol: An Antiageing Drug with Potential Therapeutic Applications in Treating Diseases, Pharmaceuticals 2: 194-205

81. Donati A., Cavallini G., Carresi C., Gori Z., Parentini I., Bergamini E., 2004, Anti-ageing effects of anti-lipolytic drugs, Experimental Gerontology 39: 1061-1067

82. Klöting N., Blüher M., 2005, Extended longevity and insulin signaling in adipose tissue, Experimental Gerontology 40: 878-883

83. Ng A.C., Miller R.E., 1971, Intraarterial injection of procaine, American Journal of Roentgenology 111(4): 791-793

84. Sellevold O.F.M., Berg E.M., Levang O.W., 1995, Procaine is Effective for Minimizing Postischemic Ventricular Fibrillation in Cardiac Surgery, Anesth. Analg. 81: 932-938

85. Gradinaru D., Margina D., Borsa C., 2009, In Vitro Studies Regarding the Antioxidant Effects Of Procaine, Gerovital H3 and Aslavital, Revue Roumanie de Chimie 54(9): 761-766

86. Badea I.A., Vladescu L., 2005, Simultaneous Determination of Procaine and Benzoic Acid by Derivative Spectrometry, Analele Universitatii Bucuresti - Chimie I-II: 401-406

87. Skulachev V.P., 2007, A Biochemical Approach to the Problem of Ageing: "Megaproject” on Membrane-Penetrating lons. The First Results and Prospects, Biochemistry 72(12): 1385-1396

88. Turner L., 2004, Biotechnology, bioethics and anti-ageing interventions, TRENDS in Biotechnology 22(5): 219-221

89. Gonçalves L., Gama E.F., Maifrino L.B.M., Mor N., Souza R.R., 2012, Influence of resistance exercise on the effects of ageing upon the rat myocardium, J. Morphol. Sci. 29(2): 104-107

90. Živaná H., Maric L., Gradošová I., Švejkoská K., Hubená S., Živný P., 2012, The Effect of Mud-Bath on Bone Status in Rats During Adjuvant Subchronic Arthritis, Acta Medica 55: $133-137$

91. Korkusuz F., Özukul A., Burgu I., 1993, Isolation and in vitro reproduction of periosteal cells, Turk. J. Med. Res. 11(3): 107-111 
92. Karagülle M.Z., Tütüncü Z.N., Aslan O., Başak E., Mutlu A., 1996, Effects of thermal sulphur bath cure on adjuvant arthritic rats, Phys. Rehab. Kur. Med. 6: 53-57

93. Min G., Kim J.W., Lee B-H., 2012, The refractive index measurement technique based on the defocus correction method in full-field optical coherence tomography, Proc.of SPIE 8428: 84281M

94. Hatai S., 1918, The Refractive Index of the Blood Serum of the Albino Rat at Defferent Ages, The Journal of Biological Chemistr 35(3): 527-552

95. Wang Z., Tangella K., Balla A., Popescu G., 2011, Tissue refractive index as marker of disease, Journal of Biomedical Optics 16(11): 116017

96. Men L., Lu P., Chen Q., 2008, High-resolution reflectometer for monitoring of biological samples, Proc. of SPIE 7099: 70990B

97. Garzón J., Gharbi T., Meneses J., 2008, Determination of the Refractive Index and Thickeness in Tissue by Chromatic Confocal Microscopy, Revista Colombiana de Física 40(1): 140-142

98. Ding H., Lu J.Q., Wooden W.A., Kragel P.J., Hu X-H., 2006, Refractive indices of human skin tissues at eight wavelengths and estimated dispersion relations between 300 and 1600 nm, Phys. Med. Biol. 51: 1479-1489

99. Rappaz B., Marquet P., Cuche E., Emery Y., Depeursinge C., Magistretti P.J., 2005, Measurement of the integral refractive index and dynamic cell morphometry of living cells with digital holographic microscopy, Optics Express 13(23): 9361-9373

100. Rappaz B., Charrière F., Depeursinge C., Magistretti P.J., Marquet P., 2008, Simultaneous cell morphometry and refractive index measurement with dualwavelength digital holographic microscopy and dye-enhanced dispersion of perfusion medium, Optics Letters 33(7): 744-746

101. Liang X.J., Liu A.Q., Zhang Z.M., Yap P.H., Ayi T.C., Yoon H.S., 2005, Determination of Refractive Index for Single Living Cell Using Integrated Biochip, SENSOR 1497421(2): 1712-1715

102. Yu L., Wang S., Kogure Y., Yamamoto S., Noguchi K., Dai Y., 2013, Modulation of TRP channels by resveratrol and other stilbenoids, Molecular Pain 9: 3

103. Jafari M., Long A.D., Mueller L.D., Rose M.R., 2006, The Pharmacology of Ageing in Drosophila, Current Drug Targets 7(11): 1479-1483

104. Jafari M., Rose M.R., 2006, Rules for the use of model organisms in antiageing pharmacology, Ageing Cell 5(1): 17-22

105. McLean A.J., Le Counter D., 2004, Ageing Biology and Geriatric Clinical Pharmacology, Pharmacolo. Rev. 56: 163-184

106. Divi S.M., Bellamkonda R., Dasireddy S.K., 2012, Evaluation of antidiabetic and antihyperlipedemic potential of aqueous extract of Moringa olifera in fructose fed insulin resistant and stz induced diabetic Wistar rats: A comparative study, Asian J. Pharm. Clin. Res. 5(1): 67-72

107. Leve S.T., Banga H., Shankar P., Dixit R.K., 2013, An experimental study of a novel combination of a herbal drug with an allopathic drug to evaluate the antihyperglycemic effect of irbesatan plus curcumin and comparison with glibenclamide, Int. J. Basic Clin. Pharmacol. 2(2): 182-186

108. Sahna E., Olmez E., Acet A., 2002, Effects of physiological and pharmacological concentrations of melatonin on ischemia-reperfusion arrhythmias in rats: can the incinence of sudden cardiac death be reduced?, J. Pineal Res. 32: 194-198

109. Namita P., Mukesh R., Tirath K., 2012, Evaluation of anti-inflammatory potential of Kigelia pinnata leaf extract in Wistar rats, Asian J. Pharm. Clin. Res. 5(1): 95-97

110. Cambria R.P.B., Vannucchi H., De-Oliveira L.M., 1997, Food intake and weight of lactating rats maintained on different protein-calorie diets, and pup growth, Braz. J. Med. Biol. Res. 30(8): 985-988

111. Mahdavi M.R.V., Roghani M., Khalili M., Dalir R., 2009, The effect of food restriction on learning and memory of male Wistar rats: A behavioral analysis, Basic and Clinical Neuroscience 1(2): 20-23

112. De Meneses J.A., Lopes C.A.J., Velarde L.G.C., Boaventura G.T., 2011, Behavioral analysis of Wistar rats fed with a flaxseed based diet added to an environmental enrichment, Nutr. Hosp. 26(4): 716-721 
113. Martínez C., González E., García R.S., Salas G., Constantino-Casas F., Macías L., Gracia I., Tovar C., Durán-de-Bazúa C., 2010, Effects on Body Mass of Laboratory Rats after Ingestion of Drinking Water with Sucrose, Fructose, Aspartame, and Sucralose Additives, The Open Obesity Journal 2: 116-124

114. Moura L.P., Figueredo G.A., Bertolini N.O., Ceccato M., Pereira J.R., Sponton A.C.S., De Mello M.A.R., 2012, Dietary restriction, caloric value and the accumulation of hepatic fat, Lipids in Health and Disease 11:2

115. Deng X., Cheng J., Zhang Y., Li N., Chen L., 2010, Effects of caloric restriction on SIRT1 expression and apoptosis of islet beta cell in type 2 diabetic rats, Acta Diabetol. 47(1): 177-185

116. McCarthy K., DeVellis J., 1980, Preparation of separate astroglial and oligodendroglial cell cultures from rat cerebral tissue, J. Cell Biol. 85: 890-902

117. O'Connell T.D., Berry J.E., Jarvis A.K., Somerman M.J., Simpson R.U., 1997, 1,25Dihydroxyvitamin $D_{3}$ regulation of cardiac myocyte proliferation and hypertrophy, Am. J. Physiol. 272 (Heart Circ.Physiol. 41):H1751-1758

118. Blondel B., Roijen I., Cheneval J.P., 1971, Heart cells in culture: a simple method for increasing the population of myoblasts, Experientia 27:356-358

119. Gojny P., 2005, Method for producing a cosmetically applicable marine mud extract, EP 1244425 B1

120. Belipanni G., 2010, Topical formulation for the treatment of cellulite, EP 2197414 A1

121. Zeev M. et al., 2003, Cream composition comprising Dead Sea Mud, US 6582709 B1

122. Kaessmann H-J., 2005, Method for the production of a mud suspension for bandage tissue, US 20050159059 A1

123. Flusser D., Abu-Shakra M., Friger M., Codish S., Sukenik S., 2002, Therapy with mud compresses for knee osteoarthritis: comparison of natural mud preparations with mineral-depleted mud, J Clin Rheumatol. 8(4):197-203.

124. Wollina U., 2009, Peat: a natural source for dermatocosmetics and dermatotherapeutics, J Cutan Aesthet Surg. 2(1):17-20.

125. Suárez M, González P, Domínguez R, Bravo A, Melián C, Pérez M, Herrera I, Blanco D, Hernández R, Fagundo JR, 2011, Identification of organic compounds in San Diego de los Baños Peloid (Pinar del Río, Cuba), J Altern Complement Med. 17(2):155-65.

126. Grinhut T., Hadar Y., Chen Y., 2007, Degradation and transformation of humic substances by saprotrophic fungi: processes and mechanisms, Fungi. Biol. Rev. 21: 179-89.

127. Chilom G, Bruns AS, Rice JA, 2009, Aggregation of humic acid in solution: Contributions of different fractions, Org Geochem. 40: 455-60.

128. Paul E.A. (ed.), 2007, Soil Microbiology, Ecology, And Biochemistry.3rd edition. Elsevier Academic Press, p. 532

129. HUR J., LEE B.M., 2011, Comparing the heterogeneity of copper-binding characteristics for two different-sized soil humic acid fractions using fluorescence quenching combined with 2D-COS., SCIENTIFICWORLDJOURNAL. 1(11):1865-76

130. Yan M., Dryer D., Korshin G.V., Benedetti M.F., 2013, In situ study of binding of copper by fulvic acid: comparison of differential absorbance data and model predictions, Water Res. 1;47(2):588-96.

131. Cao Y., Conklin M., Betterton E., 1995, Competitive complexation of trace metals with dissolved humic acid, Environ Health Perspect. 103 Suppl 1:29-32.

132. Banaszkiewicz W., Drobnik M., 1994, The influence of natural peat and isolated humic acid solution on certain indices of metabolism and of acid-base equilibrium in experimental animals, Rocz Panstw Zakl Hig 45:353-60.

133. Lopez M.J., Vargas-García M.C., Suárez-Estrella F., Moreno J., 2006, Biodelignification and humification of horticultural plant residues by fungi, Int. Biodet. Biodegrad. 57: 2430.

134. Badis A., Ferradji F.Z., Boucherit A., Fodil D., Boutoumi H., 2009, Characterization and biodegradation of soil humic acids and preliminary identification of decolorizing actinomycetes at Mitidja plain soils (Algeria), Afr. J. Microbiol. Res. 3(13): 997-1007. 
135. Piccolo A., 2002, The supramolecular structure of humic substances. A novel understanding of humus chemistry and implications in soil science, Adv. Agron. 75 :57134.

136. Patti A F, Clarke M, Scott J L., 2010, Ionic Liquid Extractions of Soil Organic Matter. 19th World Congress of Soil Science, Soil Solutions for a Changing World 1 - 6 August, Brisbane, Australia. Published on DVD.

137. Yamada P, Isoda H, Han JK, Talorete TP, Abe Y., 2007, Inhibitory effect of fulvic acid extracted from Canadian sphagnum peat on chemical mediator release by RBL-2H3 and KU812 cells, Biosci Biotechnol Biochem. 71(5):1294-305.

138. Motojima H, O Villareal M, Han J, Isoda H., 2011, Microarray analysis of immediatetype allergy in KU812 cells in response to fulvic acid, Cytotechnology 63(2):181-90.

139. Tachibana Y, Hiribe S, Tawa R., 2004, Studies of antioxidative activity of humic substances in peat (1), Trace Nutrients Res 23:104-108.

140. Van Rensburg CEJ, van Straten A, Dekker J., 2000, An in vitro investigation of the antimicrobial activity of oxifulvic acid, J Antimicrob Chemother 46:853-854

141. Van Rensburg CEJ, Malfeld SCK, Dekker J., 2001, Topical application of oxifulvic acid suppresses the cutaneous immune response in mice, Drug Dev Res. 53:29-32.

142. Kodama H; DENSO, 2007, Antitumor effect of humus extract on murine transplantable L1210 leukemia, J Vet Med Sci. 69(10):1069-71.

143. Sherry L, Jose A, Murray C, Williams C, Jones B, Millington O, Bagg J, Ramage G., 2012, Carbohydrate Derived Fulvic Acid: An in vitro Investigation of a Novel Membrane Active Antiseptic Agent Against Candida albicans Biofilms, Front Microbiol. 3:116.

144. Fujita K, Nagamine Y, Ping X, Taniguchi M., 1999, Mode of action of anhydrofulvic acid against Candida utilis ATCC 42402 under acidic condition, J Antibiot (Tokyo). 52(7):628-34.

145. Gandy JJ, Snyman JR, van Rensburg CE., 2011, Randomized, parallel-group, doubleblind, controlled study to evaluate the efficacy and safety of carbohydrate-derived fulvic acid in topical treatment of eczema, Clin Cosmet Investig Dermatol. 4:145-8.

146. Ghosal S, Singh SK, Kumar,Y., 1988, Shilajit. 3. Antiulcerogenic of fulvic acids and 4methoxy-6-carbomethoxybiphenyl isolated from shilaji, Phytotherapy Research 2(4) : 187-191.

147. Carrasco-Gallardo C, Guzmán L, Maccioni RB., 2012, Shilajit: a natural phytocomplex with potential procognitive activity, Int J Alzheimers Dis. 2012:674142.

148. Gandy JJ, Meeding JP, Snyman JR, van Rensburg CE., 2012, Phase 1 clinical study of the acute and subacute safety and proof-of-concept efficacy of carbohydrate-derived fulvic acid, Clin Pharmacol. 4:7-11.

149. http://www.humicsubstances.org/

150. Swift R S, 1996, Methods of Soil Analysis Part 3: Chemical Methods, ed. D. L. Sparks, A. L. Page, P. A. Helmke, R. H. Loeppert, P. N. Soltanpour, M. A. Tabatabai, C. T. Johnson, and M. E. Summer, Soil Science Society of America, Madison, 1018.

151. Peuravuori J, Ingman P, Pihlaja K, Koivikko R., 2001, Comparisons of sorption of aquatic humic matter by DAX-8 and XAD-8 resins from solid-state (13)C NMR spectroscopy's point of view., Talanta. 55(4):733-42.

152. Peuravuori J, Monteiro A, Eglite L, Pihlaja K., 2005, Comparative study for separation of aquatic humic-type organic constituents by DAX-8, PVP and DEAE sorbing solids and tangential ultrafiltration: elemental composition, size-exclusion chromatography, UV-vis and FT-IR, Talanta. 65(2):408-22.

153. Fukushima M, Kikuchi A, Tatsumi K, Tanaka F., 2006, Separation of fulvic acid from soil extracts based on ion-pair formation with a cationic surfactant, Anal Sci. 22(2):229-33.

154. Bull I.D, Van Bergen P.F, Nott C.J, Poulton P.R, Evershed R.P., 2000, Organic geochemical studies of soils from the Rothamsted classical experiments- $V$. The fate of lipids in different long-term experiments, Org Geochem. 31: 389-408.

155. Jandl G., Schulten H-R., Leinweber P.,2002, Quantification of long-chain fatty acids in dissolved organic matter and soils, J. Plant Nutr. Soil Sci. 165:133-139.

156. Drori Y., Lam B., Simpson A., Aizenshtat Z., Chefetz B., 2006, The role of lipids on sorption characteristics of freshwater- and wastewater-irrigated soils, J Environ Qual. 35(6):2154-61. 
157. De Assis C.P., González-Vila F.J, Jucksch I., González-Pérez J. A., Neves J.C.L, Lani J.L, Mendonça E.S., 2011, Lipid abundance and composition of a humic Oxisol as a function of land use, Sci. Agric. (Piracicaba, Braz.) 68(2): 230-236.

158. Bligh E.G, Dyer W.J., 1959, A rapid method of total lipid extraction and purification, Can J Biochem Physiol. 37(8):911-7.

159. Makoi J.H. JR, Ndakidemi P.A., 2008, Selected soil enzymes: Examples of their potential roles in the ecosystem, Afr J Biotechnol 7(3): 181-191.

160. Alef K., Nannipieri P., 1995, Methods in applied soil microbiology and biochemistry, Academic Press p. 576

161. Serkiz S.M., Perdue E.M., 1990, Isolation of dissolved organic matter from Suwannee River using reverse osmosis, Water Res. 24: 911 - 916.

162. Sun L., Perdue E.M., McCarthy J.F., 1995, Using reverse osmosis to obtain organic matter from surface and ground waters, Water Res. 29: 1471-1477.

163. Beck Th., 1971, Die Messung der Katalaseaktivitat von Boden. Z Pflanzenernahr Bodenkd, 130: 68-81

164. Browman M.G., Tabatabai M.A., 1978, Phosphodiesterase activity of soils, Soil Sci Soc Am J 42: 284-290

165. Cooper A.B., Morgan H.W., 1981, Improved fluorometric method to assay for soil lipase activity, Soil Biol Biochem 13: 307-311

166. Eivazi F., Tabatabai M.A., 1988, Glucosidases and galactosidases in soils, Soil Bioi Biochem 20: 601-606

167. Eivazi F., Tabatabai M.A., 1977, Phosphatases in soils, Soil Biol Biochem 9: 167-172.

168. Ladd J.N., Butler J.H.A., 1972, Short-term assays of soil proteolytic enzyme activities using proteins and dipeptide derivatives as substrates, Soil Biol Biochem 4: 19-30.

169. Witko-Sarsat V., Friedlander M., Capeiller-Blandin C., 1996, AOPP as a novel marker of oxidative stress in uremia, Kidney Int., 49: 1304-1313

170. Witko-Sarsat V., Friedlander M., Capeillère-Blandin C., Nguyen-Khoa T., Nguyen A.T., Zingraff J., Jungers P., Descamps-Latscha B., 1998, Advanced oxidation protein products as novel mediator of inflammation and monocyte activation in chronic renal failure, J. Immunol. 161: 2524-2532

171. Barry H., Chirico S., 1993, Lipid peroxidation: its mechanism, measurement, and significance, J Cnutr. 57(suppl):7 15S-25S

172. Yamamoto T., Hsu S., Lewis J., Wataha J., Dickinson D., Singh B., Bollag W., Lockwood P., Ueta E., Osaki T., Schuster G., 2003, Green tea polyphenol causes differential oxidative environments in tumor versus normal epithelial cells, Journal of Pharmacology and experimental therapeutics 307: 230-236

173. Mosmann T., 1983, Rapid colorimetric assay for cellular growth and survival:application to proliferation and cytotoxic assays, J. Immunol. Meth. 65: 55-63

174. Lowry O.H., Rosebrough N.J., Farr A.L., Randall R.J., 1951, Protein measurement with the Folin phenol reagent, J. Biol. Chem. 193: 265-275

175. Akerboom T.P., Sies H., 1981, Assay of glutathione, glutathione disulfide, and glutathione mixed disulfides in biological samples, Methods Enzymol. 77: 373-382

176. Paoletti F., Aldinucci D., Mocali A., Caparrini A., 1986, A sensitive apectrophotometric method for the determination of superoxide dismutase activity in tissue extracts, Anal. Biochem, 154: 536-541

177. Beer R.F., Sizer W., 1952, A spectrophotometric method for measuring the breakdown of hyrogen peroxide by catalase, J. Riol. Chem. 195: 133-140

178. Re R., Pellegrini N., Proteggente A., Pannala A., Yang M., Rice-Evans C., 1999, Antioxidant activity applying an improved ABTS radical cation decolorization assay, Free Radic. Biol. Med. 26: 1231-1237

179. Himmelfarb J., McMonagle E., McMenamin, 2000, Plasma protein thiol oxidation and carbonyl formation in chronic renal failure, Kidney Int. 58: 2571-2578

180. Nourooz-Zadeh J., Tajaddini-Sarmadi J., Wolff S.P., 1994, Measurement of plasma hydroperoxide concentration by ferrous oxidation-xylenol orange assay in conjunction with triphenylphosphine, Anal. Biochem. 220: 403-409 
181. Charlton-Menys V., Liu Y., Durrington P.N., 2006, Semiautomated method for determination of serum paraoxonase activity using paraoxon as a substrate, Clin. Chem. 52: 453-457

182. Browne R.W., Koury S.T., Marion S., Wilding G., Muti P., Trevisan M., 2007, Accuracy and biological variation of human serum paraoxonase I activity and polymorphism (Q192R) by kinetic enzyme assay, Clin. Chem. 53: 310-317

183. Draganov D.I., Stetson P.L., Watson C.E., Billecke S.S., La Du B.N., 2000, Rabbit serum paraoxonase 3 (PON3) is a high density lipoprotein-associated lactonase and protects low density lipoprotein against oxidation, J. Biol. Chem. 275: 33435-33442

184. Aebi H., 1984, Catalase in vitro, Methods Enzimol. 105: 121-126

185. Marklund S., Marklund G., 1974, Involvement of the superoxide anion radical in the autoxidation of pyrogallol and a convenient assay for superoxide dismutase, Eur. J. Biochem. 47: 469-474

186. Carlberg I., Mannervik B., 1985, Glutathione reductase, Methods Enzymol. 113: 484491

187. Brigelius-Flohe R., Wingler K., Muller C., 2002, Estimation of individual types of glutathione peroxidases, Methods Enzymol. 347: 101-113

188. Habig W.H., Pabst M.J., Jakoby W.B., 1974, Glutathione S-transferase. The first enzymatic step in mercapturic acid formation, J. Biol. Chem. 249: 7130-7139

189. Cascaval D., Oniscu C., Galaction A.I., 2001, Selective Separation of Amino Acids by Reactive Extraction, Biochem Eng J. 7(3): 171-176

190. Blaga A.C., Galaction A.I., Cascaval D., 2008, Separation of amino acids from their mixture by facilitated pertraction with D2EHPA, Chem Biochem Eng Q. 22(4): 439-446

191. Stoian Maria Georgeta, 2007, Amprenta chimicã a drogurilor - o provocare pentru chimiştii criminalişti ĩn stabilirea reţelelor de traficare şi distribuţie, IGPR Institutul de Criminalistica, Simpozionul de Criminalistică de la Cluj (16-17 mai 2007)

192. Ioanid N.I., 1965, Toxicologie, Editura Didactică şi Pedagogică, Bucureşti

193. Pietrzyk D.J., Frank C.W., 1989, Universitatea din lowa, Chimie Analitică, Editura Tehnică, Bucureşti

194. http://www.ms.gov.ro/documente/Ghidul\%20de\%20preventie\%20Anexa\%208_8815_6 786.pdf - Ghidul european de prevenţie a bolilor cardiovasculare în practica clinică

195. Ovidiu Băjenaru, 2010, Actualităţi în diagnosticul şi tratamentul bolii Parkinson, Media Med Publicis, ISBN 978-606-92489-1-1

196. Ciolpan Octavian, 2005, Monitoringul integrat al sistemelor ecologice, Bucureşti, Eitura Ars Docendi, ISBN 973-558-191-4

197. Health 2020 - A European policy framework and strategy for the 21st century, WHO Regional Office for Europe, World Health Organization 2013, ISBN: 9789289002790

198. An EU framework for national Roma integration strategies up to 2020. Brussels, European Commission, 2011

199. http://ec.europa.eu/justice/policies/discrimination/docs/com_2011_173_en.pdf

200. The Roma in central and eastern Europe: avoiding the dependency trap. Bratislava, United Nations Development Programme, 2003

201. Health and the Roma community, analysis of the situation in Europe. Madrid, Fundacio Secretariado Gitano, 2009

202. Suresh Rattan, 2005, Applicable Strategies for Healthy Aging, APBN 9(15): 700-701

203. Rahman H., Manjula K., Anoosha T., Nagaveni K., Eswaraiah C., Bardalai D., 2013, Invitro anti-oxidant activity of citrullus lanatus seed extracts, Asian J.Pharm. Clin. Res. 6(3): 152-157

204. Esampally Sucharitha, Mamidala Estari, 2013, Evaluation of antidiabetic activity of medicinal plant extracts used by tribal communities in rural areas of Warangal district, Andhra Pradesh, India, Biology and Medicine 5: 20-25

205. Carilho Torrao R.B.D., Dias I.H.K., Bennett S.J., Dunston C.R., Griffiths H.R., 2013, Healthy ageing and depletion of intracellular glutathione influences $T$ cell membrane thioredoxin-1 levels and cytokine secretion, Chemistry Central Journal 7:150

206. Al Jawfi Yaser et al., 2013, Chemical and phytochemical analysis of some anti diabetic plants in Yemen, Int. Res. J. Pharm. 4(9): 72-76 
207. Shah N.Z., Muhammad N., Khan A.Z, Samie M., Khan H., Azeem S., Uddin G., Rauf A., 2013, Phytochemical Analysis and Antioxidant Studies of Conyza bonarensis, Acad. J. Plant Sci. 6(3): 109-112

208. Anjali Soni, Sheetal Sosa, 2013, Phytochemical Analysis and Free Radical Scavenging Potential of Herbal and Medicinal Plant Extracts, Journal of Pharmacognosy and Phytochemistry 2(4): 22-29

209. Mabel Parimala, Francis Gricilda Shoba, 2013, Phytochemical analysis and in vitro antioxidant acitivity of hydroalcoholic seed extract of Nymphaea nouchali Burm. f., Asian Pac. J. Trop. Biomed. 3(11): 887-895

210. Kale A., Gaikwad S., Mundhe K., Deshpande N., Salvekar J., 2010, Quantification of phenolics and flavonoids by spectrophotometer from - Juglans regia, International Journal of Pharma and Bio Sciences 1(3) Jul-Sep. 2010

211. Katalinic V. et al., 2006, Screening of 70 medicinal plant extracts for antioxidant capacity and total phenols, Food Chemistry 94: 550-557

212. Hassan K. Obied, 2013, Biography of biophenols: past, present and future, Functional Foods in Health and Disease 3(6):230-241

213. Ergin V., Hariry R.E., Karasu Ç., 2013, Carbonyl Stress in Aging Process: Role of Vitamins and Phytochemicals as Redox Regulators, Aging and Disease 4(5) : 276-294

214. M.G. Rana, R.V. Katbamna, A.A. Padhya, A.D. Dudhrejiya, N.P. Jivani, N.R. Sheth, 2010, IN VITRO antioxidant and free radical scavenging studies of alcoholic extract of Medicago sativa L., ROM. J. BIOL. PLANT BIOL. 55(1): 1522

215. Jørgensen K.M., Felberg H.S., Berge R.K., Lægreid A., Johansen B., 2010, Platelet activating factor stimulates arachidonic acid release in differentiated keratinocytes via arachidonyl non-selective phospholipase A2, Arch. Dermatol. Res. 302:221-227

216. Odubanjo V.O., Oboh G., Ibukun E.O., 2013, Antioxidant and anticholinesterase activities of aqueous extract of Uraria picta (Jacq.) DC, Afr. J. Pharm. Pharmacol. 4(41): 2768-2773

217. Mukherjee K. et al., 2011, Bioactive compounds from natural resources against skin aging, Phytomedicine 19: 64- 73

218. McKay D.L., Chen C-Y.O., Saltzman E., Blumberg J., 2010, Hibiscus Sabdariffa L. Tea (Tisane) Lowers Blood Pressure in Prehypertensive and Mildly Hipertensive Adults, J. Nutr. 140(2): 298-303

219. Huwiler A. et al., 2012, The w3-polyunsaturated fatty acid derivatives AVX001 and AVX002 directly inhibit cytosolic phospholipase A2 and suppress PGE2 formation mesangial cells, British Journal of Pharmacology 167: 1691-1701

220. Charlebois D., 2007, Elderberry as a Medicinal Plant, Issues in new crops and new uses, 284-292

221. Vladimir-Knežević S., Blažeković B., Bival Štefan M., Babac M., 2012, Plant Polyphenols as Antioxidants Influencing the Human Health, Phytochemicals as Nutraceuticals - Global Approaches to Their Role in Nutrition and Health 9:155-180

222. Devasagayam T.P.A., Tilak J.C., Boloor K.K., Sane K.S, Ghaskadbi S.S., Lele R.D., 2004, Free Radicals and Antioxidants in Human Health: Current Status and Future Prospects, JAPI 52: 794-804

223. Anwer N., Waqar M.A., Iqbal M., Mushtaq M., Sobia A., 2013, Phytochemical analysis, free radical scavenging capacity and antimicrobial properties of Impatiens bicolor plant, International Food Research Journal 20(1): 99-103

224. Sommerfelt R.M., Feuerherm A.J., Jones K., Johansen B., 2013, Cytosolic Phospholipase A2 Regulates TNF-Induced Production of Joint Destructive Effectors in Synoviocytes, PLOS ONE 8(12): e83555

225. Ivanišová E., Tokár M., Mocko K., Bojňanská T., Mareček J., Mendelová A., 2013, Antioxidant activity of selected plant products, Journal of Microbiology, Biotechnology and Food Sciences 2(1): 1692-1703

226. Brattbakk H-R., Arbo I., Aagaard S., Lindseth I., Hjelle de Soysa A.K., Langaas M., Kulseng B., Lindberg F., Johansen B., 2013, Balanced Caloric Macronutrient Composition Downregulates Immunological Gene Expression in Human Blood CellsAdipose Tissue Diverges, OMICS A Journal of Integrative Biology 17(1): 41-52 
227. Verma S., Mohanta T., Revathy T., Suthindhiran K., Jayasri M.A., 2013, Phytochemical and pharmacological evaluation of selected plants, American Journal of Biochemistry and Biotechnology 9(3): 291-299

228. Sukenik H., Buskila D., Neumann L., Kleiner-Baumgarten A., Zimlichman S., Horowitz J., 1990, Sulphur bath and mud pack treatment for rheumatoid arthritis at the Dead Sea area, Annals of the Rheumatic Diseases 49: 99-102

229. Librowski T., Moniczewski A., 2010, Strong antioxidant activity of carane derivatives, Pharmacological Reports 62: 178-184

230. Gaál J. et al., 2008, Balneotherapy in Elderly Patients: Effect on Pain from Degenerative Knee and Spine Conditions and on Quality of Life, IMAJ 10: 365-369

231. Gutenbrunner C., Bender T., Cantista P., Karagülle Z., 2010, A proposal for a worldwide definition of health resort medicine, balneology, medical hydrology and climatology, Int J Biometeorol 54:495-507

232. Darie N., Oprean L., Ognean C.F, Ognean M., 2006, Testing of Some Enzymatic Levels in Ocna Sibiului Lakes Therapeutic Mud, Acta Universitatis Cibiniensis Seria F Chemia 9(1):21-28

233. Grădinaru D., Margină D., Borşa C., 2009, In vitro studies regarding the antioxidant effects of Procaine, Gerovital H3 and Aslavital, Revue Roumaine de Chimie, 54(9): 761766

234. Varga C., 2011, The Balneology paradox, Int J Biometeorol 55:105-106

235. Grossman R.C., 2010, Experimental Models of Renal Disease and the Cardiovascular System, The Open Cardiovascular Medicine Journal, 4: 257-264

236. Anisimov V.N. et al., 2001, Melatonin Increases Both Life Span and Tumor Incidence in Female CBA Mice, Journal of Gerontology: BIOLOGICAL SCIENCES 56A(7): B311B323

237. Anisimov V.N, 2001, Life span extension and cancer risk: myths and reality, Experimental Gerontology 36: 1101-1136

238. Chistyakov V.A., M.A. Sazykina, A.A. Alexandrova, N.I. Belichenko, E.V. Mashkina, L.V. Gutnikova, P.V. Zolotukhin, T.P. Shkurat, 2010, Antimutagenic Activity of Mitochondria-Targeted Plastoquinone Derivative, Biochemistry(Moscow) 75(3):269-273

239. Skulachev V.P., 2012, What Is "Phenoptosis" and How to Fight It?, Biochemistry (Moscow), 77(7): 689-706

240. Campisi J., d'Adda di Fagagna F., 2007, Cellular senescence: when bad things happen to good cells, Nature reviews - Molecular Cell Biology 8: 729-740

241. Schulze W., 2004, Environmental proteomics - what proteins from soil and surface water can tell us: a perspective, Biogeosciences Discussions 1: 195-218

242. Tobin T., Blake J.W., 1976, A review of the pharmacology, pharmacokinetics and behavioural effects of procaine in thoroughbred horses, Br J Sports Med 10: 109-116

243. Erkkola R., Yang B., 2003, Sea buckthorn oils: Towards healthy mucous membranes, AGROFood industry hi-tech p.53-57

244. Hebert S.C., Brown E.M., Harris H.W., 1997, Role of the Ca2+-sensing receptor in divalent mineral ion homeostasis, The Journal of Experimental Biology 200: 295-302

245. Chao M.-W. et al., 2011, Diesel exhaust particle exposure causes redistribution of endothelial tube VE-cadherin,Toxicology 279: 73-84

246. Camic P.M., 2008, Playing in the Mud : Health Psychology, the Arts and Creative Approaches to Health Care, J Health Psychol 13(2): 287-298

247. Hertzog C., Kramer A.F., Wilson R.S., Lindenberger U., 2009, Enrichment Effects on Adult Cognitive Development $\sim$ Can the Functional Capacity of Older Adults Be Preserved and Enhanced?, Psychological Science in the Public Interest 9(1): 1-65

248. Baek Y.-Y. et al., 2012, Extracellular taurine induces angiogenesis by activating ERKAkt-, and FAK-dependent signal pathways, European Journal of Pharmacology 674: 188-199

249. Joe A.K, Liu H., Suzui M. et al., 2002, Resveratrol Induces Growth Inhibition, S-phase Arrest, Apoptosis, and Changes in Biomarker Expression in Several Human Cancer Cell Lines, Clin Cancer Res 8:893-903

250. Charlier R.H., Chaineux M.-C.P., 2009, The Healing Sea: A Sustainable Coastal Ocean Resource:Thalassotherapy, Journal of Coastal Research 25(4):838-856 
251. Nahas R., Goguen J., 2013, Natural Health Products, Can J Diabetes 37:S97-S99

252. Chin L.K., Liu A.Q., 2007, Differential single living cell refractometry using grating resonant cavity with optical trap, Appl. Phys. Lett. 91: 243901

253. Orrua M., Übnerc M., Orrud H., 2011, Chemical properties of peat in three peatlands with balneological potential in Estonia, Estonian Journal of Earth Sciences 60(1): 43-49

254. Hughes F.J., Turner W., Belibasakis G., Martuscelli G., 2000, Effects of growth factors and cytokines on osteoblast differentiation, Periodontology 41: 48-72

255. Mullen E., O'Reilly E., Ohlendieck K., 2011, Skeletal muscle tissue from the GotoKakizaki rat model of type-2 diabetes exhibits increased levels of the small heat shock protein Hsp27, Molecular Medicine Reports 4: 229-236

256. Caraglia M. et al., 2005, Alternative therapy of earth elements increases the chondroprotective effects of chondroitin sulfate inmice, Experimental and Molecular Medicine 37(5): 476-481

257. Cheng M-L., Ho H-Y., Huang Y-W., Lu F-J., Chiu D.T-Y., 2003, Humic Acid Induces Oxidative DNA Damage, Growth Retardation, and Apoptosis in Human Primary Fibroblasts, Experimental Biology and Medicine 228: 413-423

258. Peng C.-P. et al., 2008, Molecular mechanism of the inhibitory effect of KS-5 on bFGF-induced angiogenesis in vitro and in vivo, Cancer Letters 263: 114-121

259. Wada H. et al., 2009, Combination of interferon-alpha and 5-fluorouracil inhibits endothelial cell growth directly and by regulation of angiogenic factors released by tumor cells, BMC Cancer 9: 361

260. Basaham A.S., 2008, Mineralogical and chemical composition of the mud fraction from the surface sediments of Sharm Al-Kharrar, a Red Sea coastal lagoon, Oceanologia 50(4): 557-575

261. Robe P., Nalin R., Capellano C., Vogel T.M., Simonet P., 2003, Extraction of DNA from soil, European Journal of Soil Biology 39: 183-190

262. Abbas A., Milles J., Ramachandran S., 2012, Rosuvastatin and Atorvastatin: Comparative Effects on Glucose Metabolism in Non-Diabetic Patients with Dyslipidaemia, Clinical Medicine Insights: Endocrinology and Diabetes 5: 1330

263. Karami M., Ebrahimzadeh M.A., Mahdavi M.R., Kazemi A., 2010, Effect of Fe2+ and Fe3+ ions on human plasma cholinesterase activity, 14: 897-901

264. García C.R., Angelé-Martínez C., Wilkes J.A., Wang H.C., Battin E.E., Brumaghim J.L., 2012, Prevention of iron- and copper-mediated DNA damage by catecholamine and amino acid neurotransmitters, L-DOPA, and curcumin: metal binding as ageneral antioxidant mechanism, Dalton Trans. 41: 6458-6467

265. Uranga R.M., Katz S., Salvador G.A., 2013, Enhanced phosphatidylinositol 3-kinase (PI3K)/Akt signaling has pleiotropic targets in hippocampal neurons exposed to ironinduced oxidative stress, J. Biol. Chem. p.1-22

266. Mills E., Dong X-P., Wang F., Xu H., 2010, Mechanisms of brain iron transport: insight into neurodegeneration and CNS disorders, Future Med. Chem. 2(1): 51-64

267. Ferraza T.P.L., Fiúza M.C., dos Santos M.L.A., Pontes de Carvalho L.,. Soares N.M., 2004, Comparison of six methods for the extraction of lipids from serum in terms of effectiveness and protein preservation, J. Biochem. Biophys. Methods 58: 187-193

268. Martens D.A., Suarez D.Z., 1997, Selenium Speciation of Soil/ Sediment Determined with Sequential Extractions and Hydride Generation Atomic Absorption Spectrophotometry, Environ. Sci. Technol. 31: 133-139

269. Gavrilova N.S, Gavrilov L.A., 2012, Comments on Dietary Restriction, Okinawa Diet and Longevity, Gerontology 58:221 223

270. Conte P., Spaccini R., Chiarella M., Piccolo A., 2003, Chemical properties of humic substances in soils of an Italian volcanic system, Geoderma 117: 243-250

271. Burnett A., Abdo A.S., Geraci S.A., 2013, Geriatrics, Southern Medical Journal 106(11): 631-636

272. Varga C., 2010, Problems with classification of spa waters used in balneology, HEALTH 2(11): 1260-1263

273. Houtman C.J. et al., 2004, Toxicological profiling of sediments using in vitro bioassays, with emphasis on endocrine disruption, Environmental Toxicology and Chemistry 23(1): $32-40$ 
274. Lei P., Ayton S., Bush A.I., Adlard P.A., 2011, GSK-3 in Neurodegenerative Diseases, International Journal of Alzheimer's Disease 2011: ID 189246

275. Kalamade V.I., Pillai M.M., Kalamade I.S., 2008, Effect of Bacopa monniera (Linn.) on lipid peroxidation and lipofuscinogenesis in prostate gland of D-galactose induced aging mice, Mus musculus, Indian Journal of Experimental Biology 46: 547-549

276. Xu J. et al., 2003, Inhibition of Adrenal Cortical Steroid Formation by Procaine Is Mediated by Reduction of the cAMP-Induced 3-Hydroxy-3-methylglutaryl-coenzyme A Reductase Messenger Ribonucleic Acid Levels, Journal of Pharmacology and Experimental Therapeutics 307(3): 1148-1157

277. Marin V., Surdu O., Profir D., Demirgian S., Peloidotherapy in OsteoarthritisModulation of Oxidative Stress, Osteoarthritis - Diagnosis, Treatment and Surgery, 7: 143-156

278. Camello P.J., Camello-Almaraz C., Pozo M.J., 2012, Pharmacological Approaches to Improve Ageing, Pharmacology 13: 257-282

279. Galey F.D. et al., 1993, Estrogenic activity in forages: diagnostic use of the classical mouse uterine bioassay, J Vet Diagn Invest 5:603-608

280. Walle T., 2011, Bioavailability of resveratrol, Ann. N.Y. Acad. Sci. 1215: 9-15

281. Szkudelski T., Szkudelska K., 2011, Anti-diabetic effects of resveratrol, Ann. N.Y. Acad. Sci. 1215: 34-39

282. Lin H-Y., Tang H-Y., Davis F.B., Davis P.J., 2011, Resveratrol and apoptosis, Ann. N.Y. Acad. Sci. 1215: 79-88

283. Patel K.R., Scott E., Brown V.A., Gescher A.J., Steward W.P., Brown K., 2011, Clinical trials of resveratrol, Ann. N.Y. Acad. Sci. 1215: 161-169

284. Rensburg C.E.J., van Straten A., Dekker J., 2000, An in vitro investigation of the antimicrobial activity of oxifulvic acid, J.Antimicrob. Chemother. 46: 847-863

285. Hatai S., 1918, The refractive index of the blood serum of the albino rat at different ages, Journal of Biological Chemistry XXXV(3): 527-552

286. Koh C.H. et al., 2005, Instrumental and bioanalytical measures of dioxin-like and estrogenic compounds and activities associated with sediment from the Korean coast, Ecotoxicology and Environmental Safety 61: 366-379

287. Song M. et al., 2006, Measurement of estrogenic activity in sediments from Haihe and Dagu River, China, Environment International 32: 676-681

288. Wollina U., 2009, Peat: A natural source for dermatocosmetics and dermatotherapeutics, Journal of Cutaneous and Aesthetic Surgery 2(1): 17-20

289. Jee W.S.S., Yao W., 2001, Overview: animal models of osteopenia and osteoporosis, J Musculoskel Neuron Interact 1(3):193-207

290. Azoulay A., Garzon P., Eisenberg M.J., 2001, Comparison of the Mineral Content of Tap Water and Bottled Waters, J. Gen. Intern. Med. 16: 168-175

291. Trung L.Q., Espinoza J.L., Takami A., Nakao S., 2013, Resveratrol Induces Cell Cycle Arrest and Apoptosis in Malignant NK Cells via JAK2/STAT3 Pathway Inhibition, PLOS ONE 8(1): e55183

292. Lawless C. et al., 2010, Quantitative assessment of markers for cell senescence, Experimental Gerontology 45: 772-778

293. Sahna E., Olmez E., Acet A., 2002, Effects of physiological and pharmacological concentrations of melatonin on ischemia-reperfusion arrhythmias in rats: can the incidence of sudden cardiac death be reduced?, J. Pineal Res. 32:194-198

294. Hao J. et al., 2009, Mitochondrial nutrients improve immune dysfunction in the type 2 diabetic Goto-Kakizaki rats, J. Cell. Mol. Med. 13(4): 701-711

295. Aziz M.H., Nihal M., Fu V.X. et al., 2006, Resveratrol-caused apoptosis of human prostate carcinoma LNCaP cells is mediated via modulation of phosphatidylinositol 3'kinase/Akt pathway and Bcl-2 family proteins, Mol Cancer Ther 5: 1335-1341

296. Flusser D., Abu-Shakra M., Friger M., Codish S., Sukenik S., 2002, Therapy With Mud Compresses for Knee Osteoarthritis Comparison of Natural Mud Preparations With Mineral-Depleted Mud, Journal of Clinical Rheumatology 8(4): 197-203

297. Bernacchi F., Ponzanelli I., Minunni M., Falezza A., Loprieno N., Barale R., 1996, In vivo cytogenetic effects of natural humic acid, Mutagenesis 11(5): 467-469 
298. Nasermoaddeli A., Kagamimori S., 2005, Balneotherapy in Medicine: A Review, Environmental Health and Preventive Medicine 10: 171-179

299. Partridge L., 2012, Diet and Healthy Aging, N. Engl. J. Med. 367(26): 2550-2551

300. Khavionson V.Kh., Morozov V.G., 2003, Peptides of pineal gland and thymus prolong human life, Neuroendocrinol Lett 24(3/4): 233-240

301. Sgarbură O., Popescu B.O., Băjenaru O., 2006, Evaluarea studiilor terapeutice, Revista Română de Neurologie V(4): 198-205

302. Schepetkin I.A., Xie G., Jutila M.A., Quinn M.T., 2009, Complement-fixing Activity of Fulvic Acid from Shilajit and Other Natural Sources, Phytother Res. 23(3): 373-384

303. Mohawk J.A., Miranda-Anaya M., Tataroglu O., Menaker M., 2009, Lithium and genetic inhibition of GSK3 $\beta$ enhance the effect of methamphetamine on circadian rhythms in the mouse, Behav Pharmacol. 20(2): 174-183

304. Gupta S.C., Kannappan R., Reuter S., Kim J.H., Aggarwal B.B., 2011, Chemosensitization of tumors by resveratrol, Ann N Y Acad Sci. 1215: 150-160

305. Herzfeld J. et al., 2011, Molecular Structure of Humin and Melanoidin via Solid State NMR, J Phys Chem B. 115(19): 5741-5745

306. Park S.-J. et al., 2012, Resveratrol Ameliorates Aging-Related Metabolic Phenotypes by Inhibiting cAMP Phosphodiesterases, Cell 148(3): 421-433

307. McDonald R.B., Ruhe R.C., 2011, Aging and Longevity: Why Knowing the Difference Is Important to Nutrition Research, Nutrients 3, 274-282

308. Schulten H.-R., Schnitzer M., 1998, The chemistry of soil organic nitrogen: a review, Biol Fertil Soils 26:1-15

309. Cunha T.J.F. et al., 2009, Spectroscopy Characterization of Humic Acids Isolated from Amazonian Dark Earth Soils (Terra Preta De Índio), Amazonian Dark Earths: Wim Sombroek's Vision 20: 363-372

310. Davies G., Ghabbour E.A., 2001, Humic Acids: Marvelous Products of Soil Chemistry, Journal of Chemical Education 78(12): 1609-1614

311. Nannipieri P., Eldor P., 2009, The chemical and functional characterization of soil $\mathrm{N}$ and its biotic components, Soil Biology \& Biochemistry 41: 2357-2369

312. Choudhary N., Sekhon B.S., 2012, Potential therapeutic effect of curcumin - an update, J Pharm Educ Res. 3(2): 64-71

313. Camins A. et al., 2009, Resveratrol: An Antiaging Drug with Potential Therapeutic Applications in Treating Diseases, Pharmaceuticals 2: 194-205

314. Franzluebbers A.J., Haney R.L., Hons F.M., Zuberer D.A., 1996, Active fractions of organic matter in soils with different texture, Soil Biol Biochem. 28(10/11): 1367-1372

315. Vaiserman A.M., 2008, Life Extension by Anti-Aging Drugs: Hormetic Explanation?, Am. J. Pharm. \& Toxicol. 3 (1): 14-18

316. Murawska-Ciałowicz E. et al., 2009, Effects of melatonin on lipid peroxidation and antioxidative enzyme activities in the liver, kidneys and brain of rats administered with benzo(a)pyrene, Experimental and Toxicologic Pathology 63(1-2): 97"

317. Korkushko O.V., Khavinson V.Kh., Shatilo V.B., Antonyk-Sheglova, 2011, Peptide geroprotector from pituitary gland inhibits rapid aging of elderly people: results of 15years follow up, Bulletin of Experimental Biology and Medicine 151(3): 366-369

318. Khavinson V.Kh., Malinin V.V., 2007, Peptides and bioregulation, Geriatria XIX(1): 21 23

319. Ellis D.I., Dunn W.B., Griffin J.L., Allwood J.W., Goodacre R., 2007, Metabolic fingerprinting as a diagnostic tool, Pharmacogenomics 8(9): 1243-1266

320. Kirkwood T.B.L., 2011, Systems biology of ageing and longevity, Phil. Trans. R. Soc. B 366: 64-70

321. Munteanu C., Munteanu D., Turnea M., 2013, Modeling and simulation methodology for Aging, E-Health and Bioengineering Conference (EHB) p.1-4

322. McAllister Pryde M., Kannel W.B., 2010, Efficacy of Dietary BehaviorModification for Preserving Cardiovascular Health and Longevity, Cardiology Research and Practice 2011:820457

323. Trevisan S., Francioso O., Quaggiotti S., Nardi S., 2010, Humic substances biological activity at the plant-soil interface $\sim$ From environmental aspects to molecular factors, Plant Signaling \& Behavior 5(6): 635-643 
324. Kotková B., Balík J., Černý J., Kulhánek M., Bazalová M., 2008, Crop influence on mobile sulphur content and arylsulphatase activity in the plant rhizosphere, PLANT SOIL ENVIRON. 54(3): 100107

325. Mould D.R., Upton R.N., 2013, Basic Concepts in Population Modeling, Simulation, and Model-Based Drug Development-Part 2: Introduction to Pharmacokinetic Modeling Methods, Pharmacometrics \& Systems Pharmacology 2: e38

326. Popovich I.G. et al., 2003, Effect of delta-sleep inducing peptide-containing preparation

Deltaran on biomarkers of aging, life span and spontaneous tumor incidence in female SHR mice, Mechanisms of Ageing and Development 124: 721-731

327. Moskalev A.A., Shaposhnikov M.V., 2010, Pharmacological Inhibition of Phosphoinositide 3 and TOR Kinases Improves Survival of Drosophila melanogaster, REJUVENATION RESEARCH 13(2-3): 246-247

328. Andreux P.A., Houtkooper R.H., Auwerx J., 2013, Pharmacological approaches to restore mitochondrial function, Nature Reviews 12(3): 465-483

329. Kamioka H. et al., 2010, Effectiveness of Aquatic Exercise and Balneotherapy: A Summary of Systematic Reviews Based on Randomized Controlled Trials of Water Immersion Therapies, J Epidemiol 20(1): 2-12

330. Bender T. et al., 2004, Hydrotherapy, balneotheraphy, and spa treatment in pain management, Rheumathology International Clinical and Experimental Investigation, Springer-Verlag 2004, 10.1007/s00296 -004-0487-4

331. Robinson K.A., Sens D.A., Buse M.G., 1993, Pre-Exposure to Glucosamine Induces Insulin Resistance of Glucose Transport and Glycogen Synthesis in Isolated Rat Skeletal Muscles Study of Mechanisms in Muscle and in Rat-1 Fibroblasts Overexpressing the Human Insulin Receptor, Diabetes 42: 1333-1346

332. Antúnez L.E. et al., 2013, Effects of Mud Therapy on Perceived Pain and Quality of Life Related to Health in Patients With Knee Osteoarthritis, Reumatol Clin. http://dx.doi.org/10.1016/j.reuma.2012.09.005

333. Shalaby E.A., Shanab S.M.M., Antioxidant compounds, assays of determination and mode of action, Afr. J. Pharm. Pharmacol. 7(10): 528-539

334. Kandeler E., Gerber H., 1988, Short-term assay of soil urease activity using colorimetric

determination of ammonium, Biol Fertil Soils 6: 68-72

335. Sinclair D.A., 2005, Toward a unified theory of caloric restriction and longevity regulation, Mechanisms of Ageing and Development 126: 987-1002

336. Makoi J.H.J.R., Ndakidemi P.A., 2008, Selected soil enzymes: Examples of their potential roles in the ecosystem, Afr. J. Biotechnol. 7(3): 181-191

337. Sârbu C., 2007, Characterization and classification of romanian and german mineral waters by fuzzy clustering, Proceedings of the $10^{\text {th }}$ International Conference on Environmental Science and Technology A-1295-1302

338. Banaszynski L.A., Liu C.W., Wandless T.J., 2005, Characterization of the FKBPRapamycin-FRB Ternary Complex, J. AM. CHEM. SOC. 127: 4715-4721

339. Kolosova N.G., Stefanova N.A., Muraleva N.A., Skulachev V.P., 2012, The mitochondria-targeted antioxidant SkQ1 but not N-acetylcysteine reverses aging-related biomarkers in rats, AGING 4(10): 686-694

340. Schneegurt M.A., Dore S.Y., Kulpa C.F.Jr., 2003, Direct Extraction of DNA from Soils for Studies in Microbial Ecology, Curr. Issues Mol. Biol. 5: 1-8

341. Therkleson T., 2010, Ginger as an external treatment for osteoarthritis, Praxis Anthroposophische Medizin/ Der Merkurstab 4: 344-350

342. Hudecová A. et al., 2012, Gentiana asclepiadea exerts antioxidant activity and enhances DNA repair of hydrogen peroxide- and silver nanoparticles-induced DNA damage, Food and Toxicology 50: 3352-3359

343. Suryakumar G., Gupta A., 2011, Medicinal and therapeutic potential of Sea buckthorn (Hippophae rhamnoides L.), Journal of Ethnopharmacology 138: 268- 278

344. Mbaeyi-Nwaoha I.E., Okafor G.I., Apochi O.V., 2013, Production of oleoresin from ginger (Zingiber officinale) peels and evaluation of its antimicrobial and antioxidative properties, Afr. J. Microbiol. Res. 7(42): 4981-4989 
345. Bland J.S., 1998, The use of complementary medicine for healthy aging, Alternative Therapies 4(4): 42-48

346. Zhang X.-Y. et al., 2005, Proanthocyanidin from grape seeds potentiates anti-tumor activity of doxorubicin via immunomodulatory mechanism, International Immunopharmacology 5:1247-1257

347. Heil D.P., 2010, Acid-base balance and hydration status following consumption of mineral-based alkaline bottled water, Journal of the International Society of Sports Nutrition 7: 29

348. Miyazaki R., Ishii K., Ichikawa H., Yonei Y., 2010, Community Medicine and AntiAging: Effects of Combining a Long-Term Pedometer-Based Physical Activity Program with Anti-Aging Medical Checkups on Health and Anti-Aging Medical Indicators in Community-Dwelling Older Adults (Yurin Study 1), Anti-Aging Medicine 7(12): 143-152

349. Nomoto K., Miyazaki R., Hasegawa T., Hamada U., Ichikawa H., Yonei Y., 2010, Efficacy of a Health Promotion Program with Anti-Aging Medical Checkup and Instructions for Walking under Pedometer Management in Factory Workers, Anti-Aging Medicine 7(7): 73-84

350. Ahmadi R., Pishghadam S.,Mollaamine F., Monfared M.R.Z., 2013, Comparing the Effects of Ginger and Glibenclamide on Dihydroxybenzoic Metabolites Produced in StzInduced Diabetic Rats, Int J Endocrinol Metab. 11(4): e10266

351. Alimova I.N. et al., 2009, Metformin inhibits breast cancer cell growth, colony formation and induces cell cycle arrest in vitro, Cell Cycle 8(6): 909-915

352. Assis C.P. et al., 2011, Lipid abundance and composition of a humic Oxisol as a function of land use, Sci. Agric. (Piracicaba, Braz.). 68(2): 230-236

353. De Chen M., Chen A.Q., Lin M., Li Z.Y., Chen J., 2005, Solid Superacid Catalyzed Efficient Synthesis of 2-Diethylaminoethyl Aryloxyacetates, Chinese Chemical Letters 16(2): 197-200

354. Yonei Y., Wakabayashi G., 2012, Anti-Aging Medicine for Liver and Gastroenterology, Anti-Aging Medicine 9(4): 96-107

355. Khaki A. et al, 2009, The effects of Ginger on spermatogenesis and sperm parameters of rat, Iranian Journal of Reproductive Medicine 7(1): 7-12

356. Eberlin S., dos Santos L.M.B., Queiroz M.L.S., 2005, Uncaria tomentosa extract increases the number of myeloid progenitor cells in the bone marrow of mice infected with Listeria monocytogenes, International Immunopharmacology 5: 1235-1246

357. Surdu T.V., Ion I., Surdu M., 2012, Variaţia ph-ului sanguin pe durata peloidoterapiei, Medical Connections 1(25): 139-142

358. Arab S., Alshikh A., 2012, The use of Clay Minerals of the Dead Sea as Drugs, New York Science Journal 5(1): 112-115

359. Montagner C.C., Jardim W.F., 2011, Spatial and Seasonal Variations of Pharmaceuticals and Endocrine Disruptors in the Atibaia River, São Paulo State (Brazil), J. Braz. Chem. Soc. 22(8): 1452-1462

360. Asakawa D., Kiyota T., Yanagi Y., Fujitake N., 2008, Optimization of conditions for high-performance size-exclusion chromatography of different soil humic acids, Analytical Sciences 24: 607-613

361. Tsuda K., Takata A., Shirai H., Kozaki K., Fujitake N., 2012, A method for quantitative analysis of aquatic humic substances in clear water based on carbon concentration, Analytical Sciences 28: 1017-1020

362. Beas-Zárate C. et al., 2001, Changes in NMDA-receptor gene expression are associated with neurotoxicity induced neonatally by glutamate in the rat brain, Neurochemistry International 39: 1-10

363. Gonçalves L., Gama E.F., Maifrino L.B.M., Mor N., Souza R.R., 2012, Influence of resistance exercise on the effects of aging upon the rat myocardium, J. Morphol. Sci. 29(2): 104-107

364. Bubenik G.A., 2008, Thirty four years since the discovery of gastrointestinal melatonin, Journal of Physiology and Pharmacology 59(2): 33.51

365. Anisimov V.N., 2008, Antidiabetic drugs in aging and cancer: results and perspectives, Open Longevity Science 2: 36-48 
366. Hiraishi A., Kato K., 1999, Quinone profiles in lake sediments: Implications for microbial diversity and community structures, J. Gen. Appl. Microbiol. 45: 221-227

367. Schmitt C. et al., 2010, Characterizing field sediments from three European river basins with special emphasis on endocrine effects - A recommendation for Potamopyrgus antipodarum as test organism, Chemosphere 80: 13-19

368. Aggarwal B.B. et al., 2004, Role of resveratrol in prevention and therapy of cancer: preclinical and clinical studies, Anticancer Research 24: 2783-2840

369. Kodama H., Denso, Okazaki F., Ishida S., 2008, Protective effect of humus extract against Trypanosoma brucei infection in mice, J. Vet. Med. Sci. 70(11): 11851190

370. Lakshminarasimhan M., Rauh D., Schutkowski M., Steegborn C., 2013, Sirt1 activation by resveratrol is substrate sequencelselective, AGING 5(3): 151-154

371. Chadzopulu A., Adraniotis J., Theodosopoulou E., 2011, The therapeutic effects of mud, Prog Health Sci 1(2): 132-136

372. Goldberg A.A et al., 2010, Chemical genetic screen identifies lithocholic acid as an anti-aging compound that extends yeast chronological life span in a TOR-independent manner, by modulating housekeeping longevity assurance processes, AGING 2(7): 393-414

373. Day R.O. et al., 2010, A double-blind, placebo-controlled study of the short term effects of a spring water supplemented with magnesium bicarbonate on acid/base balance, bone metabolism and cardiovascular risk factors in postmenopausal women, BMC Research Notes 3:180

374. Oberringer M., Meins C., Bubel M., Pohlemann T., 2007, A new in vitro wound model based on the co-culture of human dermal microvascular endothelial cells and human dermal fibroblasts, Biol. Cell 99: 197-207

375. Motojima H. et al., 2009, Properties of fulvic acid extracted from excess sludge and its inhibiting effect on $\beta$-hexosaminidase release, Biosci. Biotechnol. Biochem. 73(10): 2210-2216

376. Anisimov V.N. et al., 2010, Gender differences in metformin effect on aging, life span and spontaneous tumorigenesis in 129/Sv mice, AGING 2(12): 945-958

377. Mishra L.-C., Singh B.B, Dagenais S., 2000, Scientific Basis for the Therapeutic Use of Withania somnifera (Ashwagandha): A Review, Alternative Medicine Review 5(4): 334-346

378. Wang Y., Fujii T., 2011, Evaluation of methods of determining humic acids in nuclei acid samples for molecular biolgical analysis, Biosci. Biotechnol. Biochem. 75(2): 355357

379. Cambraia R.P.B., Vannucchi H., De-Oliveira L.M., 1997, Food intake and weight of lactating rats maintained on different protein-calorie diets, and pup growth, Braz. J. Med. Biol. Res. 30(8): 985-988

380. Guillemant J., Le H.-T., Accarie C., du Montcel S.T., Delabroise A.-M., Arnaud M.J., Guillemant S., 2000, Mineral water as a source of dietary calcium: acute effects on parathyroid function and bone resorption in young men, Am J Clin Nutr 71: 999-1002

381. Finkel T., Holbrook N.J., 2000, Oxidants, oxidative stress and the biology of ageing, NATURE 408: 239-247

382. Odabasi E. et al., 2007, Lipophilic Components of Different Therapeutic Mud Species, The Journal of Alternative and Complementary Medicine 13(10): 1115-1118

383. Ceveninia E., Montic D., Franceschia C., 2013, Inflamm-ageing, Curr Opin Clin Nutr Metab Care 16(1): 14-20

384. Slagsvold B. et al., 2012, Life-course, ageing and generations in Norway: the NorLAG study, Norsk Epidemiologi 22(2): 95-102

385. Tong Y. et al., 2012, Loss of leucine-rich repeat kinase 2 causes age-dependent biphasic alterations of the autophagy pathway, Molecular Neurodegeneration 7:2

386. Hipkiss A.R., 2012, Parkinson's Disease and Type-2 Diabetes: Methylglyoxal may be a Common Causal Agent; Carnosine could be Protective, Mol Med Ther 1:2

387. Remko A., Sivý J., Kettmann V., 1996, Molecular Modelling Study of the Lidocaine, Procaine, And Their Metabolites, Chem. Papers 50(1): 35-40

388. Muller F.L., Lustgarten M.S., Jang Y., Richardson A., Van Remmen H., 2007, Trends in oxidative aging theories, Free Radical Biology \& Medicine 43: 477-503 
389. Garcia-Reyero N. et al., 2005, Estrogenic Activity in Sediments from European Mountain Lakes, Environ. Sci. Technol. 39(6): 1427-1435

390. Jambu S.C., Vilvan S., Kumar A., Tyagi M.G., 2010, Chromatographic and spectrophotometric evaluation of progesterone and estrogen, Recent Research in Science and Technology 2(6): 22-28

391. Iwasaki S. et al., 2004, Analysis of estrogen-like compounds in the environment by high performance liquid chromatography bioassay, J. Biosci. Bioeng. 97(3): 216-219

392. Rasheed A., Sravya Reddy B., Roja C., 2012, A review on standardisation of herbal formulation, Inter. J. of Phytotherapy 2(2): 74-88

393. Ramezany F. et al., 2013, Primary qualities in phytotherapy and traditional medicines: a statistical study, Journal of Drug Delivery \& Therapeutics 3(3): 1-6

394. Lin Z., Zhu D., Yan Y., Yu B., Wang Q., Shen P., Ruan K., 2008, An Antioxidant Phytotherapy to Rescue Neuronal Oxidative Stress, Evidence-Based Complementary and Alternative Medicine 2011: ID 519517

395. Ciuman R.R., 2013, Currently Applied Clinical Naturopathy and PhytotherapyKeystone for Disease Prevention and Therapy, Med Aromat Plants 2: 5

396. Shirwaikar A., Verma R., Lobo R., Shirwaikar A., 2009, Phythoterapy - Safety aspects, Natural Product Radiance 8(1): 55-63

397. Silva H.O.C.Jr., Costa R.M.R., Teixeira F.M., Barbosa W.L.R., 2011, Processing and Quality Control of Herbal Drugs and Their Derivatives, Quality Control of Herbal Medicines and Related Areas 11: 196-222

398. Camello P.J., Camello-Almaraz C., Pozo M.J., 2012, Pharmacological Approaches to Improve Ageing, Pharmacology 13: 257-282

399. Artal-Sanz M., Tavernarakis N., 2010, Opposing function of mitochondrial prohibitin in aging, AGING 2(12): 1004-011

400. d' Alessio P., Ostan R., Capri M., Franceschi C., 2013, On the Way to Longevity: How to Combat Neuro-Degenerative Disease, http://dx.doi.org/10.5772/54914, 6:135149

401. Conte M. et al., 2013, Increased Plin2 expression in human skeletal muscle is associated with sarcopenia and muscle weakness, PLOS ONE 8(8): e73709

402. Dimitrov B., Hayrapetyan G., Stanchev P., 2008, Aging and longevity control of biological systems via drugs a reliability model, R\&RATA 1(1): 29-40

403. McDonald R.B., Ruhe R.C., 2011, Aging and Longevity: Why Knowing the Difference Is Important to Nutrition Research, Nutrients 3: 274-282

404. Tacutu R., Budovsky A., Yanai H., Fraifeld V.E, 2011, Molecular links between cellular senescence, longevity and agerelated diseases - a systems biology perspective, AGING 3(12): 1178-1191

405. Oostindjer M., Amdam G.V., 2013, Systems integrity in health and aging - an animal model approach, Longevity \& Healthspan 2:2

406. Lin S.-J., Guarente L., 2003, Nicotinamide adenine dinucleotide, a metabolic regulator of transcription, longevity and disease, Current Opinion in Cell Biology 15: 241-246

407. Hayflick L., 2007, Entropy Explains Aging, Genetic Determinism Explains Longevity, and Undefined Terminology Explains Misunderstanding Both, PLoS Genetics 3(12): e220

408. Caruso C., Accardi G., Virruso C., Candore G., 2013, Sex, gender and immunosenescence: a key to understand the different lifespan between men and women?, Immunity \& Ageing 10:20

409. Farris P.K., 2011, Innovative Cosmeceuticals: Sirtuin Activators and Anti-Glycation Compounds, Semin Cutan Med Surg 30:163-166

410. Kovacic P., Somanathan R., 2010, Multifaceted approach to resveratrol bioactivity Focus on antioxidant action, cell signaling and safety, Oxidative Medicine and Cellular Longevity 3(2): 86-100

411. Ahsan M. et al., 2008, A review on culture, production and use of Spirulina as food for humans and feeds for domestic animals and fish, FAO Fisheries and Aquaculture Circular No. 1034

412. Luevano-Contreras C., Chapman-Novakofski K., 2010, Dietary advanced glycation end products and aging, Nutrients 2: 1247-1265 
413. Moorhead K., Capelli B., 1993, SPIRULINA Nature's Superfood, Published by Cyanotech Corporation

414. Henrikson R., 1989, Earth Food Spirulina How this remarkable blue-green algae can transform your health and our planet, Ronore Enterprises, Inc., Hana, Maui, Hawaii

415. Ravi m., De S.L., Azharuddin S., Paul S.F.D., 2010, The beneficial effects of spirulina focusing on its immunomodulatory and antioxidant properties, Nutrition and Dietary Supplements 2: 73-83

416. Azabji-Kenfack M. et al., 2011, Potential of Spirulina Platensis as a Nutritional Supplement in Malnourished HIV-Infected Adults in Sub-Saharan Africa: A Randomised, Single-Blind Study, Nutrition and Metabolic Insights 4: $29 \quad 37$

417. Jiménez C., Cossío B.R., Labella D., Niell F.X., 2003, The Feasibility of industrial production of Spirulina (Arthrospira) in Southern Spain, Aquaculture 217: 179-190

418. Koru E., 2012, Earth Food Spirulina (Arthrospira): Production and Quality Standarts, Food Additive, Edited by Prof. Yehia El-Samragy 11: 191-202

419. Reichert C.C., Reinehr C.O., Costa J.A.V., 2006, Semicontinuous cultivation of the cyanobacterium Spirulina platensis in a closed photobioreactor, Brazilian Journal of Chemical Engineering 23(01): 23 - 28

420. Belay A., 2002, The Potential Application of Spirulina (Arthrospira) as a Nutritional and Therapeutic Supplement in Health Management, The Journal of the American Nutraceutical Association 5(2): 27-48

421. Hug C., von der Weid D., 2011, Spirulina in the fight against malnutrition Assessment and prospects, FONDATION ANTENNA TECHNOLOGIES

422. Ali S.K, Saleh A.M., 2012, Spirulina - an overview, Int J Pharm Pharm Sci 4(3): 9-15

423. Tang G., Suter P.M., 2011, Vitamin A, Nutrition, and Health Values of Algae: Spirulina, Chlorella, and Dunaliella, Journal of Pharmacy and Nutrition Sciences 1(2): 111-118

424. Reddy G.B. et al., 2011, Inhibition of aldose reductase and sorbitol accumulation by dietary rutin, Current Science 101(9): 1191-1197

425. Ramadan M.F., Asker M.M.S., Ibrahim Z.K., 2008, Functional Bioactive Compounds and Biological Activities of Spirulina platensis Lipids, Czech J. Food Sci. 26(3):211-222

426. Bhowmik D., Dubey J., Mehra S., 2009, Probiotic Efficiency of Spirulina platensis Stimulating Growth of Lactic Acid Bacteria, World J. Dairy \& Food Sci. 4(2): 160-163

427. Patro N., Sharma A., Kariaya K., Patro I., 2011, Spirulina platensis protects neurons via suppression of glial activation and peripheral sensitization leading to restoration of motor function in collagen-induced arthritic rats, Indian J. Exp. Biol. 49: 739-748

428. Yang L. et al., 2009, Inhibitory effects of polysaccharide extract from Spirulina platensis on corneal neovascularization, Molecular Vision 15: 1951-1961

429. Teimouri M., Amirkolaie A.K., Yeganeh S., 2013, Effect of Spirulina platensis Meal as a Feed Supplement on Growth Performance and Pigmentation of Rainbow Trout (Oncorhynchus mykiss), World J. Fish \& Marine Sci. 5(2): 194-202

430. Amala K., Ramanathan N., 2013, Chlorophyll production from Spirulina platensis (single cell protein, SCP); cultivation with sodium chloride in Rice mill waste water, Int.J.ChemTech Res. 5(3): 1284-1288

431. Figueroa F.L. et al., 2003, Effects of short-term irradiation on photoinhibition and accumulation of mycosporine-like amino acids in sun and shade species of the red algal genus Porphyra, Journal of Photochemistry and Photobiology B:Biology 69:21-30

432. Dunlap W.C., Shick J.M., 1998, Ultraviolet radiation-absorbing mycosporine-like amino acids in coral reef organisms: a biochemical and environmental perspective, J. Phycol. 34: 418-430

433. Salgado L.T. et al., 2007, The influence of brown algae alginates on phenolic compounds capability of ultraviolet radiation absorption in vitro, Brazilian Journal of Oceanography 55(2): 145-154

434. Şerban R., Stoian G., 2013, Mycosporine like amino acids in brown algae, Balneo Research Journal .4(4): 158-161

435. Cardozo K.H.M et al., 2007, Metabolites from algae with economical impact, Comparative Biochemistry and Physiolog Part C 146: 60-78 
436. Yuan Y.V., Westcott N.D., Hu C., Kitts D.D., 2009, Mycosporine-like amino acid composition of the edible red alga, Palmaria palmata (dulse) harvested from the west and east coasts of Grand Manan Island, New Brunswick, Food Chemistry 112:321-328

437. Cornish M.L., Garbary D.J., 2010, Antioxidants from marcoalgae: potential applications in human health and nutrition, Algae 25(4): 155-171

438. Klisch M., Häder D.-P., 2008, Mycosporine-Like Amino Acids and Marine Toxins - The Common and the Different, Mar. Drugs 6: 147-163

439. Carreto H.I., Carignan M.O., 2011, Mycosporine-Like Amino Acids: Relevant Secondary Metabolites. Chemical and Ecological Aspects, Mar. Drugs 9: 387-446

440. Singh S.P. et al., 2008, Mycosporine-like amino acids (MAAs): Chemical structure, biosynthesis and significance as UV-absorbing/screening compounds, Indian J. Exp. Biol. 46: 7-17

441. Zheng R., 2011, Aging Predictive Models and Simulation Methods for Analog and Mixed-Signal Circuits, A Thesis Presented in Partial Fulfillment of the Requirements for the Degree Master of Science, Arizona State University

442. Kider J.T.Jr., 2012, Simulation of 3D model, shape, and appearance aging by physical, chemical, biological, environmental, and weathering effects, A dissertation in Computer and Information Science Presented to the Faculties of the University of Pennsylvania in Partial Fulfillment of the Requirements for the Degree of Doctor of Philosophy

443. Cvijovic M., 2009, Mathematical Model of Accumulation of Damaged Proteins and its Impact on Ageing, Dissertation zur Erlangung des Doktorgrades der Naturwissenschaften eingereicht am Fachbereichs Mathematik und Informatik der Freien Universität Berlin

444. Thiebaut S., Armstrong A., Ventelou B., 2009, Healthy aging versus demographic trends: the french case, estimated by markovian microsimulation methods, Groupement de Recherche en Economie Quantitative d'Aix-Marseille(GREQAM), Document de travail $n^{\circ}$ 2009-42

445. Sampath Kumar K.P. et al., 2010, Medicinal uses and health benefits of Honey: An Overview, J. Chem. Pharm. Res. 2(1): 385-395

446. Mattison J.A. et al., 2012, Impact of caloric restriction on health and survival in rhesus monkeys: the NIA study, Nature 489: 7415

447. Cava E., Fontana L., 2013, Will calorie restriction work in humans?, AGING 5(7): 507-514

448. Kenyon C., 2012, Could a hormone point the way to life extension? Mice that have been genetically modified to produce high levels of fibroblast growth factor-21 live longer than mice with normal levels of this hormone, eLife 1:e00286

449. Gems D., Partridge L., 2013, Genetics of Longevity in Model Organisms: Debates and Paradigm Shifts, Annu. Rev. Physiol. 75: 621-644

450. Hursting S.D., Dunlap S.M., Ford N.A., Hursting M.J., Lashinger L.M., 2013, Calorie restriction and cancer prevention: a mechanistic perspective, Cancer \& Metabolism $1: 10$

451. Magalhães J.P., Wuttke D., Wood S.H., Plank M., Vora C., 2012, GenomeEnvironment Interactions That Modulate Aging: Powerful Targets for Drug Discovery, Pharmacol Rev 64(1):88-101

452. Pallauf K., Giller K., Huebbe P., Rimbach G., 2013, Nutrition and Healthy Ageing: Calorie Restriction or Polyphenol-Rich "MediterrAsian" Diet?, Oxidative Medicine and Cellular Longevity 2013: ID 707421

453. Roth L.W., Polotsky A.J., 2012, Can we live longer by eating less? A review of caloric restriction and longevity, Maturitas 71: $315 \quad 319$

454. Hursting S.D., Lavigne J.A., Berrigan D., Perkins S.N., Barrett J.C., 2003, CALORIE RESTRICTION, AGING, AND CANCER PREVENTION: Mechanisms of Action and Applicability to Humans, Annu. Rev. Med. 54: 131-52

455. Ioncică R., Bubulică M.-V., Chirigiu L., Mogoşanu G. D., Popescu R., Popescu H., 2010, Researches upon the heavy metals content of Rubus caesius L. (Rosaceae), Current Health Sciences Journal 36(1):51-54 
456. Wagner H., Bladt S., 2001, Plant Drug Analysis A Thin Layer Chromatography Atlas, Second Edition, Springer-Verlag Berlin Heidelberg New York

457. Capasso A., 2013, Antioxidant Action and Therapeutic Efficacy of Allium sativum L., Molecules 18: 690-700

458. Ali S.J., Shapour H., Hassan M., 2013, Beneficial effects of Achillea millefolium aqueos extract against cyclophosphamide-induced reproductive toxicity, J Exp Integr Med 3(2):0-0, DOI 10.5455/jeim.110313.or.061

459. Sharafzadeh S., 2013, Medicinal Plants as Anti-Ageing Materials: A Review, Glob. J. Med. Plant Res. 1(2): 234-236

460. Parengkuan L., Yagi M., Matsushima M., Ogura M., Hamada U., Yonei Y., 2013, Antiglycation Activity of Various Fruits, Anti-Aging Medicine 10(4): 70-76

461. Pereira V., Albuquerque F., Cacho J., Marques J.C., 2013, Polyphenols, Antioxidant Potential and Color of Fortified Wines during Accelerated Ageing: The Madeira Wine Case Study, Molecules 18: 2997-3017

462. Fahmi A.I., El-Shehawi A.M., Nagaty M.A., 2013, Antioxidant and antimutagenic activities of taif grape (Vitis vinifera) cultivars, American Journal of Biochemistry and Biotechnology 9(2): 102-117

463. Miller S.C., 2005, Echinacea: a Miracle Herb against Aging and Cancer? Evidence In vivo in Mice, eCAM 2(3): 309-314

464. d'Abzac P, Bordas F, Joussein E, van Hullebusch ED, Lens PN, Guibaud G. Metal binding properties of extracellular polymeric substances extracted from anaerobic granular sludges. Environ Sci Pollut Res Int. 2013 Jul;20(7):4509-19.

465. Sheng GP, Xu J, Luo HW, Li WW, Li WH, Yu HQ, Xie Z, Wei SQ, Hu FC. Thermodynamic analysis on the binding of heavy metals onto extracellular polymeric substances (EPS) of activated sludge. Water Res. 2013 Feb 1;47(2):607-14.

466. Lind Y, Glynn AW. Intestinal absorption of copper from drinking water containing fulvic acids and an infant formula mixture studied in a suckling rat model. Biometals. 1999 Jun;12(2):181-7.

467. Lind Y, Glynn AW. The influence of humic substances on the absorption and distribution of cadmium in mice. Pharmacol Toxicol. 1999 Jun;84(6):267-73.

468. Cheam V, Gamble DS. Metal-fulvic acid chelation equilibrium in aqueous NaNo3solution. $\mathrm{Hg}(\mathrm{II}), \mathrm{Cd}(\mathrm{II})$, and $\mathrm{Cu}(\mathrm{II})$ fulvate complexes. Canadian Journal of Soil Science, 1974, 54 (4), 413-417.

469. Markich SJ. Uranium speciation and bioavailability in aquatic systems: an overview. ScientificWorldJournal. 2002 Mar 15;2:707-29.

470. Kazinskaya IE, Goryachenkova TA, Novikov AP, Vinokurov SE, Tkachev VV. Association of radionuclides with components of fulvic acids isolated from soils. Radiochemistry. February 2012, Volume 54, Issue 1, pp 87-91.

471. Yamamoto M, Sakanoue M. Interaction of humic acid and Am(III) in aqueous solution. J Radiat Res. 1982 Sep;23(3):261-71.

472. Hirata S. Stability constants for the complexes of transition-metal ions with fulvic and humic acids in sediments measured by gel filtration. Talanta. $1981 \mathrm{Nov} ; 28(11): 809-15$.

473. Feinman R.D., Fine E.J., 2013, Fructose in perspective, Nutrition \& Metabolism 10:45

474. Shi Q. et al., 2012, Single-cell proteomic chip for profiling intracellular signaling pathways in single tumor cells, PNAS 109(2): 419-424

475. Lavu S., Boss O., Elliott P.J, Lambert P.D, 2008, Sirtuins - novel therapeutic targets to treat age-associated diseases, Nature Reviews $\sim$ Drug Di 7: 841-853

476. Woodward M.C., 2002, Constipation in Older People Pharmacological Management Issues, Journal of Pharmacy Practice and Research 32(1): 37-43

477. Collins,A.R., Azqueta,A., and Langie,S.A.S. (2012) Effects of micronutrients on DNA repair. Eur. J. Nutr., 51, 261-279.

478. Dusinska $\mathrm{M}$, Collins $\mathrm{A}$. The Comet assay in human biomonitoring: gene-environment interactions, Mutagenesis, 2008, 23(3). 191-205.

479. Dusinska,M., Staruchova,M., Horska,A. et al. (2012) Are glutathione S transferases involved in DNA damage signalling? Interactions with DNA damage and repair revealed from molecular epidemiology studies. Mutat. Res., 736, 130-137. 
480. Gaivão,I., Piasek,A., Brevik,A. et al. (2009) Comet assay-based methods for measuring DNA repair in vitro; estimates of inter- and intra-individual variation. Cell Biol. Toxicol., 25, 45-52.

481. Møller,P. and Loft,S. (2006) Dietary antioxidants and beneficial effect on oxidatively damaged DNA. Free Rad. Biol. Med., 41, 388-415.

482. Staruchova M, Collins AR, Volkovova K, Mislanová C, Kovacikova Z, Tulinska J, Kocan A, Staruch L, Wsolova L, Dusinska M. Occupational exposure to mineral fibres. Biomarkers of oxidative damage and antioxidant defence and associations with DNA damage and repair. Mutagenesis, 2008, 23(4), 249-260.

483. Lustgarten MS, Price LL, Chale A, et al. (2013) Branched chain amino acids are associated with muscle mass in functionally limited older adults. J. Gerontol. A Biol. Sci. Med. Sci., 2013, doi: 10.1093/gerona/glt152.

484. Harris, DM, Li L, Chen M, et al. (2012) Diverse mechanisms of growth inhibition by luteolin, resveratrol, and quercetin in MIA PaCa-2 cells: a comparative glucose tracer study with the fatty acid synthase inhibitor C75. Metabolomics, 8, 201-210.

485. Esteves EA, Oliveira, LG, Pires ST, Batista AG, Dessimoni-Pinto NAV, Santana RD (2011) Nutritional composition of Copaifera langsdorffii Desf. aril flour and its effect on serum lipids and glucose in rats. Food Res. Int., 44, 2357-2361.

486. Hellum, B.H., Tosse, A., Høybakk, K., Thomsen, M.W., Rohloff, J., and Nilsen, O.G. 2010 Potent in vitro inhibition of CYP3A4 and P-glycoprotein by Rhodiola rosea. Planta Med., 76, 331-338.

487. Menni C Kastenmüller G, Petersen AK,, Bell JT, Psatha M, et al. (2013) Metabolomic markers reveal novel pathways of ageing and early development in human populations. Metabolomics, 42, 1111-1119.

488. Sissener NI, Hemre GI, Lall, SP, Sagstad A, Petersen K, Williams J, Rohloff J, Sanden M (2011) Are apparent negative effects of feeding genetically modified MON810 maize to Atlantic salmon, Salmo salar caused by confounding factors? Br. J. Nutr., 106(1), 42-56.

489. Rohloff, J., Kopka, J., Erban, A., et al. (2012) Metabolite profiling reveals novel multilevel cold responses in the diploid model Fragaria vesca (woodland strawberry). Phytochemistry, 77, 99-109.

490. Kauko K. Mäkinen (2012). Use of Polyols in Oral Biology Research, Oral Health Care - Prosthodontics, Periodontology, Biology, Research and Systemic Conditions, Prof. Mandeep Virdi (Ed.), ISBN: 978-953-51-0040-9, InTech, Available from: http://www.intechopen.com, p 144-164 
a

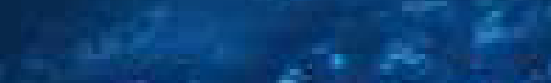

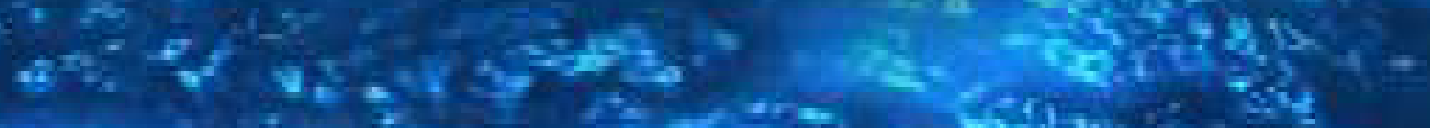

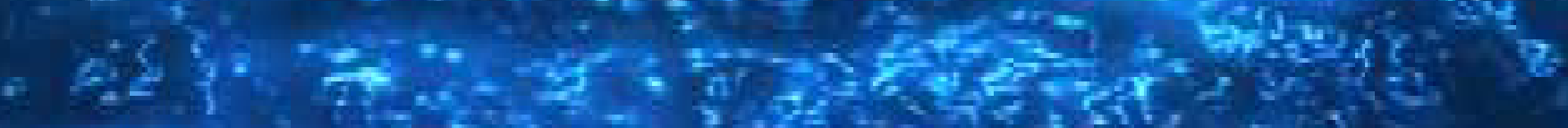
$+1$ 